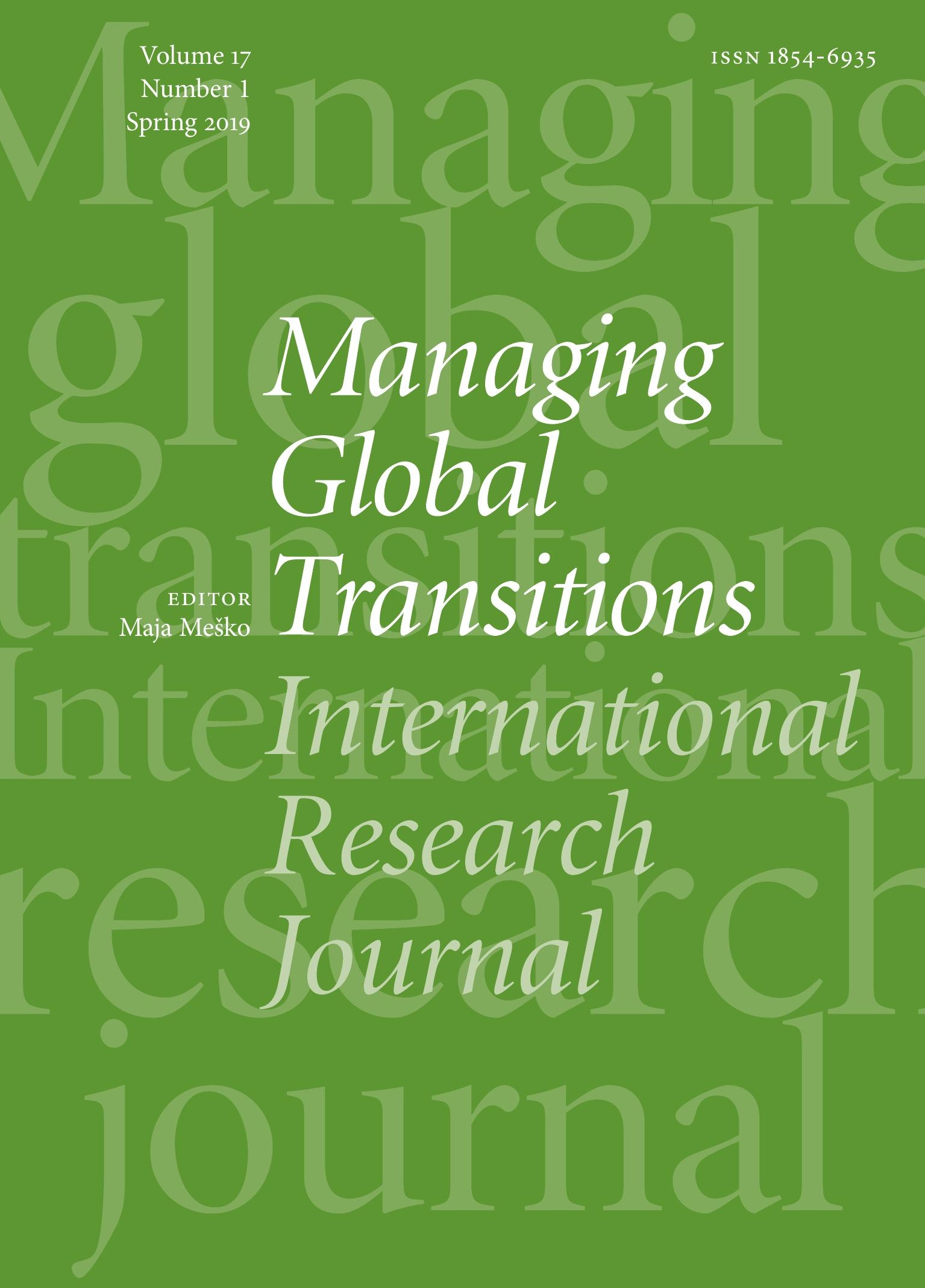




\section{Managing Global Transitions International Research Journal}

ISSN $1854-6935 \cdot$ www.mgt.fm-kp.si

EDITOR

Maja Meško, University of Primorska, Slovenia,maja.mesko@fm-kp.si

ASSOCIATE EDITORS

Andrej Bertoncelj, University of Primorska, Slovenia, andrej.bertoncelj@fm-kp.si

Gandolfo Dominici, University of Palermo, Italy,gandolfo.dominici@libero.it

Alexander Laszlo, Buenos Aires Institute of Technology, Argentina, alaszlo@itba.edu.ar

MANAGING AND PRODUCTION EDITOR

Alen Ježovnik, University of Primorska Press, Slovenia,alen.jezovnik@upr.si

EDITORIAL BOARD

Jani Bekő, Univerza v Mariboru, Slovenia, jani.beko@uni-mb.si

Heri Bezić, University of Rijeka, Croatia, bezic@efri.hr

Guido Bortoluzzi, University of Trieste, Italy, guido.bortoluzzi@deams.units.it

David L. Deeds, University of St. Thomas, usA,david.deeds@gmail.com

Evan Douglas, Griffith Universitiy, Australia, e.douglas@griffith.edu.au

Dean Fantazzini, Moscow School of Economics, Russia, fantazzini@mse-msu.ru

Henryk Gurgul, A GH University of Science and Technology, Poland, henryk.gurgul@gmail.com

András Inotai, Hungarian Academy of Sciences, Hungary, inotai.andras@krtk.mta.hu

Felicetta Iovino, University of Sannio, Italy, fiovino@unisannio.it

Hun Joon Park, Yonsei University, South Korea,hjpark@yonsei.ac.kr

Renata Karkowska, University of Warsaw, Poland,rkarkowska@wz.uw.edu.pl

Tanja Kosi Antolič, Institute of Macroeconomic Analysis and Development, Slovenia, tanja.kosi-antolic@gov.si
Leonard H. Lynn, Case Western Reserve University, UsA, leonard.lynn@case.edu Monty Lynn, Abilene Christian University, USA, monty.lynn@coba.acu.edu

Massimiliano Marzo, University of Bologna, Italy,massimiliano.marzo@unibo.it

Judita Peterlin, University of Ljubljana, Slovenia, judita.peterlin@ef.uni-lj.si

Mirjana Pejić Bach, University of Zagreb, Croatia,mpejic@efzg.hr

Sanja Peković, University of Crna Gora, Montenegro,psanja@ac.me

Sandra Penger, University of Ljubljana, Slovenia,sandra.penger@ef.uni-lj.si

Zdenko Prohaska, University of Rijeka, Croatia, zdenko.prohaska@efri.hr

José Solana Ibánez, Technical University of Cartagena, Spain, jose.solana@cud.upct.es

Marinko Škare, University of Pula, Croatia, mskare@unipu.hr

Nada Trunk Širca, International School of Social and Business Studies, Slovenia, trunk.nada@gmail.com

Šárka Velčovská, Technical University of Ostrava, Czech Republic, sarka.velcovska@vsb.cz

Manfred Weiss, Johann Wolfgang Goethe University, Germany, m.weiss@jur.uni-frankfurt.de

INDEXING AND ABSTRACTING

Managing Global Transitions is indexed/ listed in the International Bibliography of the Social Sciences, EconLit, I z Z Online, DoAJ, Erih Plus, EconPapers, Cabell's, EBsCO, and ProQuest.

SUPPORTED BY

Slovenian Research Agency.

Revija Managing Global Transitions je namenjena mednarodni znanstveni javnosti; izhaja $v$ angleščini s povzetki $v$ slovenščini. Izid revije je finančno podprla Javna agencija za raziskovalno dejavnost Republike Slovenije iz sredstev državnega proračuna iz naslova razpisa za sofinanciranje izdajanja domačih znanstvenih periodičnih publikacij. 


\section{Managing Global Transitions International Research Joumal}

VOLUME 17 • NUMBER 1 - SPRING 2019 • ISSN 1854-6935

5 Digital Environment and Internet Mobile Trends: Hotels and Travel Agencies Perspective Daniela Garbin Praničević, Anja Križan, and Judita Peterlin

19 Our Great Depression of Post-Capitalism and Not of Capitalism (New Deal as the Managerial Revolution and Understanding of our Times)

Tonči Kuzmanić

51 Forecasting the Success Rate of Reward Based Crowdfunding Projects Ivelin Elenchev and Aleksandar Vasilev

79 Defining the Unemployment Determinants of the Post-Transition Central European EU Member Countries Marija Bušelić and Jurica Bosna

105 Abstracts in Slovene 
AIMS AND SCOPE

Managing Global Transitions (MGT) is a quarterly, scholarly journal that covers diverse aspects of transitions and welcomes research on change and innovation in increasingly digitalized and networked economic environments, from a societal, organizational, and technological perspective. MGT fosters the exchange of ideas, experience and knowledge among developed and developing countries with different cultural, organizational and technological traditions. MGT invites conceptual, theorydevelopment, empirical and review papers and case-based studies advancing the field of transitions in societies, organizations and technologies.

\section{TOPICS COVERED}

\section{Transitions in Societies}

- Geo-political transitions, transition experiments, pathways and mechanisms

- Social, demographic, cross-cultural, ethical, geo-political and security aspects of transitions

- Social change, prosperity, wellbeing, happiness

- Policy making, government regulation, social responsibility

- Knowledge-based society and world futures

- New and emerging metrics for measuring, assessing and evaluating societal transitions

\section{Transitions in Organizations}

- Organizational analysis and design, modeling, developments and changes in organizational learning and behavior

- International strategy and strategic alliances, networked businesses and operations

- Entrepreneurship and leadership, decision making

- Knowledge sourcing and innovation management, personal development, education and training, HRM

- Business systems and business models

- Connective intelligence and collective intelligence in organizational behavior
Transitions in Technologies

- Managing technological/organizational change and innovation

- Technology networks, technology transfer benefits and risks, technology acquisition and diffusion

- Smart technologies and development discontinuities, renewable sources and sustainability

- Digitalization, гот, гст, cybernetics, forecasting

- Technological traditions, strategic surprise and response systems

- Studies that promote understanding of the dynamics of socio-technical systems change

- Science and technology policy that fosters transformative advancement

- Modeling technological change in vucA (volatile, uncertain, complex, ambiguous) environments

SUBMISSIONS

The manuscripts should be submitted as e-mail attachment to the editorial office at mgt@fm-kp.si. Detailed guide for authors and publishing ethics statement are available at www.mgt.fm-kp.si.

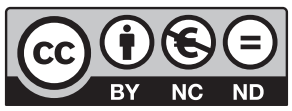

EDITORIAL OFFICE

University of Primorska

Faculty of Management

Cankarjeva 5, 6104 Koper, Slovenia

mgt@fm-kp.si · www.mgt.fm-kp.si

PUBLISHED BY

University of Primorska Press

Titov trg 4, 60oo Koper, Slovenia

zalozba@upr.si·www.hippocampus.si

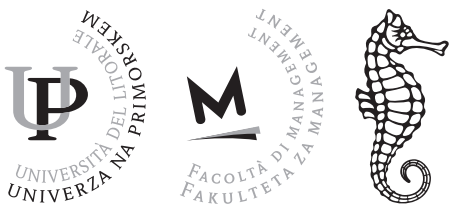




\title{
Digital Environment and Internet Mobile Trends: Hotels and Travel Agencies Perspective
}

\author{
Daniela Garbin Praničević \\ University of Split, Croatia \\ daniela@efst.hr \\ Anja Križan \\ $3 T$ Software labs, Germany \\ anja.krizano3@gmail.com \\ Judita Peterlin \\ University of Ljubljana, Slovenia \\ judita.peterlin@ef.uni-lj.si
}

The academics consider that due to the process of digitalization, the data collected by recording the digital traces became a valuable source to analyse various aspects of customer behaviours. In that context, the mobile traffic data exploration provides new insights in tourism market dynamics. Over time, it becomes crucial to approach both new frameworks and real-time monitoring systems to understand how the customer dynamics perceived over mobile traffic, shape the structure of tourism sector in order to make better planning decisions and improve management. Following the stated, the intention of this study is few, namely: (i) to highlight significant figures referring EU-28 digital environment, (ii) to present and elaborate Internet mobile trends, generally and referring hotel and travel agency area, and (iii) to strengthen the tourism managers' level of awareness regarding the role of mobile internet for business benefits. In research, both theoretical and empirical part, are reproduced secondary data of EU28 country, mainly for Croatia and Slovenia respectively. In conclusion part are discussed perspectives of mobile internet in current digital environment, as well as its position within the hotel and travel agencies areas.

Key Words: Internet mobile trends, mobile traffic, EU-28, hotels, travel agencies

JEL Classification: M15

https://doi.org/10.26493/1854-6935.17.5-17

\section{Introduction}

The evolution of Internet technologies as well as Internet penetration growing rate (https://internetworldstats.com) has indicated many changes in tourism. Over time, mobile devices become an inevitable distribution 
of ePlatform in tourism and hospitality business (Buhalis and Licata 2011) which induced, specially smart mobile, new experiences in tourism demand side (Navio-Marco, Ruiz-Gomez, and Sevilla-Sevilla 2018). Moreover, the emergence of mobile technologies has been stimulated the development of various applications with onward reflexion on new relations as well as new markets based on the transformation of existing markets (Aldebert, Dang, and Longhi 2011).

Complementary, Internet mobile traffic in tourism which refers to the usage of mobile devices to buy/sell the tourism products/services also goes up, but differ among tourism subjects. In spite of several potential benefits, its acceptance is not yet wide and it is also under-researched among scholars (Wei-Han Tan and Ooi 2018a). Wang et al. (2016) researched readiness of hotels to adopt mobile hotel reservation systems and found out that the readiness depends on the hotel size, technology competence, compatibility and critical mass, and argued that the diffusion of technology innovation depends on readiness of consumers and merchants. Consequently, it reveals as important to research both inhibitors and enablers to sell the products and services on mobile websites (Wei-Han Tan and Ooi 2018a). On the same trace, factors that play important roles in influencing tourists behaviour intention are behaviour intent to adopt mobile social media advertising in receiving tourism-related ads, social influences and cost of mobile devices and services (Wei-Han Tan et al. 2018b).

Anyhow, it is not surprising that up to date trends indicate the higher growth in websites visits due to mobile than the desktop devices (Chaffey 2018). The latest source also highlights the higher mobile conversion rates in comparison with the desktop one, as well as mobile app in regards to the mobile site usage. The rising frequency of Google searches on mobile has been recognized, widely (Google 2016). Nowadays, according to the Internet Live Stats around $40 \%$ of the world population has an internet connection (see http://www.internetlivestats.com), while the number of unique mobile internet users is about 3.7 billion (see https://www.statista.com/topics/1145/internet-usage-worldwide). Over time, the way to access the Internet and Internet search is changing. Initially, there were just desktop devices (personal computers, desktops and laptops), but over time and due to Internet technology development, internet search has been realized more and more via mobile and tablet devices. Such shift deeply changes whole 'informative' environment and ways of information flow (Castells, Fernandez-Ardevol, and Qiu 2006). 


\section{Digital Environment of EU Members and Some Reflexions in Tourism}

According to Eurostat (https://ec.europa.eu/eurostat), among the EU members in 2015 the largest number of households with access to internet was in Luxemburg (97\%), the Netherlands (96\%), followed by the Scandinavian countries. Data for Slovenia, in 2015 shows that $78 \%$ households had a computer (in EU-28: 82\%). The number of households with laptops and tablets is growing comparing with number of desktop computers. 2015 in Slovenia, $78 \%$ of households had access to internet (in EU-28: $83 \%$ ), Croatia is one place behind Slovenia. Onward, as main reasons for not having internet access is stressed as follows: the lack of need or interest (46\% of households without internet access in 2017), insufficient skills (43\%) and high access and equipment costs $(32 \%)$.

In extension, data for 2017 confirm the growing importance of digital skills as barrier against digital exclusion (see https://ec.europa.eu/digital -single-market/en/desi). Namely, in $2017,43 \%$ of the EU population had an insufficient level of digital skills. $17 \%$ of them had none at all, as they did not use the internet or barely did so. These figures imply serious risks of digital exclusion in a context of rapid digitisation. There are still major disparities across EU members. The share of people with at least basic digital skills ranges from $29 \%$ in Bulgaria and Romania (despite noticeable progress in both these countries in 2017) to $85 \%$ in Luxembourg and $79 \%$ in the Netherlands. Slovenia (19th place) and Croatia (25th place) are both bellow EU-average.

Following Digital Economy and Society Index (see https://ec.europa.eu /digital-single-market/en/desi), the indicator of Eu country digital achievements (i.e. digital inclusion digital skills, use of internet services, integration of digital technology, and digital public services), the online services growth is quite slow, although moderate increases were evident in on line activities such as: reading news online, participating in social networks, shopping online and using internet banking. Onwards, the participation in online social networks reaches $65 \%$ of $\mathrm{EU}$ internet users in 2017. The younger population share is dominant, namely among 16- to 24-year olds, the share of users participating in social networks neared $90 \%$, whereas this number was $68 \%$ for the $25-54$ and $40 \%$ for the age from 55 to 74 . The country with the largest proportion of internet users on social networks was Malta (87\%), followed by Hungary $(84 \%)$, Belgium and Romania (both $82 \%$ ). Finally, the largest increases in the share 
of internet users participating in social networks between 2016 and 2017 were registered in Romania (8\%) and Slovenia (7\%). France had the lowest share of users ( $49 \%$ ), followed by Germany ( $56 \%$ ), the Czech Republic and Slovenia (both $57 \%$ ).

INTERNET AND MOBILE TRENDS IN CROATIA AND SLOVENIA

According to the Consumer Barometer (2016), the number of internet users in Croatia also increases, annually. In 2013, $70 \%$ of the population used the internet, in 2014 the percentage rise to $74 \%$, while the data for both, 2015 and 2016, showed a share of $7 \%$. Regarding the younger population (up to 35 years), the share of internet users is growing more significantly. Namely, in 2013, 95\% of such internet users were officially registered. The same data was $99 \%$ in 2016 . The number of smartphone users in Croatia was $65 \%$ in 2016 compared with $39 \%$ three years ago. The share of younger users as defined above (up to 35) with own smartphone was $96 \%$ in 2016 , while in 2013 the share was $70 \%$. On the other side, it is a fact that having smart phones really corresponds but not reveals the exact frequency of using them for on line search. The above mentioned survey indicated that in the year 2016, 65\% of Croatian citizens used smartphones for the Internet search at least as much as they used computers for the same activity, while the same share in 2013 was $31 \%$. Within the younger population this figure is $55 \%$ for 2013 and $85 \%$ for 2016 . Additionally, $40 \%$ of Croatian users on their mobile device compare products and prices, $24 \%$ search for reviews and tips for the products and services they're interested in, $22 \%$ search for locations and directions, $16 \%$ of users search for where to buy a product/service online, $16 \%$ discovered a relevant brand/company for their research, and only $5 \%$ of users made contact with the seller via the mobile device (see www.consumerbarometer.com).

Furthermore, $96 \%$ of Slovenes use mobile phones (basic mobile phone and smartphones), $70 \%$ smartphones, $77 \%$ computers, $27 \%$ tablets, $94 \%$ TV, $11 \%$ MP 3 player, and $2 \%$ eReader. Slovenes use smartphones for setting alarm clock (70\%), telling time (68\%), taking photos/videos $(61 \%)$, checking weather (46\%), listening to music (33\%), playing games $(23 \%)$ and accessing travel/traffic/maps (22\%). $24 \%$ of Slovenes go more often online via smartphone than computer/tablet. $63 \%$ of Slovenes use search engines, $51 \%$ visit social networks, $45 \%$ watch online videos, $31 \%$ look for product information, $8 \%$ play games, $6 \%$ purchase products/services on their smartphones at last weekly (see www.consumerbarometer.com). Finally, the latest source highlights that $25 \%$ of Slovenes research on- 
line/purchase online, $39 \%$ research online/purchase offline, $10 \%$ research offline/purchase online, $43 \%$ research offline/purchase offline. In order to make their purchase, $89 \%$ of Slovenes use computers, $4 \%$ smartphones, $4 \%$ tablets, $3 \%$ other internet-enabled devices.

\section{INTERNET MOBILE TRAFFIC IN TOURISM}

As mentioned before, Internet mobile traffic is perceived as traffic realized through mobile devices, such as smart phones, tablet devices and other mobile devices with Internet access that is constantly growing proportionally with upward trend of internet searches. According to Eurostat (https://ec.europa.eu/eurostat), on average, $21 \%$ of all $\mathrm{E} U$ internet users used websites or apps to arrange accommodation services, and $10 \%$ of all used them to arrange transport services. In $\mathrm{EU}$, this figure ranges from over $35 \%$ in the UK to $6 \%$ in the Czech Republic and 6\% in Cyprus. The differences across observed countries correspond with institutional, legal and market-related aspects. The valuable observation is that Internet users with high education level are considerably more active in this respect. Namely, for both transport and accommodation, the share is more than threefold for this category compared to the low-or-no education group (see https://ec.europa.eu/digital-single-market/en/desi).

In addition, smart tourism technologies usage such as travel-related websites, social media, and smartphones in travel planning cycle has been growing too (Huang et al. 2017). Mobile computing additionally enables the development of mobile Recommender System (RS) that captures personal, social and environmental parameters and delivers accurate and effective situation-aware recommendation (Gavalas et al. 2014). In the period 2014-2016, according to Google (2016), the majority of Internet searches realised by mobile usage was just focused on tourist service search. The stated trends have shown how often users search for tourist services and related information through mobile devices. Consequently, even $70 \%$ of all mobile phone users said they were looking for tourist/guests information on their smartphones. Google (2016) also revealed that $85 \%$ travellers do not plan all activities before the trip, but only after they arrive at the destination. Moreover, travel searches via mobile devices grow over $50 \%$, annually.

Furthermore, the latter source discloses that the many mobile users use their mobile devices when they are already 'on the road.' The same principle can be applied to different tourism segments, such as booking accommodation, trips in destinations or restaurant seats. Statistics (Google 
2016) show that $31 \%$ of leisure travellers and $53 \%$ business travellers have made their reservations by mobile. Almost half of the passengers who searched for information in that way approve that they made a purchase decision on their mobile phone, than changed the device and purchased the product. The mentioned indicated the following: (1) booking and purchasing processes on particular websites are still not sufficiently customized and responsive, and (2) the mobile users feel lack of confidence or trust in particular websites and consequently avoid purchasing online (Gefen 2002; Agag and El-Masry 2016).

On the other side and despite the fact that increasing number of tourism related people recognize and actively use digital services over the internet (online booking through the web pages, social networking, etc.) still smaller number of them participate in mobile internet traffic and related opportunities. Namely, Consumer Barometer Survey (www.consumerbarometer.com) data provides more realistic perspective of the mobile device usage in Europe, referring recently booked hotel accommodation facilities In accordance with the mentioned source, only $8 \%$ of hotel reservations were made by mobile devices which refer to tablets and smart phones usage.

The interesting fact is that mobile Internet searches for travel data exceed search rates on desktop devices over the weekend (Google 2016). This indicates that hotels and other tourism subjects websites have to provide responsive web design and accordingly make their web page to 'look good,' not only on desktops, but also on tablets, and smart phones. In extension, Baraković and Skorin-Kapov $(2017,311)$ reveals the existence of: '(1) negative impact of number of taps to reach the desired Web content on perceived Web site loading time; (2) negative impact of Web site loading time (in case of smartphones), and positive impacts of Web site aesthetics and quality of Web site information on perceived Web site usability; (3) negative impact of number of taps to reach the desired Web content and positive impact of quality of Web site information on perceived Web site aesthetics; and (4) positive impact of Web site aesthetics on perceived quality of Web site information.'

It means that hotels and travel agencies need to invest more effort and resources to increase their website responsiveness and thus better customize them to potential guests. Namely, over $30 \%$ of TUI Travel and Thomas Cook's sales were performed online in 2013 (Euromonitor International 2018). Online hotel sales are growing in Western Europe and catching up with air online sales (Euromonitor International 2018). Gen- 
erally, if the hotel, travel agency or any other company do not implement a suitable online mobile commerce strategy, the risk of losing the market, competitiveness and profit arises (The Integer Group 2017). In other words, if any tourism company misses to adapt to the online environment, they will inevitably lag behind their competitors. The relationship between Internet facilities and performances in tourism sector has been explored in studies (Sigala et al. 2004; Buhalis and Zone 2007; Tsai, Song, and Wong 2009; Law, Qi, and Buhalis, 2010; Garbin Praničević, Alfirević, and Indihar Štemberger 2011).

\section{Empirical Research}

First part of the empirical research explores the share of mobile traffic in total hotel and travel agency web sites traffic. As data source has been used the Google Analytics outputs. The collected data were processed in the Microsoft Office Excel 2016. Additionally, Google Analytics tool provided web statistics for period from 2010 to 2016 . The data were gathered from Croatian, 7 hotels and 5 travel agencies websites. The total is based on 35.208.541 registered user visits on hotels websites, and 15.471.016 on travel agencies, respectively. Due to the relatively smaller sample, the collected data are used only as an indicator of the mobile internet traffic trend. Devices used in this research were divided into 3 categories, such as desktop computers (personal computers), mobile devices, and tablet devices. The research involved all customer visits, regardless of country or traffic sources.

Second part of the same research was focused on both, the role of mobile traffic regarding business results (reservations) and the share of mobile traffic in total traffic. Besides statistics used in the previous section, in this part we used conversions (or eCommerce transactions) as new metric appropriate for hotel and travel agency websites that have online booking and payment system.

\section{RESEARCH RESULTS}

The first research part results are presented in table 1.

Regarding hotel websites visits, the findings evident continuous decline in traffic realized by desktop and computers, and the growth in traffic realized by mobile and tablet devices. In 2013, growth was recorded on desktop computers and falls in traffic realized by mobile and tablet devices. Such inconsistency of the trend may be due to changes in the web site design either in the way of data tracking. 
TAB LE 1 Hotels and Travel Agencies Web Site Visits by Devices (\%)

\begin{tabular}{|c|c|c|c|c|c|c|}
\hline \multirow[t]{2}{*}{ Year } & \multicolumn{2}{|c|}{ Desktop } & \multicolumn{2}{|c|}{ Mobile } & \multicolumn{2}{|c|}{ Tablet } \\
\hline & (1) & (2) & (1) & (2) & (1) & (2) \\
\hline 2010 & 99 & 99 & 1 & 1 & $\mathrm{O}$ & $\mathrm{o}$ \\
\hline 2011 & 97 & 97 & 3 & 4 & $\mathrm{O}$ & $\mathrm{o}$ \\
\hline 2012 & 90 & 92 & 5 & 2 & 5 & 3 \\
\hline 2013 & 81 & 83 & 10 & 2 & 9 & 7 \\
\hline 2014 & 78 & 72 & 18 & 6 & 6 & 10 \\
\hline 2015 & 64 & 62 & 27 & 10 & 10 & 11 \\
\hline 2016 & 60 & 57 & 34 & 22 & 10 & 9 \\
\hline
\end{tabular}

NOTES Column headings are as follows: (1) hotel, (2) travel agency. Authors' research, based on 35.208.541 hotel website visits 35.208.541 travel agency website visits.

TABLE 2 E-Commerce Transaction Statistics, for Hotels and Travel Agencies (\%)

\begin{tabular}{|c|c|c|c|c|c|c|}
\hline \multirow[t]{2}{*}{ Year } & \multicolumn{2}{|c|}{ Desktop } & \multicolumn{2}{|c|}{ Mobile } & \multicolumn{2}{|c|}{ Tablet } \\
\hline & (1) & (2) & (1) & (2) & (1) & (2) \\
\hline 2010 & 100 & 100 & o & 1 & o & o \\
\hline 2011 & 99 & 96 & 1 & 4 & o & o \\
\hline 2012 & 94 & 97 & 1 & 2 & 5 & 1 \\
\hline 2013 & 90 & 96 & 6 & 2 & 4 & 2 \\
\hline 2014 & 96 & 93 & 2 & 6 & 2 & 1 \\
\hline 2015 & 86 & 89 & 5 & 10 & 9 & 2 \\
\hline 2016 & 79 & 68 & 6 & 22 & 15 & 10 \\
\hline
\end{tabular}

Notes Column headings are as follows: (1) hotel, (2) travel agency. Authors' research, based on 35.208.541 hotel website visits 35.208 .541 travel agency website visits.

As far as travel agencies websites are considered, the data indicate that in 2010, $99 \%$ of traffic was recorded through desktop devices, while mobile traffic was $1 \%$. In 2012, tablet devices slowly appear with $3 \%$ of share. During the whole period is evident the permanent decline of internet traffic realized by desktop and permanent growth of internet traffic realized by mobiles and tablets. The aggregated data for 2016 point out that $34 \%$ of internet traffic were realized by mobile devices. Compared with the data referring the hotel websites, it is evident that the growing trend of internet traffic realized by mobile devices is present in both, hotels and travel agencies.

The second research part results are as presented in table 2 . 


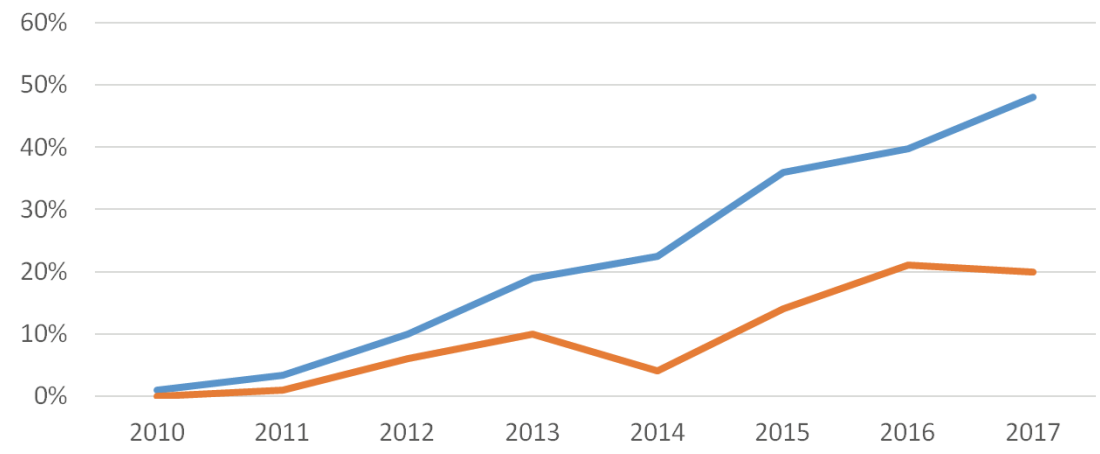

FIGURE 1 Hotel Websites Visits and Conversions Realised by Mobile Devices/Growth Trend (authors' research, based on 35.208.541 hotel website visits; blue visits, red - conversions)

Regarding eCommerce transactions realised by mobile device on hotel websites, it is evident less growth on mobile and tablet transaction than in previous research part focused on the web site visits realised by mobile devices. Many users still do not feel safe when it comes to online payments, especially through mobile devices, so when they pay online; they actually do it on desktop computers.

Referring travel agencies web sites, their arrangements provide required more interaction between users and agencies before the final sale. The related process enabled shopping activities tracking through the available web site analytics tools. For this reason, the conversion types used in this research are requests from the agency's web site. Significant growth referring the mobile and tablet conversion has been recorded since 2014 onward. According the findings, the traffic over desktop participates with more than $95 \%$ in total conversions over the web site. It means that the majority of the websites visits come from Croatia and the rest from abroad, respectively. Following the same, the Croatian users seems as still mistrustful towards digital technologies; moreover they prefer personally contact with staff, both in agency office and by phone, less by emails correspondence.

Figure 1 and figure 2 indicate the growth in mobile Internet traffic regarding visits and conversions trend, for hotel and travel agency respectively.

Referring to hotel websites (figure 1) the visit curve has a steep slope of conversion curves, which was expected due to fact that online booking and online payment options are not still supported by many websites. 


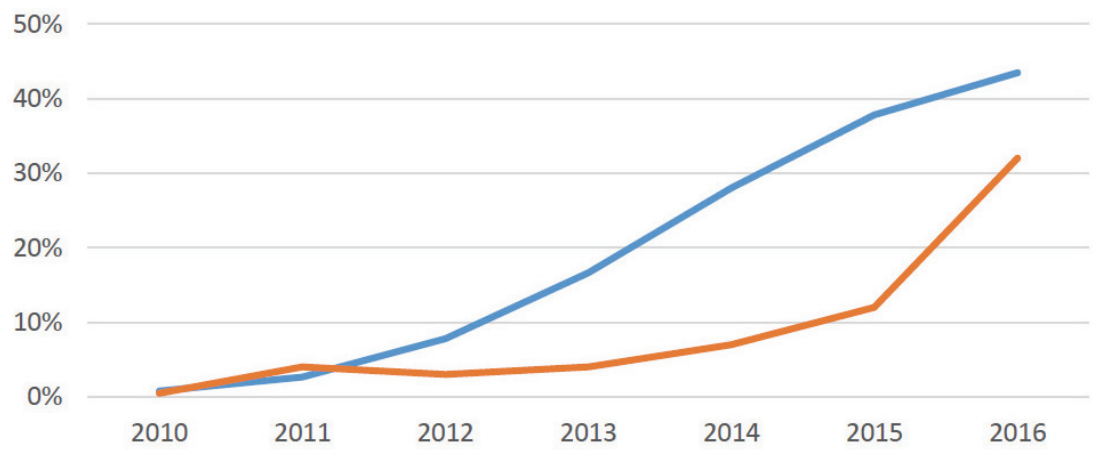

FIGURE 2 Travel Agency Websites Visits and Conversions Realised by Mobile Devices/Growth Trend (authors' research, based on 35.208.541 hotel website visits; blue - visits, red - conversions)

Despite the small sample of the data covered by this research, the trend of mobile Internet traffic growth is quite evident.

Figure 2 indicated the growth in mobile Internet traffic regarding visits and conversions trend but in the travel agencies segment. The same as in hotel sector, the visit curve show the higher growth rate than the conversion curve. As the curve of the visit slowly increases, the conversion curve indicate the more noticeable shift in 2015 as a result of a significant increase in mobile internet traffic in the last two research years.

Although, as stressed above, the data sample data is quite small, it shows a positive correlation between site visits and mobile conversions over a longer time period. Increasing the share of visits to web site visitors by mobile devices are growing rapidly. Recognizing tourism responsibilities regarding the role of mobile internet traffic become crucial for coping with the global market challenges. Adapting any website to its user needs and habits results in positive user experience i.e. increase the number of satisfied users. Moreover, customer satisfaction claims to be more analysed as one of the key performance indicators (KPIS) within the digital environment.

\section{Discussion and Conclusions}

The trends of mobile Internet traffic rise has closely correspond with the significant growth in mobile devices (smartphones and tablets) sales and usage. Furthermore, the constant development of mobile device functionality additionally facilitates the Internet searches through the mobile devices and thus supports the Internet traffic trend. Moreover, mo- 
bile information services, owing to their ubiquitous nature supported with the $\mathrm{a} / \mathrm{m}$ growing usage of tablets and other personal portable devices (e.g. mobile and smart phones), offer potential to overcome namely the stationary of the desktop Internet services. With mobile devices, particular smartphones, the omnipresent mobile Internet strongly 'touch' people daily. Having in mind that the demand on high-quality mobile services rises, both, hotel and travel agency, responsibility should adapt their websites toward more responsive design, and professional contents, as well.

The growth of internet traffic through mobile devices is present both, globally and locally, in particular EU countries. The population broadly uses mobile devices. The tourism sector follows the same trend. The use of mobile devices is evident in all travel phases including both, informative and interactive activities. Namely, apart from the information search, there is registered an increase in online hotel/agencies goods and services purchase rate. The younger (up to 35 ) especially support stated trends since, following Burkhard, Kow, and Fuggle (2017) they prefer to be more independent regarding planning the entire trip (transportation, accommodation, activities, etc.). Moreover, in accordance with Google (2016) already two thirds of the younger travellers have no problem with running the entire process on their mobile devices. Finally, according to CISCO (2019) complemented with Gaugliemo (2018) considerations, the future rise in mobile traffic are expected to be continued primary due to a shift in device mix toward smarter devices, but also due to other factors such as: more mobile users, more mobile connections, more responsive design, more secure on line payments, etc.

However, the broadly evident digital skills shortage should be considered as potential obstacles to $\mathrm{a} / \mathrm{m}$ processes realisation. Based on overall insight in digital $\mathrm{EU}$ environment, the practical implications of this research are directed to raising awareness for the need of developing digital skills of: (i) hotel and travel agency managers to adapt their business to up to date mobile platforms, but also concurrently prepare, and educate if necessary, their staff to participate professionally, and (ii) business students in $\mathrm{EU}$ and abroad as generation that will soon cope with all forthcoming challenges of worldwide digitalisation. In spite of all, it seems that advancements in information and communication technologies supplemented with the raising availability of tourism products and services on mobile networks will permanently both support and create market dynamics. 


\section{References}

Aldebert, B., R. J. Dang, and C. Longhi. 2011. 'Innovation in the Tourism Industry: The Case of Tourism@.' Tourism Management 32 (5): 1204-13.

Agag, G., and A. El-Masry. 2016. 'Understanding the Determinants of Hotel Booking Intentions and Moderating Role of Habit.' International Journal of Hospitality Management 54:52-67.

Baraković, S., and L. Skorin-Kapov. 2017. 'Modelling the Relationship between Design/Performance Factors and Perceptual Features Contributing to Quality of Experience for Mobile Web Browsing.' Computers in Human Behavior 74:311-29.

Buhalis, D., and M. C. Licata. 2011. 'The Future eTourism Intermediaries.' Tourism Management 23 (3): 207-20.

Buhalis, D., and M. Zone. 2007. 'The Strategic Impact of the Internet on the Tourism Industry. In Information and Communication Technologies in Tourism, edited by M. Sigala, L. Mich, and J. Murphy, 481-92. Wien: Springer.

Burkhard, S., N. Kow, and L. Fuggle. 2017. 'Travel Trend Report.' 2017. https://www.trekksoft.com/en/library/ebook-travel-trend-report $-2017$

Castells, M., M. Fernandez-Ardevol, and J. L. Qiu. 2006. Mobile Communication and Society. Cambridge: MIT Press.

Chaffey, D. 2018. 'Mobile Marketing Statistics Compilation.' Smart Insights, 11 July. https://www.smartinsights.com/mobile -marketing/mobile-marketing-analytics/mobile-marketing-statistics/

Cis co. 2019. 'Complete Visual Networking Index (VNI) Forecast.' https:// www.cisco.com/c/en/us/solutions/service-provider/visual -networking-index-vni/index.html

Euromonitor International. 2018. 'The New Online Travel Consumer.' https://www.euromonitor.com/the-new-online-travel-consumer/ report

Garbin Praničević, D., N. Alfirević, and M. Indihar Štemberger. 2011. 'Information system Maturity and the Hospitality Enterprise Performance.' Economic and Business Review 13 (4): 227-49.

Gaugliemo, C. 2018. 'Mobile Traffic Will Continue To Rise, Rise, Rise as Smart Devices Take over the World.' Forbes, 5 February. Https://www .forbes.com/sites/connieguglielmo/2014/02/05/mobile-traffic-will -continue-to-rise-rise-rise-as-smart-devices-take-over-the-world/ \#7fibf26a28a5

Gavalas, A., C. Konstantopoulos, K. Mastakas, and G. Pantziou. 2014. 'Mobile Recommender Systems in Tourism.' Journal of Network and Computer Applications 39:319-33. 
Gefen, D. 2002. 'Reflections on the Dimensions of Trust and Trustworthiness among online Consumers.' ACM SIGMIs Database: The Database for Advances in Information Systems 33 (3): 38-53.

Google. 2016. 'Travel Trends 2016: Data Consumer Insights.' https://www .thinkwithgoogle.com/advertising-channels/mobile/travel-trends -2016-data-consumer-insights/

Huang, C. D., J. Goo, K. Nam, and C. W. Yoo. 2017. 'Smart Tourism Technologies in Travel Planning: The Role of Exploration and Exploitation.' Information \& Management 54 (6): 757-70.

Law, R., S. Qi, and D. Buhalis. 2010. 'Progress in Tourism Management: A Review of Website Evaluation in Tourism Research.' Tourism Management 31 (3): 297-313.

Navio-Marco, J., L. M. Ruiz-Gomez, and C. Sevilla-Sevilla. 2018. 'Progress in Information Technology and Tourism Management: 30 Years on and 20 Years after the Internet - Revisiting Buhalis \& Law's Landmark Study about eTourism.' Tourism Management 69:460-70.

Sigala, M., D. Airey, P. Jones, and A. Lockwood. 2004. 'ICT Paradox Lost? A Stepwise DEA Methodology to Evaluate Technology Investments in Tourism Settings.' Journal of Travel Research 43 (2): 180-92.

The Integer Group. 2017. The Checkout. https://integer.com/shopper -culture/white-papers

Tsai, H., H. Y. Song, and K. K. F. Wong. 2009. 'Tourism and Hotel Competitiveness Research.' Journal of Travel \& Tourism Marketing 26 (5-6): 522-46.

Wang, Y., H. Li, C. Li, and D. Zhang. 2016. 'Factors Affecting Hotels' Adoption of Mobile Reservation Systems: A Technology-OrganizationEnvironment Framework.' Tourism Management 53:163-72.

Wei-Han Tan, G., and K. B. Ooi. 2018a. 'Gender and Age: Do They Really Moderate Mobile Tourism Shopping Behavior?' Telematics and Informatics 35 (6): 1617-42.

Wei-Han Tan, G., V. Hsien Lee, J. J. Hew, L. B. Keng-Boon Ooi, and L. W. Wong. 2018b. 'The Interactive Mobile Social Media Advertising: An Imminent Approach to Advertise Tourism Products and Services?' Telematics and Informatics 35 (8): 2270-88.

This paper is published under the terms of the AttributionNonCommercial-NoDerivatives 4.o International (CC B Y-NC-ND 4.o) License (http://creativecommons.org/licenses/by-nc-nd/4.o/). 

Our Great Depression of Post-Capitalism and Not of Capitalism

(New Deal as the Managerial Revolution and Understanding of our Times)

\author{
Tonči Kuzmanić \\ University of Primorska, Slovenia \\ tonci.kuzmanic@fm-kp.si
}

The main aim of the paper is to reopen the problem of Capitalism from two different perspectives. Firstly, to reopen it from the perspective of the 'language games' in the sense of the Wittgensteinian methodology. Within this kind of 'Wittgensteinian argument' the connection between the 'name' (capitalism) and the 'thing' (to pragma, this of that physical thing) is of paramount importance. The emphasis is to show that capitalism is not just a 'thing' it is much more. Secondly, paper is trying to reopen the problem of the 'Great Depression' and to show that the capitalism, as we usually understand it, had already 'evaporated' in the thirties and forties of the 20 th century. The aim of this second part and simultaneously the aim of the paper is to show that the post-capitalism ('managerial revolution' not only in the sense of Burnham, but above all in that of F. D. Roosevelt) has actually already defeated capitalism: but not its own language games spoken still today. The central thesis of the paper is that without seriously re-thinking of the irreversible revolutionary (!) changes from the thirties and forties, we cannot seriously understand today's 'globalisation' and 'global crisis' (actually new post-modern depression) and are literary doomed to failure in thinking of the given 'global society'.

Key Words: post-capitalism, capitalism, death of capitalism, language games, depression, economy, managerial revolution, Big Society

JEL Classification: A12, Noo, P16

https://doi.org/10.26493/1854-6935.17.19-49

\title{
Methodological Remark
}

This is not an easy text to read, let alone amuse based on post-modern bric-a-brac forms of rhetorical entertainment. Due to the complex macro objective I try to tackle, I have tried to be as simple and clear as possible. Firstly, I tried to avoid all technicalities of citations and bringing the evidence into the text somehow 'from the outside.' I am of the opinion 
that text has to stand as its own proof: it must rest in and simultaneously on itself. Alternatively, I offer some of the most important elements and units of outstanding ('classical') literature used in the paper only in the bibliography. Secondly, I have also tried to develop simple wording in the sense of repeating the simplest possible forms of language, regardless of the style and possible rhetorical attraction contained in it. In this regard I followed two authors who are - in my opinion - worth of admiration: Aristotle and Wittgenstein. My aim was not to construct anything beautiful and amusing, let alone splendid text but rather something as accurate as possible in the form of Wittgensteinian 'apodictic' sentences. The argument is mainly carried out through frequent repetitions of fussed sentences, reducing diverse possible meanings and (mis)understandings. The intention is a reduction through consistency of words regardless of the scholarly rhetorical effects, which occasionally drives the argument to the edge of simplicity, and could operate as bored. The texts I prefer are not the terrain of the artistic fire-works, neither are they of moral or 'works of love, that are predominant in today's writing of post-modern academia. Accordingly, the price that one has to pay for achieving such a kind of 'apodictic execution' is the style. The present text is thus aiming at almost mathematical borders of the exactness itself. Namely, today's bric-a-brac post-structural, deconstructive exhibitionism cannot compete with the contemporary economic (already managerialised!) metalanguage being the core of the problem. A real battle needs exact and precise forms of thinking and arguing, already at the very level of opening the elementary logical forms of existing problems.

\section{Capitalist Language Games}

Within the proposed kind of Wittgensteinian perspective of thinking the argument about the connection between the 'name,' Capitalism ${ }^{1}$ in our case, and the 'reality', 'thing' (gr. to pragma, ger. das Ding), is of the pivotal importance. The perspective within which the concentration is both on the epistemological and ontological problems of 'being' (gr. to on) and speech/speaking (gr. logisthai and not language) is the Aristotelian and not Plato's. More precisely, the point here is not either 'name' or 'thing' perspective, but something completely different, firstly developed in Aristotle's Peri hermeneias.

This perspective of thinking (dianoia and not gnosis) is dealing with something very basic, namely with the fact that the 'being itself' is not a Thing. It is rather something that is at least two-fold if not many-fold in 
'its meaning.' Saying in 'its meaning' already stands for the language 'use' and numerous possible 'language games.' To put it in a more simple way, when one speaks about Capitalism as a 'thing' for example, and tries to ask the question of what-capitalism-is, he or she always somehow 'in advance forgets' the fundamental problem of the 'being-of-capitalism, as Heidegger used to express this with regard to Being (Sein). In a very strange way we a priori 'forget' even to take into account the fact that capitalism 'is' (if it is at all!). To put it in more existentialist form, instead of re-thinking the very existence of capitalism (namely, that(if)-it-is), we automatically presuppose its existence, as if capitalism were something natural, a selfunderstandable or God-given Thing. In such a way capitalism suddenly becomes naturalised, unquestionable and out of our thoughts. The central point in this context is exactly that what should be presented and even proven in its very existence ('that-it-is'), and this - in some magic (postreligious) way of not-thinking - starts to function (in our own language games) as that-unquestionable. In such a kind of thoughtless methodological process - that is the machinery of gnosis on which all social sciences are still based - a certain Thing (for example Capitalism in our case) is appearing as always already (a priori) proven and even existing from always, so to speak from 'the beginning of time, as well as for ever. Precisely on the basis of such a void and unquestionable presumption of 'the existence of capitalism,' we then - instead of posing the necessary question about what it is supposed 'to be', and thus instead of targeting the very existence of capitalism - comfortably and even 'scientifically' start to ask the relaxed question about What-capitalism-is. The tragedy of such a position of today's thoughtless (Arendt), and at the same time highly rhetorically developed social sciences, is that there is no bigger logical and argumentative mistake which can be made in the realm of thinking, and it thus represents the mistake of all mistakes.

My main aim in this paper is to redirect the question of what is capitalism towards the rethinking of Capitalism itself, which today means at the level of the questioning scientific meta-language games. To put it differently, the aim is not a 'critique of capitalism,' since capitalism has already been profoundly criticized: not only by authors such as Karl Marx and others in theory, but also by actors such as F. D. Roosevelt and its team in practice (see the second part of the paper). The thesis of the paper is twofold: firstly, that capitalism 'as reality of our economical, social and political life' evaporated in the thirties and forties of the previous century (New Deal). And secondly - the key point - that what remains of it and 
even expands its own existence is a vast body that appears to be Capitalisms as language games in which Capitalism itself is hyper-produced. That hyper-production, a kind of overall mumbling, is what I call the meta-language of Capitalism and which can also be called 'economic,' or better, 'social scientific fundamentalism' subsisting at the core of all our post-modern debates and problems. In these meta-language games the non-thing (of Capitalism) operates similarly as in religions, ideologies and related phenomena: the more 'God is dead,' the more religious appears the fundamentalist discourse originating from it.

THE USE OF CAPITALIST-LANGUAGE GAMES IS OUR REALITY

The given problem can be schematised in a more empirical and even political way: the so-called Left and Right are here and now endlessly 'arguing' about Capitalism. But how? Naturally, the right is 'for capitalism, and the left is 'against it.' Similarly, as couple of centuries ago when the 'right' was 'for God' (Angels, Demons ...), and the 'left' was 'against.' Of central importance here is not either the Left or Right ... perspective and matrix of both, but the brutal fact that they are both speaking the same language, that both are revolving around the same epicentre - that of Capitalism. This common language shared by both sides is one of the problems to be posed, since it is not at all seriously examined.

The task here is to go beyond the Capitalist rhetoric, or better, to escape the kingdom of Capitalist either-or thinking that persists in the academia and media heavens of the meta-language of today Capitalism. Consequently, the real problem is how to (re)open the debate(s) about language games of Capitalism, and - in that way - the very ground on which it functions. Or to put it in a form of more precise question: how to show the common ground of all sides which in the pro et contra 'conflict' are targeting the would-be-Capitalistic quasi reality? The decisive emphasis is that the problem is neither 'the Thing' (Capitalism) nor it is its 'Name' (singular). The problem is the plurality of the language games we are using (and are used by, since we are forced to use them, too) about Capitalism. Exactly that kind of quasi plurality of use of Capitalism-language games by all sides of today's academics and media is producing the quasi 'reality of capitalism' as its own result, or, better, which is - in the last analysis - the reality of the Capitalism itself.

My perspective is to show that this kind of would-be-Capitalism is our virtual and 'scientific' reality in which we are imprisoned. We are not living only in the midst of the 'reality of things' (as it could look from the 
post-religious perspective of today's highly mediated social sciences), but above everything in the midst of the reality of (Capitalist) meta-language games. They are our 'real virtual' surrounding, at the same time presupposing and transcending all techniques and technologies of what is usually understood as the 'virtual space' and 'virtual reality.' What we should try to grasp is thus the endless quantity and usages of language games about Capitalism. More precisely, the emphasis should not be put on a 'thing' (to pragma - something from which all pragmatisms, materialisms, empiricisms necessary begin!) but on something which is not at all 'ordinary', let alone 'natural' language. In fact, the language which is the problem is the language of all today's (post-modern) social sciences themselves, which are endlessly mumbling about Capitalism. This should be understood as a highly problematical meta-language which desperately needs rethinking and understanding.

\section{RIGHT-LEFT BINARY QUASI DIFFERENCES}

How to pose the problem of the existing Right and Left (Capitalist) metalanguage games? Or, better still, how to open up debate about the total closure produced by Left and Right wing mumbling about Capitalism? Quite simply one of the important questions from which it is possible to start an Aristotelian process of thinking is to look at the cause or causes (gr. arhe-in, arhai). Of course not the causes in the sense of 'the Thing' (that would be Plato's direction leading to more or less absolute knowledge of the gnosis dealing with the One), but to try to think about the causes (pl.) which enable the movement and articulation of the Capitalist meta-language games and of quasi-descriptions that automatically follow from them.

Without a serious possibility of a mistake, it is possible to argue that there are basically two fundamental, important 'families' and 'grammars' (Wittgenstein ${ }^{2}$ ) of capitalist language games in the sense of their causes and - based on those causes - of all the quasi descriptions which are they able to produce. First of them is 'Nature,' the second 'History.' To put this in the simplest possible way - the quasi argument in 'Right' Capitalist language games (today's neo-liberalism, neo-conservatism, ...) is as simple as possible: 'capitalism-is-natural'! That 'means' that the previous sentence (actually 'command' - Wittgenstein) should be read and grasped in a more profoundly and fundamental way as: 'Capitalism "is" the same as nature'! The opposite is also possible: 'nature "is" the same as Capitalism'! This kind of (tautological) meta-language is still caught at least in 
medieval theological and scholastic distinctions dealing with 'Substance' grasped as One (sing.), God's-Thing and accidence(s) (plural.) of humanthings. The 'situation' in this scholastic matrix is in the last instance to say that 'Nature' means something at least 'unchangeable' and simultaneously 'out of time,' and even 'before time.' Fixation on the 'unchangeable grammar' is the-quasi-argument in the sense of The-Thing with which one has to deal within this matrix of language which are/is? based on the quasi argument of 'Nature.'

The Left arguments (neo-socialism, neo-communism, post-communists, ...), starts from the second chain of causes in which the main also quasi argument - is History. History is here just another name for 'Change' being made substantial, 'fundamentalised' and absolute as God functions in scholasticism. In this language game the matrix of argument is slightly different from that based on Nature. The Thing here is not Capitalism as such - which means as substantive - but it puts that 'capitalistic' in adjective form. Here the substantive is something like a perpetuum mobile of (self)changing-society (self/changing-production, self/changingeconomy, ...). With regard with something which is 'fixed,' 'capitalistic' is in the position of the 'accidence' (adjective). That which is fixed in the Left 'discourse', is - in last analysis - always the same: self-changing Progress in the sense of the endless Change/Revolution (permanent revolution included), representing the same as in theology: namely, the Infinity itself (as illustrated in fairy tales about endless Progress of 'productive forces', of 'liberalisation,' of 'freedom' and even 'democracy').

\section{COMMONALITY AND COMMUNITY OF RIGHT AND LEFT LANGUAGE GAMES}

The result of both sides (Right and Left) is not philosophical - as it seems - but rather the rhetorical matrix of the language games about Capitalism. The point which I would like to emphasise here - of course in order to re-open the exit out of the given thoughtless matrix - is the following: it is not important what, why, when and how Right or Leftwing Capitalist meta-language games are arguing. What counts is the common result of the language games in the sense of blocking the possibility of our thinking, understanding, reasoning, and acting when we are trapped within them.

Moreover, I should especially underline that 'we' of today are trapped in one of these language games (Left or Right). But also we could be and usually we are - trapped in one of the even less/more? important as- 
pects of the problem. Most importantly, the more serious problem lies in the possibility of not only being trapped in one of them (Left or Right), but trapped within both of them. Saying that, I am mainly signalling something additional: problem is - even more dangerous - located in something which can be described as the community and commonality of both Left and Right wing sayings, namely their common (Capitalist) meta-language itself. More precisely, Capitalist meta-language games are neither left nor Right - as it looks like - but are simultaneously Left and Right!

THE THIRD ELEMENT OF ENDLESS USAGE OF CAPITALIST META-LANGUAGE

If we accept the 'naturalness,' 'reality', objectivity of the above schematically described capitalist language games (the main row material of 'our' mind-set of today), then the only remaining way to change it is to change the alleged 'inner side' of Capitalism. We are, so to speak, academically and in media - 'free' only to choose either Left or Right quasi-position of that quasi argumentation. This means that in our quasi freedom we are literally jailed in a beautiful circulus vitiosus cage midst which we are endlessly 'looking' for the 'solution' of the circle's square. In such ('given') circumstances it is per definitionem not possible to break through the 'glass ceiling, let alone to seriously think about the community and commonality of 'both' quasi argumentative sides (Left and Right). What needs to be done is at least the strongest possible emphasis on the fact that the Capitalist meta-language games are not at all made only of One or of Two 'parts' or 'sides', as it appears. It rather appears as something infinite in its usages.

The real problem here is thus not choosing between 'one or another' (Left or Right) as usually we are 'thinking.' The proper location and place (gr. topos) of the problem we are trying to tackle is exactly that the 'or' itself should be grasped and 'translated' as 'and'! The result of such understanding (and change at the same time) of or into and could be the following one: Left and Right 'argumentations' are of course exclusive (Left is exclusive towards Right and vice versa) but they are not at all excluding each other as it appears to the ordinary audience being trapped midst the media and academic discourses of Capitalism. Quite the opposite is the case: Right and Left are - as far as the meta-language of Capitalism is concerned - actually two complementary positions. Together - and only together! - they successfully produce a commonality and simultaneously 
a something as 'third element' that is actually superior to both of them. That 'third element,' resulting out of the exclusivity (but not out of exclusion!) of Left and Right, is the common master to both of them (and consequently to us in the sense of those who try to think, understand,...).

This 'Third element' is an ultra-important part of the matrix of Capitalist meta-language games, functioning at a higher (or, at least, very different) level with regard to both, Left and Right. Moreover, the 'Third element' - as far as the relationship 'between' Left and Right is concerned - is neither 'one' of the already existing Left and Right sides, nor is it the 'third side' (that is the reason why it is 'invisible'). It word for word transcends - in the Hegelian manner of ger. Aufhebung - both sides (Right and Left) and any 'side' or even 'side-ness.' 'Transcends' here means the ability to 'produce' always new and completely unexpected results 'going beyond' something 'given here.'

But why and how is that possible? It is possible mainly due to the endless appearance of the infinite chain of empty mumbling about Capitalism published in books, reviews, being at work in the air, on the radio or $\mathrm{TV}$, and in other 'virtual' transmissions, capturing global audiences. This 'liquid' (mediated) form of the Capitalist meta-language quasi-spoken from all walks of life (media and academia, the so called specialists, ...) is disseminated in a total and totalitarian way. It is disseminated from the top of all media and academia and also from two additional 'sides', but these are neither Left nor Right side. These two additional 'sides' are, firstly, 'from everywhere,' and, secondly, 'from Nowhere,' thus at same time from everywhere and nowhere, since that is the definition of 'media virtual space' we are forced to live today.

In sum, our target here is, strictly speaking, not the Right or Left form of the Capitalist meta-language games, but, though/through? dissemination by the media (academia ...), the language appears as something totally 'natural', 'neutral' and even 'objective' or real, and thus dislocated into the mystical areas of unthinkable (sub-consciousness) and even 'natural.' This entirety, covered by the mist of today's media coverage and produced in the post-modern academy - mainly in social sciences: economic and managerial 'theorise' - is the Third, 'invisible element' we were looking for at least in the sense of emphasizing its meaning and importance.

The problem from the point of view of this paper is how to challenge this naturalised, so to speak Absolute, within the totality of today mediaenclosed Capitalist self-picture of meta-language? My attempt goes towards rethinking of the completely forgotten and totally silent - but pow- 
erful and extremely successful! - revolution of capitalism itself (historical capitalism!), that happened in the Us A of the thirties. While in the first part of the text I looked at the issues in the abstract levels of the language and language games ..., the task of the second part of the paper is 'radically' different: to put some flesh - historical flash above everything - on the already schematised bones of the language games of Capitalism.

\section{Historical Perspective: Not of Capitalism but of Capitalist Evaporation - New Deal}

The core thesis of the second part of the paper - also of the paper as such - is that capitalism is already dead for approximately three quarters of century and that - simultaneously (but not less importantly for this paper and its arguments) - its consequences are somehow still 'alive' today. ${ }^{3}$ This, however, does not mean that Capitalism - in the sense of its language games - did not survive its 'real death.' Quite the contrary is the case (and exactly that is The problem). The language games of Capitalism persist with its own divine, 'endless' life to which I will try to pose certain additional limits. Thus the main aim of the second part of the paper is to reopen the minimal possibility of re-thinking the problem of how the 'managerial revolution'4 defeated capitalism within its own language and installed post-capitalism. The target is also to show how Capitalist language games (being tackled in the first part of the paper) actually still survived and persisted exactly on the - it is possible to say - 'basis' of the missing 'real capitalism' or capitalism at the level of reality.

The beginning of the 'practices' of dissolution (fading away and simultaneously disappearance) of capitalism took place around the years of the 'Big depression.' These revolutionary events are still less analysed and sometimes even systematically forgotten or not at all grasped in the proper manner. Forgetting this extraordinary - world epoch changing - revolution is mainly the result of highly ideological and militarised forms of 'our' own (Western) kind of thinking, circling mainly around the already mentioned and targeted economical meta-language of Capitalism. In this kind of fundamental ideological surrounding - fundamental language games are becoming something as new, post-modern religion of our days - we are able only to 'see' the Things of 'revolutions' (Russian, Fascist, National-Socialist, ...) and wars (First and Second World War ...). My point here is that the global - to put it in Burnham (1945) parlance - 'managerial revolution' of capitalism actually took place/s (pl.!) in at least two various ways, forms and also locations. Firstly, they took 
place from 'within' the already highly developed form of capitalism (in the USA) of the thirties, and simultaneously from the 'outside' in the sense of the - revolutionary of course - changes of underdeveloped forms of capitalisms (soviet Russia, fascist Italy, Nazi Germany, ...) too.

Both kinds of managerial revolutions of capitalism after ww II merged into the global post-capitalist (and not any more capitalist!) post-modern ultra-development which is The-Thing being today in a Great depression. Or to put it in more simple way of definition: what is really in depression today is not at all (that 'old') capitalism of the Great depression, since the Great depression was the End of that capitalism itself! The Big depression is - that is the main hypothesis of the paper and simultaneously also the challenge at the level of existing language games - just another name for the end-of-capitalism, and the managerial revolution being installed in these days.

Managerial revolution - that is post-capitalism, that which came after dying capitalism - was the way out of depressed capitalist surrounding into something revolutionary, radically new. That radically and revolutionary new is something which I am defining and naming as postcapitalism. Today's Great depression after 2008 is the depression of immensely more complicated and complex post-capitalist societies and not any more that of the 'good old' and radically 'simple,' even transparent capitalism which literally evaporated in the depression of the thirties. ${ }^{6}$ As far as Capitalism (not capitalism) is concerned, it is besieged by a great desperation of the existing meta-languages, especially of the fundamental economical (and managerial) one which unfortunately still controls our gaze by covering the horizons and hiding away both: any kind of new possibility and perspective at the same time.

TOTAL REVOLUTIONS ${ }^{7}$ OF SOCIETY AND NOT ONLY

OF ECONOMY

Of course all this is not at all something which is possible to think and grasp - let alone to accept - within the predominant meta-language games of today's economics (social sciences included, since the metalanguage of economics is the 'basis' for their kind of thoughtlessness ${ }^{8}$ as well). In this second part of the paper I will try to speak a kind of a more historical, empirical, and less formal form of speech while dealing with two crucial 'aspects' of the 'real' capitalism and not of Capitalism of today's meta-language of economics and social sciences (managerial above everything). The emphasis will be on problems of property and will also 
concern the problem of society in the largest possible sense. Let me start with the second one, since it is far more complex problem.

The mentioned fundamental and global changes (appearance of postmodern society, post-modern forms of life and ways of life, ...) whose appearance is possible to locate in time between two World Wars, did not mark the change of this or that part of capitalism, of this or that of its subsystems. Instead, it was the fundamental change of capitalism itself - of its very foundations! Or to put it differently, the point is in the capitalist system as such, the change of its whole-ness, challenging its very fundamental principles. This was thus not at all only presenting the change 'in economy', as usually understood in fundamental economic technical 'thinking.' It was not a revolution 'in technology' or anything similar and 'partial', but the change of the entire society, the society as such ..., its leadership (and system of government, domination included) above everything. In Europe (also in Japan and elsewhere) this was a quite visible alteration, even though the very long chain of similar changes happened all around the (capitalist) globe of the time. More precisely, it is possible to say that it was the Change of all changes. Socialist (1917), Fascist (1922) and Nazi (1933) revolutions challenged not this or that part of 'their' societies of the day (being already in deep crisis due to the World War I), but literary attacked the very foundations of the society itself in the sense of its own fundamental principles (that of 'capitalism' and 'capitalistic' included). All these visible revolutions - more or less connected with the WW I (also in the sense of the consequences of the war ${ }^{9}$ ) - targeted the existing society in its entirety, in its foundations, main principles at the level of the way of life included. The aims of all these revolutions were without any exception simple, but this ultimate premise is not recognised yet, let alone incorporated in our common thinking and understanding. Instead, we are still trapped into the superficially economic, actually techno-metalanguage of the former capitalist forms from 19th century and we are still mumbling a kind of partial language of the 'economics.'

The aim of all these revolutions was - even at the level of the declarations and published legal documents (not to mention numerous books from that time) - exactly 'New Society'. Moreover, the purpose was even also openly posed - to produce the 'New man', sometimes even explicitly exposed in the sense, that the aim is the Übermensch. Only if we start to think these somehow buried and forgotten 'events' (and situations) from the perspective of totality (all three mentioned revolutions still 'bear' the name of totalitarianism) in the sense of the total change (revolution) of 
the System as such, it becomes possible to grasp the fundamental 'spirit' of these years and decades. Emphasis here is on the System as such, and not on the change of any kind of partiality, be it economy or anything else. Of course, all these revolutions and their leaders also talked about the 'changing of economy', 'changes in economic system,' about the 'change of this or that' part of society (changes in various sub-systems), but the fundamental emphasis was One and the same in all surroundings: the total revolution of the System as such. The System was The Target, which means the existing way of life of the time!

Only while keeping in mind this kind of explicit 'desire for totality' and starting exactly from the point of view of totality as the 'regulative idea' of these revolutions, it is possible to work out and maybe to comprehend - the historical magnitude of these very global (!) events (long chain of very painful changing events). The entire late modern history of the 'developed West' cannot offer anything comparable to these total revolutions and events of the thirties. There are no similar, parallel events in the whole late history of the Western (global humanity included) society. Today's 'Arab revolutions,' for example, are very far from the similar magnitude, but this is rather another question and problem. Meanwhile, the highly celebrated and mystified quasi Big revolutions of the '68, for example, were - in comparison with these events - childish games presented to the already infantilised audience by the media and propaganda of these years.

\section{BIG SOCIETY \& SMALL SOCIETY}

Where to start from in order to understand The problem we should try to face? From the Big depression! Yes, but how?! Simply asking in genitive (genesis/genesthai method in Aristotle's terminology): Big depression 'of-what'? The answer is: the point was not the Big depression of economy (only economy, to put it in more simple form) as it was - and still it is - falsely presented in connection with our own today's fundamental depression of society (depression after 2008 is of similar magnitude and is not only dealing with economy, but with society as such). It was the case of the Big depression of the entire society, of its deepest (that means 'capitalist'!) foundations, principles and causes (gr. stoicheion and arhein). To put it differently, it was a total depression of capitalist society (in its most developed form in Us), and exactly that was the reason for the appearance of the phrase Big (society) and its 'family' (Wittgenstein) of language games which we have to try to understand. 
Firstly, how to comprehend that 'Big'? What was that 'Big'? The 'Great,' 'Big' was not anything in the sense of quantitative 'Big thing' only. It was a qualitative Big in the sense of something completely, revolutionary New, of something which was not seen ever before. In order to grasp the main point in the 'family' of language games about that 'Big' one should get rid of the 'déjà-vu' matrix which is the main obstacle in thinking of the 'New' which we are trying to pose as The Problem/Target of thinking and understanding. Otherwise we are forced to make the very elementary (logical included) mistake of reductio ad absurdum and translate everything that-is-new into something 'already seen,' that already 'had been.' That form of logical mistake at the level of conclusions is going extremely well together with already mentioned - actually technological meta-language of economy, with the neo-theological mumbling and void rhetorical argumentations 'based' on 'Nature,' 'Un-changeable,' etc. To put it in Wittgensteinian way: only the perspective of not confounding 'quantitative' Big (in terms of mathematics and statistics, for example) with 'qualitative' Big (for example in the sense of philosophy) language games, opens the chance for understanding the next two very important notions from these important years: that of 'New Deal' and of 'Big Society' itself.

F. D. Roosevelt was the first to spoke seriously (at the level of the concept, idea) about the New Deal in political and not in just economic terms. That is something which appears in connection with the elections, which he won exactly on the political platform based within the language games of the 'Big society.' Why is so important to emphasize so 'obvious' element of analysis? The reason was that in the circumstances of the 'Big depression' - that type of argument was the starting point for his administration - the Old Deal (and that is 'capitalist society') was not functioning well any more and (even) was not even possible any more (in the sense of the previous form/s of its functioning). 'New Deal' - in radical difference to Old Deal - was not Roosevelt's pre-ordered and planned enterprise in the sense of any kind of violent revolution in European sense of party revolutionaries (as in Italy, Germany, ...) It was rather something into which he was forced and even not prepared for (how to be prepared for the 'death' of something or someone?).

Besides, in the given circumstances of the us a of the time, the force and violence were not primarily on the side of the party revolutionaries (subjectively producing revolutionary violence), but it was rather on the side of the Old (capitalist and in crisis/depression!) System itself! Roosevelt and Us A as such, grasped as system's totality, so to speak were 
forced by the given (unexpected) events and circumstances - such as hunger, unemployment, threat of Left and Right revolutions (in European sense from the beginning of the 2oth century) - midst the dissolution/implosion of the entire capitalist society. In that kind of 'unexpected New reality' - without any preparation for it ... - the New Deal itself was so to speak an 'emergency exit' and hope for us a as such. Simultaneously, the New Deal in the narrower sense was as kind of New Method of building something as the New society. ${ }^{10}$ New Deal appeared as the possibility to escape the existing capitalist trap of depression. 'Capitalist trap'?

Of course! It was - for the generations from the thirties (not before and not afterwards) - a kind of 'capitalist trap' which captured the entire (capitalist!) society, its citizenry, producers, owners, all forms of life, within a definite dead end! How is it possible to explain this - according to my understanding - most important point (even in the 'ontological sense' if I am aloud to use that kind of designation)? My answer is: only outside of the dominant meta-language of today's economics. What I'm trying to emphasize is also that Roosevelt's argumentation was not at all revolving around economy of the time (for example 'for or against capitalism,' 'for or against productivity and efficiency,' and similar types of thinking/arguing). It was - it seems to me that nothing else was possible - spoken out mostly in terms of 'entire society', trapped and self-blocked within the capitalist dead end. Of 'entire society'? Definitely! If it were not the entirety of the society under the threat, it would not be at all possible to generate exceptionally important revolutionary concepts, opening the possibility of entirely new, Big Society.

Our next important question posing the problem is: what were the political and rhetorical functions of the 'Big Society' at the level of language games of that time? There are no serious doubts that Big Society was the key concept ('meta language' of the rime) that was - above everything - critically targeting exactly its opposite. Moreover, Big Society was the powerful (linguistic, rhetorical, political and analytical) device at least for opening the new prospects for tens of millions of citizens, workers and farmers who supported the president. One should thus ask about the reason(s) (arhein) of the application of the very term 'Big Society' and its family of language games? The term (entire family of terminology revolving around it) was functioning as completely New revolutionary language game targeting something of the highest importance. The problem here is that exactly the most important thing, it's opposite (opposite 
of 'Big Society'), was not even mentioned and really functioned chiefly as an 'invisible-No-Thing.' This invisible could and should be termed as 'small society', without any prospect of making a mistake. To put in short form, in order to grasp the full 'meaning' of the 'Big Society', its central and most decisive role in the language games of the time, we should first of all discuss the problem of its opposite, that of the 'small society.'

What was, what could be the 'small society'? The answer: everything concerning the 'Old society', the capitalist society being in depression, the form of society being not desired and not possible any more, the society which came into a dead end exactly with the appearance of the 'Big depression.' But why would one employ the name 'small' (society) in order to understand the proper meaning of 'Big Society'? The reason is again rather simple one. As a matter of fact New Deal was presented as literally The-Deal-For-All: for ordinary people (workers, farmers, intellectuals, whites, blacks, even foreigners, ...) and not only for 'the few' (as Roosevelt used to speak of it). ${ }^{11}$ Finally, the main point of distinction between 'Big' and 'small' in the dominant family of society language games of those terrible days, was radical and revolutionary (all conservatives immediately realised the dangerous revolutionary potentials of Roosevelt's position). New Deal was articulated in terms of inclusiveness and not exclusiveness, to put it in another, today probably more understandable perspective.

Synthetically speaking, Roosevelt's 'New Deal' grasped as Big Society's revolution was not 'violent revolution' against something (as it was the case in Europe in all above mentioned revolutions: socialist in Russia, fascist in Italy and nazist in Germany) but rather silent revolution 'for something.' That 'for something' - and not against (for example 'against capitalism,' as was the logic of socialist revolution in Russia, partly also in Italy and Germany, and only partly) - was and remains the Big Society itself as a kind of a 'positive new project', to put it in today's managerial parlance. The 'Big' here - within the societal language games of the time meant primarily inclusiveness of the Society for all inhabitants of the USA (decades later, L. Johnson was repeating the same' Big Society' language games in times of Vietnam war, of racist conflicts in the South, and the same - in vain, of course - tried Obama, even Trump today).

SILENT AND FORGOTTEN TOTAL SOCIETAL REVOLUTION OF INCLUSION

Who and what was the target of 'Big Society' and the 'New Deal' approaches and practices? Abstract answer is already given: small society 
was the target, and the old deal was the target as well. But that is only one, in my understanding less important side of the highly important coin we are trying to understand. The question needed here is: what was the 'concrete meaning' of that kind of revolution midst the given desperate circumstances of the thirties? Analysis of the Roosevelt's legislation and governmental measures shows that in reality his main target was primarily Big Capital (that is the reason for opposition coming from these sides of society, for big fights against the New Deal, ...). Exactly Big Capital was the epicentre around which was organised that which was - from Roosevelt's administration - targeted as 'small society'. Exactly Big Capital as the epicentre of small society ${ }^{12}$ - was 'The-reason' for the problems of (Big) depression. In order to reach the Promised Land of Big Society (that of inclusion of all Americans), Roosevelt was forced (observing from his perspective there were no other solutions!) to somehow exclude or at least to diminish exactly the role of the Big Capital. Consequently, through targeting Big Capital and only (only!) in this indirect way (difference with regard to more direct Europeans leaning on party violence) of targeting the capitalism itself, it was possible to hope and even to develop Big Society and get a highly desired New Deal. This goal was reached primarily through the numerous governmental (and managerial!) measures.

It was reached, for example, through the 're-setting' of the old existing financial 'settings' (Roosevelt's first move after the elections targeted financial/banking sub-system), and through opening of the society (that is New Deal and New Society as the new direction of post-capitalist development!), through the enormous legislative production at the beginning of the thirties. ${ }^{13}$ Of substantial importance here is to understand that just at the point when - economically understood - industrial production of things has stopped ('Big depression' of small capitalist society!), the enormously legislative productivity of Roosevelt government started. Started to do what? It started to unlock the possibilities for development of the New Society, of the Big Society, of the New Society of inclusion. The point was not at all solely to open the possibility for the 'new economy' - that was a socialist perspective, for example in Soviet's NEP (new economic politics) during Lenin's and Stalin's years and conservative perspective in the USA - but for the New Society in the largest sense. Economy as 'production of things' remained more or less the same in all these years. Rapidly changing was the very context, the entire New Society in the sense of 'implementation' of completely, revolutionary new Inclusive Society (Big Society) which 'resulted' in post-capitalism. ${ }^{14}$ 
But this is only one side of a rather multifaceted coin. It cannot be underlined enough that this completely extraordinary situation of depression should under no circumstances be termed in categories of free-will (as usually is the case in social sciences, especially among those leaning to the left). This would as a rule result in language games about 'making revolution,' or 'manufacturing revolution, by this or that 'revolutionary subject.' Roosevelt and his government were not any such kind of (revolutionary) Subject, and Post-capitalism was not at all in advance planned form of New society by any sort of a free subject or any subjective free will whatsoever. Post-capitalism was thus not firstly premeditated and then implemented grandiose project (as socialism, for example), it was and remains incrementally established counter-system (counter to capitalism), born out of the purest possible necessity of Big/Great depression. It was somehow the 'only' solution within the given extreme circumstances and not any kind of choice being open to this or that kind of free will. The Us A and Roosevelt came to post-capitalist 'anti-position' and 'anti-system' not through attacking capitalism but from the opposite direction: by defending it! Post-capitalism was not longed for but happened as an entirely unpredicted result of the struggle for elementary survival of the System of society as such. Exactly such silent and unpredictable path of post-capitalism's materialisation amounts to the explanation why there is almost no serious sign of the recognition of the very existence of post-capitalism whatsoever.

Anyway, here it is possible to isolate at least four basic moves of Roosevelt's government, but only in an abstract way, of course. First, already mentioned financial consolidation, connected with the numerous 'faith' and 'trust building' procedures. These were the task for governmental legislation, but consisted to the large extent of the rhetorical (and political) 'food,' being packed in numerous presidential speeches which aimed at the 'trust building', or better, at the creation of hope midst the completely hopeless surrounding of the day. Radio speeches and newspaper dissemination were the paramount vehicle for this kind of hard governmental work, lasting for a few of the harshest years. Second, rather careful and step-by-step marginalisation of the decisive influence of the richest ('anti-trust', anti-monopoly legislation, diminishing profits for private enterprises, ...) took place, and simultaneously a promotion of the 'activity' of 'ordinary working people' (opening the space for trade unions, new strike legislation, etc.). Third, only on the basis of two additional elements was it possible to rebuild the social trust: with the control over 
the prices (wages of farmers \& workers, 'prices' of capital \& interest rates included) and with enormous investments into the work force, and not in Capital (that was conservative conception, and this difference is the central one for understanding the 'concept' and idea of New Deal). All these (and much more of them not even mentioned) measures were promising only on the basis of highly sophisticated (for that time) managerial (governmental) control over the role of the 'blind' Market forces.

\section{INVESTMENTS IN SOCIETAL BEINGS}

At this essential point we reached now with regard to investments, we should be extremely cautious and as exact as possible. They were not investments into the work as such but rather, the investments into the workforce. The question is how to grasp this sensitive, and not so ordinary conceptual difference correctly? There were not only investments in hungry people and their possibility for survival, but also into something as 'their dignity', and exactly that was a highly important 'moral side' of the Roosevelt project, which cannot seriously be tackled here. ${ }^{15}$ However, as far as this element is concerned, as it is consisting of the so called 'public works,' I should say a few additional sentences about it. Public works were the Roosevelt's revolutionary project which perhaps even saved the us of the time (in the sense of 'from the violent revolution' at least). Public works (electrification, road \& bridge building, infrastructure, ...) were not at all profitable in any of possible hard economic terms or meta-language games of Capital(ism)! Quite the opposite was the case: judged from the point of view of economic efficiency and Capital(ism) they were completely 'unproductive' (exactly that was the ground for the attacks on them from the conservatives). These huge investments were in a way explicitly anti-capitalist (anti-small-society), and simultaneously that is the core of my thesis - post-capitalist! Observing from the point of view of capitalism ('small society' being in Big depression) there were par excellence new kind of investments. Besides, such a move was only possible on the basis of the already mentioned 'Roosevelt's morality' and due to the launching of 'virtual' ('not-yet-existing') money-profit which was taken from the next generations, creating the problem of debt, still present in USA.

Nevertheless, the central emphasis in this connection is the following one: although they were not 'productive' - observed from the perspective of narrow economic language games (and from the point of view of capi$\mathrm{tal} /$ ism in the sense of many-profit), they were extremely productive from 
the point of view of the Big Society (post-capitalism) and its endurance. It was the investment into the foundation of the New, Big Society which was the 'real object' of Roosevelt's 'desire' and his ideals. The crux of the matter here is this one: the very inner logic of escaping the Great depression developed by Roosevelt's government was not at all economic one! It was rather the societal (and social - here is the location of the mentioned Roosevelt's morality). These two different 'logics and principles' (economic and societal) are not at all the same and One logic and principles! They are not the same language games resulting into the same politics and action and into the same results. As already emphasized above, the investments which took place were not invested in capital(ism), not in production grasped in economical way (in productivity, efficiency), but into the work force, and later on - especially in $\mathrm{WW} \mathrm{II}$, when the opportunity appeared - also into the working places.

The important - if not even decisive - question here is: what that 'work force' meant, how to understand that revolutionary new point (especially from the perspective of the history of the Us)? It was simply the investment in the working people in the sense of the all members of Big (not any smaller) Society. To put it in more direct way, these investments did not go to the members of this or that enterprise and factory any more (that is something that 'new capitalist' himself had to do), but in the completely new, social and societal direction! The investments went to the members of the Big, inclusive Society (a kind the us form of 'welfare state') of social beings. The underlying logic of Roosevelt's government was not economy \& capital (capitalist logic) any more. That logic was even seen as a kind of 'ill object' in desperate need of larger/societal and social care. The underlying logic of Roosevelt was (Big) Society itself. Exactly that revolutionary change in emphasis form/from economy to Society as such (which is not possible to 'see' from the perspective of economical/capitalist fundamentalism) was The revolutionary new paradigm which was - if at all - only partially and marginally present in the context of the previous, pre-depressed (small) capitalist society. The point was: in that radically new perspective, human beings, men and women, were grasped as social beings ('Thomistic element' from which the new morality progressed) within the new notion of Big Society, within New Society. Individual in Roosevelt's eyes was not only homo faber any more (as in economic fundamental capitalist form of conservative thinking of these and latter days) but was rather a social being (ens socialis in Aquinas parlance).

What counts here is different understanding of something very funda- 
mental still today. No more investments in capital and in workers (as it was in socialism, fascism and nazism) and consequently in 'production of things,' but above all in a completely new creature: that of a buyer, consumer grasped as 'social being.' To put it differently, the largest context that needs to be grasped about Roosevelt's fundamental moves is that his point and emphasis was not only production and economy (as in capitalism, socialism, fascism and national-socialism included), but rather investment in societal beings and their 'societal' consumption which started to function as new - now it is possible to say and properly understand 'societal economy' (post-capitalism). That was the beginning of 'social economy' about which all today's managerial (not economical in the narrow sense anymore!) theories are speaking when arguing about 'social capital' and similar 'new paradigms.' ${ }^{\text {'6 }}$

Fourthly, and most importantly, Roosevelt's government took the initiative which is completely unthinkable in any kind of former capitalist arrangements (understanding capitalism as a whole). It took the position of the Manager of the entire (Big) Society in silent, invisible, but deeply revolutionary manner. Various governmental bodies - employed and led by government, even by Roosevelt himself - started to lead the entire body of Us A Big Society as being one and big family/social enterprise. To put it differently and in slightly oversimplified form: the role that once upon the time (before Big depression) was played by capitalist (in capitalism) at the level of the factory (enterprise, company) was somehow overshadowed and even overtaken by the revolutionary new supreme role of government, led now by governmental managers. In these circumstances Roosevelt himself became The Manager of all (his) managers. They managed not this or that company, but now the entire Big Society of AmericaAs-One-Big-Company.

That New Big Society of the US A was not understood any more as society (die Gesellschaft) or community (die Gemeinschaft) of workers and capitalists (company, enterprise, economic type of fundamental miss understanding) in previous sociological and economic language games. It was rather grasped in a radically different way and developed ('social constructivism'), as a lively organism in terms of the total 'Social Body' (Aquinas). For example, the 'enterprise' was not any more the centre of society (as it was in capitalism and socialism, consequently the role of economy as a kind of 'basic-all discipline,' 'science'), it was not 'the central cell of society' anymore, but only of economy (schematically speaking: predominance of society over economy in USA, and predominance 
of state over economy in Europe, ...). In that way a completely New kind of Enterprise (social, societal enterprise) in the sense of the 'Enterprise of Big Society' took the supreme, most decisive role which is still not yet at all grasped in entire social sciences, still trapped in economical fundamentalism. Only from that kind of the fundamental revolutionary changes (the changes in the fundaments of the 'fabric of the social') and on that Roosevelt's 'basis' from the thirties it was possible that 'international' and 'big enterprises', 'multi-national-enterprises' which appeared after WW II, shape our entire today's existence. Solely on that 'societal' post-capitalist (and not capitalist anymore!) basis from the thirties globalisation has become possible...

\section{Management of the Big Society as the New Paradigm of Post-Capitalism}

There were three outstanding points and sets of new forms through which it is possible to understand the 'silent' - still in a way invisible - Roosevelt's post-capitalist revolution aiming at the Factory of Society or projecting the Big Society as productive Factory that include all Americans. Firstly, it was already mentioned that there was complex of macro leadership of (governmental) managers functioning, of course, from top to the bottom of entire Big Society. Secondly, there were crucial, revolutionary important changes in the complex of investments (especially in the mentioned concentration and the direction of investments), and thirdly, there were, consequently, radical changes in the complex of property.

\section{MANAGER AS THE KEY PERSON IN TOTAL SOCIETAL}

REVOLUTION OF THE BIG SOCIETY

Besides what was said above we should also strongly emphasise the very logic and magnitude of changes in leadership (managerial leadership-ofBig-Society). Traditionally, capitalism was grasped as led by the invisible hand,' which meant that the sovereign role of the market was somehow central to any capitalist economy. But that is - as already shown - only the economic (partial) side of the societal coin which was of paramount importance for Roosevelt's revolutionary project. Society could not be led in the same way (that is the point which conservatives of all walks of life were never able to understood), especially not in an allegedly democratic surrounding. On the contrary, society is desperately in need of something more and different from the capacities of the invisible hand. Speaking at 
the metaphorical level, society desperately needs something like 'visible hand. ${ }^{17}$

Such metaphorical 'visibility' is not just about 'the government being visible, or that the 'governmental business' should be 'transparent,' as it is usually argued in conservative and liberal literature which is based on the meta-language, still fundamentally mumbling about economy. Neither is it about setting down 'basic parameters' for 'business' (the 'minimal state' post-modern ideology in various forms). The problem of society-leading and of total, societal (not only social!) leadership, is revolving around the problem that the leaders of society should somehow plan and even predict the 'coming' events. Or better, they should plan and even produce the events and (post-festum) re-present them as 'inevitable.' These events - at the level of society - cannot function like the 'natural phenomena' in the sense that their appearance is left to society's own 'natural laws' (as fundamental meta-language of conservative economy uses to put it when speaking on Market/invisible Hand).

Society-leading means much, much more: it means the ability of - literally - manufacturing events in the sense of production of the society itself (society as self-production). 'Producing society' here means to produce 'fitting' societal relations and 'right,' proper social forms of 'normal' relationships and behaviour at large (in totality). To put it in the form of a very old distinction: the economic logic is a logic which can function at the level of this or that kind of 'production of things' (commodities, their consumption included). The societal (not necessarily social) logic is mainly the logic of the 'production of people, to put it into Marxian words, of their physical, social, psychological, and 'behavioural existence' in the sense of becoming 'social' and not 'anti-social beings.'

This extremely large, not any more minimal 'machination' of the people enclosed in the factory, is approximately that which Foucault detected as 'bio-politics', and should now be present strictly in every cell of the Big Society itself. It must be ingredient of planning immigration, jobs, schooling, social behaviour, of the very planning of the rates of mortality and even of 'normal' criminality (not to speak about the planning of Wars). Leadership of total, Big Society, should not count on the regulative institution/fiction of Market as its automatic organiser (Descartes' idea of automaton). There is no - not in the nature and not elsewhere in human creativity - such a thing as a man or a woman 'as thing.' The point that we should face today - understood in an extreme form - is the following: if one (regardless of whom and why) wants to produce such kind of 
commodity - man and women as the thing, as commodity - one must be able of far reaching, so to speak total, planning. One has to be able of total (total!) organisation, of total producing and controlling of the societal ('bio') enterprise of society! Exactly that was the point in Roosevelt's revolution based on the people (Big Society, 'American people') and not on 'things' - the pattern which died together with the Roosevelt's fundamental revolution of old (capitalist) society. ${ }^{18}$

The crucial point here to understand is the very centrality of that historically new person, of the Manager as a new form of social being (ens socialis) or a Social-being-proper. There is no doubt that from the point of view of economic (and economic meta-language games) capitalist (private ownership, private initiative, private investments, the role of the market) and capitalism are the very centre of the system. But observed from the point of view of the entire society (Big Society not known in the USA before Roosevelt's revolution), the very economy (and capitalist, commodity production included) has become just one of (or among) subsystems of the Big Society and nothing more!

\section{FUNDAMENTAL ${ }^{19}$ REVOLUTION IN (GOVERNMENTAL)}

PUBLIC INVESTMENTS

Roosevelt's macro analysis concerning the 'small society' and 'old deal' - in the meaning of capitalism which led to the crisis and depression was in a fact very simple one and simultaneously quite exact and elaborate. Investments (based also on credits and banks which caused problem of financial looses in 1929) were mainly in private (capitalist) hands and their interest groups and larger groupings. In order to struggle against the depression Roosevelt's team targeted exactly that areas of small society which were based on old deals among big capitalists (magnates, tycoons, ...), especially those tightly knitted around the banking, financial sub-system. New managers from the Roosevelt's government strictly blocked the money flow towards these groupings ('small society') and redirected it. They redirected it in the first place towards the government (themselves), and towards the Big Society as explained above. In result the government (its managers!) suddenly became the very epicentre of all the revolutionary events, and/or the main investors. The government also became (in the forties, especially due to the World War II) the main 'spending factor' ('militarisation of society' was described in Us A sociology only in fifties and sixties, after epochal speech given by Eisenhower!) at the level of entire Big Society. Exactly spending (under the influence of 
Keynesianism from Europe) has become the dominant form of regulation of the entire metabolism of society (Body Society). To put in another parlance, the spending (and not production!) has become the very epicentre of the planning of entire 'fabric of Big Society.' And that was already the very foundation of the post-capitalist problems we are facing in our own depression of today (2007/2008 and onward).

\section{REVOLUTIONARY CHANGES IN THE STRUCTURE \\ OF PROPERTY: MANDATORY PROPERTY}

Today's reasoning about property is usually trapped into still important but simultaneously oversimplified distinctions made by Berle and Means (1968) theories, targeting the 'difference' between possession (property) and its 'use.' The 'management' of property in this 'distinction' is understood in a way that capitalist simultaneously somehow represents both, owner and manager, while the manager is just someone managing/using capitalist property. The problem with this quite important distinction, which has become 'classical' in social sciences as such, was and remains that it simultaneously opened a new possibility of thinking but it also kept secret - if not even completely hidden - something even more important: namely, the very appearance of a new form of property, that which somehow transcends the private property. The point is that Berle and Means' (1968) 'distinction' was still made under the fundamental and monistic (Locke's!) quasi understanding of property in the sense of private property horizons as absolute ones.

As already strongly emphasized, the very central figure in the revolutionary post-capitalist new situation of the thirties was not capitalist any more. It was rather a completely new kind not of proprietor but that of the leader, actually of Manager. As far as the property was (and is!) concerned it is important to realise that the manager was not any more 'playing' any kind of 'production game' with and for his own, private money, property and financial resources. He was rather playing the game with something radically else and mostly 'invisible': namely - and that is the pivotal point of the paper - with public money or to put in a better form, with public debts! The new game of post-capitalism was played through the so-called 'financial industry,' mostly through the 'politics of debts' and trading also with debts: first with credits and later on with leasing (during and after WW II, starting with land-lease 'projects' Roosevelt-Churchill ... ${ }^{20}$ ). Our problem of thinking and understanding the contemporary situation in that ${ }^{21}$ connection is that today is not enough to speak about produc- 
tion or trade or commerce and similar 'economical problems.' Today we mainly have problems with production, trade and commerce with debts. We are in radically different non-position and non-situation: we are not in any 'positive position' but rather in totally 'negative situation,' we are not dealing with money, but rather with debt!

If one wants to put here the (here) merely tackled problem of property into the 'pure form' of a model, then it is possible to say that for capitalist (within the circumstances of capitalism in which the figure of capitalist is the central one) it is completely normal and even natural (that 'naturalness' is crucial for entire economical meta-language of today fundamentalism) that in the game of production (of things!) he (or she) is going to win or lose his (or her) own private property. This means that he or she is per definition extremely responsible to him/herself (looses in crises witnessed tens and perhaps hundreds of suicides of capitalists, but how many managers in 2007/2008/2009 took their lives?). And yet, what is for capitalist normal, is for the manager (central post-capitalist creature) - for a very good reason - not normal at all, but rather completely abnormal! Manager - and this is very important - is not the owner in the sense in which the capitalist used to be the owner of almost everything in the production (except of the work force that was hired). Moreover, if manager lost, that means that the public and not his own, private money was lost as well as maybe also his or her employment ('working place'). This radically new situation - unknown in history before the managerial revolution and post-capitalism - appears as 'illogical' and even immoral (quasi argument of 'greed' so often present in today neo-Thomist economic moralizing) only within the highly sophisticated and totally mistaken economic meta-language of today's thoughtless matrix. The problem is radically different and it must be grasped from an entirely different perspective: the fact that while losing, managers ('bad managers') are still gaining - also in times of total depression and great loses - is something completely normal in the sense of their leader-work as employees and not as capitalists any longer.

The central feature and new 'basis' of post-capitalist life (not only in the USA) which has not yet been seriously recognised and analysed by economists (let alone social scientist) was and remains the invention of a completely new form of property. ${ }^{22}$ This was a kind of 'public' or even 'societal' or 'socialised property' which - in times of Roosevelt - was first concentrated and then administrated (through huge public investments at the level of totality of society) exactly by the governmental managers 
of the Big Society themselves. The point here is that there was no escape from capitalist depression and economy in the late twenties and thirties without exactly this kind of revolutionary innovation in the field of property. Concentration of almost all societal resources (resources of entire society) in the hands of the government, projected debts as the main tool for investment, centralisation of all funds and investments, concentration of the entire capital of the nation/society, is just another way of describing the new form of 'public,' 'societal property'.

Such an exit from the depression was not at all possible within the old, small society of capitalism revolving around the private property and of invisible hand of market surrounding. A new brand of post-capitalist Big Society, now revolving around the public (mostly clouded in debts), 'societal' property, has come to existence. Moreover, within these revolutionary circumstances the production was not based on former, past accumulation (in hands of private capitalist) any longer but was shaped as the quasi production established on the (non)accumulation yet to come in the future. Because of the political circumstances in the Us A in which the elections are the same as the fight for management of total 'societal' investments of exactly this 'public,' 'societal' property, I call this new form of property 'mandatory property'. The winner of the elections is by definition winning exactly the mandate to manage (total management) the property of entire nation/society, that of private investors in banking systems, insurances, etc., of course, included.

To put it more philosophically: if by now the property used to function (still today's fundamental rhetoric of economy) as 'to have' (gr. ehein) complex, after the post-capitalist Roosevelt's revolution it has become the question of 'to be' (gr. einai). Moreover, in our times it developed into the problem of 'to be or not to be', which is just another way of definition of what today's globalisation is about as well as about its own, now visible, horizons and absolute limits.

In sum, mainly due to typically Western and ad infinituum exaggerated preoccupation with wars and 'political' (violent) revolutions, definitely The biggest and The most important revolution of the 2oth century - that of New Deal! - still remains completely invisible. The Big depression and the New Deal as a response to the depression of the time in the Us a was not any kind of the 'continuation of the capitalism with another means,' but it was rather the revolutionary turning point of no return! It was the way out/beyond of capitalism and towards the post-capitalism. 
Thus capitalism, as we usually understand it, evaporated already in the thirties and forties of the 2oth century. But its own language games still persist as the document of former times in which we are still trapped. These language games are becoming even more and noisier: they are literary shouting on us and even blocking our elementary potentials for thinking and understanding our own time. These increasingly fundamental and simultaneously completely void Capitalist language games of the previous dominant form of life sill persist mainly within today's new managerial forms of knowledge, in that of economics and social sciences at large. Moreover, they persist above all in our own quasi natural language, highly mediated and manipulated by the media machinery. It is mainly language of today academia and media. This is why the desperately needed criticism of managerial and economical as fundamental meta-language of today's social sciences is one of the most crucial necessity for serious re-thinking of our own time and its global problems.

In order to go 'beyond' these problems (as a matter of fact to reach 'here' and to 'come back' from the heavens of religions, ideologies, sciences and knowledge, preaching endless managerial Progress) it is completely out of place to try to explain what capitalism was. We rather need to understand what post-capitalism is about. Even less appropriate is, in order to come to grips with our own, existing depression of postcapitalism, to celebrate the alleged hopeful past of capitalism. We must be aware of and at least try to face the existing reality of nothingness which is exactly the nothingness of the post-capitalism itself. We have no problems with capitalism any more, our problem is post-capitalism, capitalism is not any more in crisis - it is dead - that which today is in crisis is post-capitalism.

\section{Notes}

1 I am using 'Capitalism' with capital 'C' to illustrate 'the ontological extent' ('substantial') of language games, while 'capitalism' with small c-letter stands for anti-political (republican and not democratic!), economic and social system in its Western existence ('existential', to put it in scholastic parlance). The very fact that the reality of Capitalism is obviously 'stronger' in today prevalent reductionist and deductionist kind of thinking and argumentations, and that it even hides the very possibility of thinking thatwhich-is outside of the intense generalised Capital-mumbling (ideological, political, pro et contra with regard to Capitalism), is among the reasons for my 'attack' on Capitalism as the kind of meta-language. The aim in 
this level of argumentation is to emphasize that capitalism is not material, empirical, 'real' pre-supposition of or for Capitalism, but that the contrary is the case: meta-language of Capitalism itself - its endless ideological language games, polemics, pro et contra 'argumentations' (from right, left and centre of spectrum) - is literally producing something as quasi Capitalism (mumbling capitalist language games) in its infinity. In that kind of 'bad infinity' we are mainly trapped as in our own golden 'scientific' cage.

2 The idea of 'language game/s' is mainly developed in Wittgenstein 1998 that of 'grammar' - connected with the concept of language games, of course in Wittgenstein 2004.

3 What I'm trying to emphasize is that we are somehow still living the same 'historical epoch' which started at the end of the twenties of the former century. 'The world economy is still struggling with its most severe crisis since the Great Depression, which started in 1929 and lasted until the mid 1930 s. On the one hand, the present crisis is a financial crisis which started with the collapse of the subprime mortgage market in the Us in summer 2007, which then gained momentum with the breakdown of Lehman Brothers in September 2008 and which reached another climax with the euro crisis in early-mid 2010. Under the conditions of deregulated and liberalised international financial markets the financial crisis has rapidly spread all over the world. On the other hand, the present crisis is a real crisis, which started well before the financial crisis, with an economic downswing in the Us. The financial crisis and the real crisis have reinforced each other, and the world economy has been hit by a decline in real GDP in 2009 - something not seen for generations. Major regions in the world are only slowly recovering from this decline, in particular the Euro area, the u $\mathrm{K}$ and Japan.' (Hein and Truger 2010, 1)

4 The 'managerial revolution' is quite important, but mainly overlooked and simultaneously undermined concept of James Burnham (1945), which tried to emphasize the epochal historical changes which took place during the thirties.

5 The very designation of 'Big depression' is grasped in this paper as that which - as something 'already worse' - has happen before Roosevelt and not that he made the 'depression worse.' The second, still today quite usual type of argumentation s coming from his critics, see for example in Higgs (1995).

6 Today depression (or at least crisis) could be also seen as the kind of continuation of the depression from the 1929/1932 (Hein and Truger 2010).

7 The language of revolution is something quite normal in today interpretations and understanding of New Deal, but it was different decades ago. Among probably the best explanations of literature in that sense is Franklin 
D. Roosevelt and his Third American Revolution, by Mario R. Dinunzio (2011). Dinunzio is emphasizing that the revolutionary 'measure of security and well-being for Americans became more explicit (exactly) in the New Deal.' (p. 2) So the New Deal is appearing as the visible and important historical revolution being paralleled with 'traditional' American Revolution ..., and put in the same line with revolutionary historical events as decolonisation of USA.

8 Speaking about thoughtless/ness I, of course, have in mind Hannah Arendt and her argumentations dealing with Eichmann.

9 'The very violent post-World War I downturn in 1920-1921 was the last of the "classical" recessions, where there was not significant consumer debt in the economy, and so prices could be allowed to drop precipitately. Once there was significant consumer debt outstanding, a drop in prices - deflation - was catastrophic because debt repayments then had to be made in more expensive dollars.' (Richards 2010, 7)

10 Top 10 New Deal Programs and agencies of the 1930s in the sense of building New Society and organized at the level of government were: Civilian Conservation Corps (CCC), Civil Works Administration (CWA), Federal Housing Administration (FHA), Federal Security Agency (FSA), Home Owners' Loan Corporation (HOLC), National Industrial Recovery Act (NIRA), Public Works Administration (PWA), Social Security Act (ssA), Tennessee Valley Authority (TVA), Works Progress Administration (W PA) (Kelly 2018).

11 Roosevelt usually spoke and emphasized the points in this rhetorical way: 'The test of our progress is not whether we add more to the abundance of those who have much; it is whether we provide enough for those who have too little.' (Example is from second inaugural address, 20. Jan. 1937).

12 Exactly that is the very (short, of course) 'definition' of the problem, as it was seen from the perspective of the new-dealers: 'Big Capital as the epicentre of small society', Big society as the alternative to 'small society' which means to Big Capital.

13 See more in Hawley (1966) and Hein and Truger (2010).

14 'Several of FDR's New Deal programs continue to help Americans today. Some of the more important programs that still exist offer the following benefits and protections. 1. A National Pension System. The Social Security system pays out old-age pensions (and has been expanded to include aid to other groups). It is funded through taxes on employers and employees. 2. Oversight of Labour Practices. Created by the Wagner Act, the National Labour Relations Board (NLRB) oversees labour unions. It also investigates disputes between management and labour. 3. Agricultural Price Supports. This program pays farmers to raise crops for domestic use rather than 
export. To receive payments, farmers must agree to limit the space they devote to certain crops. 4. Protection for Savings. After the bank holiday of 1933, the Federal Deposit Insurance Corporation (FDIC) was created. The FDIC insures bank deposits up to $\$ 100,000$. It replaces the deposits of individuals if banks close. 5. Regulation of the Stock Market. A federal agency called the Securities and Exchange Commission watches the stock market. It makes sure companies follow fair practices for trading stocks.' (https://www.quia.com/files/quia/users/nygardgeo/TheGreatDepression/ Effects-of-the-New-Deal)

15 Short, comprehensive and easy graspable some important macro data concerning the Great Depression and New Deal is possible to see in Richards (2010), for the 'humanitarian' aspect of the New deal see Eliot (1992).

16 The kind of arguments being implemented by Roosevelt is moral, not economical one. The most important word of those days was 'charity', also in the sense of his 'charitable government.'

17 See well elaborated Chandler (2002).

18 Critique of F. D. Roosevelt usually still today emphasizes another side of the coin in the sense that 'There are many economists, who feel that F D R's New Deal not only weakened capitalism, but that it also prolonged the Great Depression' (Rememberingtherepublic.blogspot.com 2015). This kind of total misunderstanding the point being the case in New Deal is not the subject of this paper.

19 Another important meaning of the 'fundamental' - which is not discussed here - is that dealing with the 'new class', that of 'proletariat', or to put in precise Dinunzio (2011, xi) parlance: 'Franklin D. Roosevelt's New Deal transformed a proletariat into a new class and in doing so fulfilled one of the promises of the original American Revolution. In the process Roosevelt saved American capitalism from its own excesses and won the enduring hatred of those thus rescued. Their venom was stirred not only by the cost of economic reform (any suggestion of even modest levels of taxation implied the demonic), but also and perhaps more intensely because this new revolution threatened the privileged status in American society that reserved to them a self-defined superiority'

20 See Clarke (1982).

21 Not new as such but new in the context of the US A history, while Europe and other parts of the world were already familiar with various forms of public, common and numerous another forms of property.

22 'People' ('American People,' 'American Nation') was radically redefined with the appearance of the Big Society. It has - among other 'things' - lost any political emphasis in terms of 'la nation' of the French revolution! 


\section{References}

Berle, A., and G. C. Means. 1968. The Modern Corporation and Private Property. New York: Harcourt, Brace and World.

Burnham, J. 1945. The Managerial Revolution or What is Happening in the World Now. London: Penguin.

Chandler, A. D. jr. 2002. The Visible Hand: The Managerial Revolution in American Business. London: Belknap.

Clarke, R. 1982. Anglo-American Economic Collaboration in War and Peace, 1942-1949. Oxford: Clarendon.

Dinunzio, M. R. 2011. Franklin D. Roosevelt and his 'Third American Revolution.' Santa Barbara, CA: A B C-CLIO.

Eliot, T. H. 1992. Recollections of the New Deal: When the People Mattered. Boston, M A: Northeastern University Press.

Hawley, E. 1966. The New Deal and the Problem of Monopoly. Princeton: Princeton University Press.

Hein, E., and A. Truger. 2010. 'Finance-Dominated Capitalism in Crisis The Case for a Keynesian New Deal at the European and the Global Level.' Paper presented at the 7 th International Conference Developments in Economic Theory and Policy, Bilbao, 1-2 July.

Higgs, R. 1995. 'How F D Made the Depression Worse.' The Free Market 13 (2). https://mises.org/library/how-fdr-made-depression-worse

Rememberingtherepublic.blogspot.com. 2015. 'F D R's New Deal Weakened Capitalism.' http://rememberingtherepublic.blogspot.com/2015/10/ fdrs-new-deal-weakened-capitalism.html

Richards, G. 2010. 'How Did the New Deal Work Out?' American Thinker, 29 June. https://www.americanthinker.com/articles/2010/06/how_did _the_new_deal_work_out.html

Kelly, M. 2018. 'Top 10 New Deal Programs of the 1930s.' ThoughtCo, 7 September. https://www.thoughtco.com/top-new-deal-programs104687

Wittgenstein, L. 1998. Philosophical Remarks. Oxford: Blackwell. - 2004. Philosophical Grammar. Oxford: Blackwell.

This paper is published under the terms of the Attribution-

NonCommercial-NoDerivatives 4.o International (CC B Y-NC-ND 4.0)

License (http://creativecommons.org/licenses/by-nc-nd/4.o/). 



\section{Forecasting the Success Rate of Reward Based Crowdfunding Projects}

Ivelin Elenchev

Independent researcher, Bulgaria

ineooo@aubg.bg

Aleksandar Vasilev

Independent researcher, Bulgaria

alvasilev@yahoo.com

The present paper develops three models that help predict the success rate and attainable investment levels of online crowdfunding ventures. This is done by applying standard economic theory and machine learning techniques from computer science to the novel sector of online crowd-based micro-financing. In contrast with previous research in the area, this paper analyses transaction-level data in addition to information about completed crowdfunding projects. This provides a unique perspective in the ways crowd-finance ventures develop. The models reach an average of $83 \%$ accuracy in predicting the outcome of a crowdfunding campaign at any point throughout its duration. These findings prove that a number of product and project specific parameters are indicative of the success of the venture. Subsequently, the paper provides guidance to capital seekers and investors on the basis of these criteria, and allows participants in the crowdfunding marketplace to make more rational decisions.

Key Words: microfinance, entrepreneur finance, crowdfunding

JEL Classification: G17, G19

https://doi.org/10.26493/1854-6935.17.51-77

\section{Introduction}

Crowdfunding is a method of financing business and non-profit endeavours that has a lot in common with micro-finance and crowdsourcing. In some aspects it is similar to the traditional forward contract. Crowdfunding gives entrepreneurs the ability to request capital from a large number of individuals in exchange for interest payments, equity or the delivery of a product at a future date. This is often done through an online platform that grants the project creator the ability to specify the amount of capital he/she is seeking, the duration of the campaign as well as any information about the firm or product that he/she wishes to present to potential 
investors. For other uses of web marketing, e.g., by energy companies, the interested reader is referred to Iovino and Migliaccio (2016; in press).

Giving a clear definition to crowdfunding is somewhat challenging as this emerging field of finance takes several forms. The oldest and most developed one is debt crowdfunding or peer-to-peer lending, which matches lenders directly with borrowers. Another subset of crowdfunding is equity crowdfunding in which investors receive shares of the projects they support. The present paper focuses on the reward-based form of crowdfunding which offers investors the chance to buy a product or receive a reward that will be delivered in the future.

Reward-based crowdfunding can be regarded as an over the counter forward contract between the campaign creator and the buyer or a preorder agreement with constraints set by the capital-seeker and the platform. The paper focuses on the prevalent in practice all-or-nothing scheme of reward-based crowdfunding, in which the funds gathered through the campaign are transferred to the project creator only if the project manages to reach its investment target. Otherwise, the investments are returned to the contributors after the end date of the campaign has passed. Neither the campaign creator nor investors face any charges in case of failure. If the project succeeds a portion of the gathered capital - usually less than $2 \%$ - is taken by the platform in the form of commissions, the rest is immediately transferred to the project creator. All projects that manage to reach or surpass their investment target in the specified duration are regarded as successful. Generally, platforms allow projects to continue receiving investments even after the campaign goal has been reached, unless the project creator has specified that he/she does not wish to do so.

The reward-based form of crowdfunding is a novel financing approach which is largely ignored by standard microeconomic theory and current studies. There is a clear lack of peer-reviewed research regarding the topic as crowdfunding researchers focus predominantly on more traditional peer-to-peer financing methods such as debt and equity crowdfunding in which risk can be easily defined. Through the application of existing theory to the investment dynamics of crowdfunding this paper develops several models that forecast the likelihood of success of crowdfunding ventures. The present paper is unique in crowdfunding literature as it analyses the development of crowdfunding projects throughout their duration as opposed to looking only at already completed ventures.

The information that the models provide serves as an objective mea- 
sure of risk which can be used by entrepreneurs to judge when their product has reached a stage of development that would be sufficient for them to receive the support of investors. Furthermore, the models aid capital seekers in determining how changes in project parameters such as the amount of capital required or the duration of the venture would affect perceived risk. Last but not least, the paper aims to provide entrepreneurs and investors with more precise expectations about the outcome of reward-based microfinance projects and thus allow them to make the optimal financing decision.

In the introductory section of the paper we will outline background information such as research goals and an overview of existing literature. This is followed by a section on data gathering and analysis which describes how information about crowdfunding campaigns was collected and how the factors affecting project success are evaluated. Subsequently, these factors are used in the creation of three distinct models forecasting crowdfunding success. Finally, the paper gives recommendations to capital-seekers and investors on the basis of the robustness of each model.

\section{CROWDFUNDING RESEARCH MOTIVATION}

Crowdfunding has some considerable weaknesses when compared with traditional finance, which include lacking or ineffective legislation, poor fraud control, reputation damages due to failed campaigns - all of them driven primarily by the lack of public information and understanding of the topic. However, the field is worth examining due to a number of factors, which according to the phenomenal growth of crowdfunding in recent years heavily outweigh the dangers and disadvantages. The unique opportunity for diversification that crowdfunding provides offers investors desirable outcomes at a low risk. The spread out campaign risk is allocated among a large number of buyers with similarly sized contributions. This allows the successful development of projects which would have been rejected by banks and venture capitalists.

Furthermore, the crowdfunding financing method allows for a lot of flexibility for both investors and project creators. For example crowdfunding platforms help producers in adapting to the underlying market demand at the early stages of production. They provide a market testing mechanism - the crowdfunding venture itself - that is more representative of actual market demand and often cheaper than a general consumer survey. Additionally, the all-or-nothing rule of crowdfunding enforced by the minimum funding threshold serves as a guarantee to consumers 
TABLE 1 Crowdfunding Growth Forecast by The World Bank

\begin{tabular}{lrrrrrrr}
\hline Year & 2009 & 2010 & 2011 & 2012 & 2013 & 2014 & 2015 \\
\hline Volume & 0.53 & 0.85 & 1.47 & 2.81 & 6.12 & 16.23 & 34.4 \\
\hline
\end{tabular}

NOTES In billion USD. Adapted from The World Bank (2013).

that the venture will be pursued only if the demand is met. This ensures consumers that they will not receive a lesser product in the event of inadequate funding. Furthermore, the active participation of consumers allows producers to determine which product features are desirable by consumers and ultimately enables investors to shape the final product through project feedback.

Platforms can be utilized to demonstrate consumer demand like in the case of Pebble, the first smart watch, which was initially rejected by venture capitalists. After quickly reaching and even surpassing its funding goal on the crowdfunding platform Kickstarter the product managed to attract a large amount of vc capital. Similarly, unsuccessful campaigns give their creators reliable information about the demand for their product at a very low cost. Furthermore, crowdfunding is sometimes used for marketing purposes. It allowed the creators of the Ouya video game platform to attract the attention of game developers before the product was released. The success of the campaign generated a lot of media coverage, which allowed the founders to draw more venture capital.

The rapid growth that crowdfunding has experienced in recent years certainly cannot be ignored. As presented in table 1 the total yearly funding volume of crowdfunding projects has expanded over 60 times from 2009 to 2015 reaching over $\$ 34$ billion. A recent report of The World Bank (2013) predicts that crowdfunding campaigns will reach $\$ 98$ billion by 2025 . The same report states that the industry is likely to surpass venture capital investments as early as 2018. This geometric growth rate is distributed among several industries and encompasses projects of widely varying size. A large number of local projects seek small amounts of capital. These ventures usually take the form of cultural events that do not generate revenue or small local businesses. These campaigns often have capital goals of less than $\$ 3000$ and are financed predominantly by regional investors. However, there is an increasing interest from entrepreneurs looking for an alternative to venture capital and traditional finance. The control, flexibility, low transaction costs and speed that crowdfunding provides to entrepreneurs and investors has resulted in 
a substantial number of large undertakings like the first commercially available $3 \mathrm{D}$ printer, the first virtual reality set, numerous music albums, movies, and $\mathrm{TV}$ shows.

\section{RESEARCH GOALS}

Although crowdfunding receives a lot of media coverage there is a lack of research and adequate regulation focusing on the subject. This is especially true when discussing the reward based form of crowdfunding which unlike debt and equity based crowdfunding rarely benefits from existing government policies. In many countries contributions to rewardbased crowdfunding campaigns are regarded as donations and project creators are not held responsible for their actions after their campaign has been successfully funded. This lack of government interest is in part due to the public belief that reward-based crowdfunding is wild, unpredictable and driven predominantly by fads. The unclear to the public mechanisms through which crowd-based microfinance functions leave the impression that the success of such projects is a matter of random chance. The current lack of information and clear understanding of risk in crowdfunding is damaging for all parties involved as entrepreneurs have to resort to less efficient financing opportunities and contributors are left unaware of the hazards associated with crowdfunding campaigns.

The goal of this paper is to show that consistent dynamics underlie the majority of crowdfunding ventures. This makes their development and eventual outcome predictable at a very early stage, which means that with the help of adequate technology both project creators and supporters could react accordingly. This greater understanding of the evolution of each project would result in a financing mechanism more widely available and more flexible than any form of traditional finance.

\section{LITERATURE REVIEW}

There has been little published peer-reviewed work on the topic of crowdfunding. Initially, the scientific discussion around crowdfunding revolved around the legal aspects of this novel financing mechanism. Subsequently a number of empirical studies dating as early as 2010 analysed market data and investor questionnaires and built the first economic frameworks for understanding crowdfunding. This section will provide a brief overview of the most significant studies relevant to this paper.

First, empirical studies in the capital-seeking category are mainly concerned with the factors leading to campaign success, the legal restric- 
tions of crowdfunding and the motivation of entrepreneurs for choosing this financing option. Belleflamme and Schwienbachner (2011) performed interviews with project creators in order to identify the main reasons for choosing crowdfunding instead of traditional sources of capital. The prompt collection of funds was pointed out as the main objective. Other motives included attracting public attention and testing market demand for the product or service. In similarly structured interviews Hemer (2011) identified another significant reason why entrepreneurs preferred crowdfunding - the opportunity to obtain financing at early stages of product development.

Belleflamme, Omrani, and Peitz (2015) explore the factors driving crowdfunding project success. He identifies that projects with a social cause or non-profit oriented structure have a higher probability of success. According to his research investors perceive non-profit organizations as more credible than small businesses. Mollick (2013) analyses transaction data from a popular crowdfunding platform and concludes that the probability of project success decreases as the project capital target or project duration increases. In addition, Mollick (2014) finds a relationship between the size of a project creator's public social following and the probability of project success. Agrawal, Catalini, and Goldfarb (2011) analysed a market of musicians seeking capital through crowdfunding to understand whether crowdfunding exhibits location constraints similar to venture capital fundraising. His findings suggest that this is indeed the case, although to a lesser extent compared to angel investing and venture capital funding. Burtch, Ghose, and Wattal (2013) examined how timing has affected 100 similar crowdfunding campaigns, finding that projects created on week days exhibit a slightly higher chance of success. Cultural, local and emotional biases seem to be the causes of this relationship, as discussed by Lin, Prabhala, and Viswanathan (2009), Viswanathan and Prabhala (2013) and Burtch, Ghose, and Wattal (2013).

Next, understanding the way investors analyse crowdfunding campaigns is vital to building a model that accurately represents the dynamics of crowdfunding projects. Allison et al. (2014) and Lin, Boh, and Goh (2014) both reach the conclusion that capital providers are not motivated only by financial rewards. Interviews with supporters of crowdfunding campaigns indicate that their investment decisions are in part driven by the interaction with other likeminded individuals due to the close relationship that crowdfunding projects build between creators and supporters. Others state that a general interest in the category of the product fuels 
their decision to support projects for the sake of innovation. These findings were confirmed by Gerber, Hui, and Kuo (2012) who also found that a large share of project supporters desire to be able to interact with the project through social media. Several studies Everett (2010), Freedman and Jin (2014) and Zvilichovsky, Inbar, and Barzilay (2013) discover that larger social networks increase the probability of funding. Herzenstein and Andrews (2008) and Dholakia (2011) examine the degree to which investors mimic their peers and conclude that the herding investment behaviour reduces default rates of peer-to-peer loans. Kuppuswamy and Bayus (2013) find evidence of herding behaviour in reward-based crowdfunding - according to them the herding behaviour is due to payoff externalities as backers tend to support projects closer to reaching their capital goal due to the higher probability of project success.

Studies of investment timing show consistent signalling behaviour that encourages other supporters Koning and Model (2013). Qui (2013) found that blog posts and media coverage in general is positively correlated with project success. Kim and Viswanathan (2013) focused on crowdfunding in the market for mobile applications and found that early endorsement by industry experts increases the likelihood of project success. Hildebrand et al. (2013) shows that endorsements by others are seen as more credible if they are linked with investments, however increased publicity by word-of-mouth also proves to be beneficial to a lesser extent. According to Mollick (2014), investors rely on quality signals similar to those used by venture capitalists such as previous success of the entrepreneur, team quality and product development stage.

Crowdfunding platforms facilitate the matching between entrepreneurs and investors. They are communication, information and interaction portals that determine many of the factors influencing project success. According to Elsner (2013) as well as Haas, Blohm, and Leimeister (2014) the role of the platform is crucial in alleviating information asymmetry and deterring fraud. Ordanini et al. (2011) outlines the business models that the major platforms employ and shows the measures through which they facilitate the building of trust between creators and supporters. Wash and Solomon (2014) analyse whether the all-or-nothing funding model is optimal for all campaigns and conclude that investors tend to contribute higher amounts and at a higher rate in such projects. The researchers recommend the all-or-nothing approach to platforms targeting high risk projects that are at an early stage of development.

Chen, Ghosh, and Lambert (2014) researched whether employing the 
TABLE 2 Number of Analysed Crowdfunding Projects

\begin{tabular}{llr}
\hline Platform & Date range & Number of projects \\
\hline Kickstarter & $05 / 2009-12 / 2016$ & 422,392 \\
Indiegogo & $04 / 2010-12 / 2016$ & 247,820 \\
FundRazer & $10 / 2011-12 / 2016$ & 114,952 \\
RocketHub & $04 / 2010-12 / 2016$ & 45,640 \\
\hline
\end{tabular}

auction model in order to fund crowdfunding projects would result in a more efficient market by analysing recorded transactions on the platform Prosper.com. His research indicates that the auction model does not generate outcomes in the best interest of capital seekers. The increased level of competition in crowdfunding platforms was analyses by Maeschle (2012). Her findings suggest that with the surge of new investment platforms capital providers tend to prefer more open platforms that publish business information about the projects such as firm size, ownership structure, location and balance sheet data.

All these papers offer valuable information, but few research projects to date have provided large-scale insight on the empirical dynamics of crowdfunding. The majority of existing studies have been aimed at campaign investors, not project creators. Since crowdfunding is a new financing method it could potentially be disruptive to traditional finance. There are several areas that should be researched further before we can truly understand what can be achieved through crowdfunding. First, we must find out if the successes and failures of crowdfunding projects are driven by similar underlying dynamic as Venture Capitalist campaigns, or other known financing schemes. Second, since crowdfunding is less dependent on geographic location in comparison to traditional finance we must understand the role, if any, that location has in successful campaigns. This paper attempts to build upon the existing research in these two areas.

\section{Discussion of Data: Some Stylized Facts}

The data used in the development and analysis of the models that this paper builds was gathered from four global online crowdfunding platforms, namely Kickstarter, Indiegogo, Rockethub and Fundrazer. A total of 830,804 crowdfunding ventures were analysed. Table 2 provides a breakdown by platform of the projects used in the analysis.

The data features information about both successful and failed projects. The development of each campaign is represented by a time series of ob- 
servations taken at equal intervals throughout the duration of the campaign. Each observation contains information about the amount of capital invested at that period and the number of investors. Additionally campaign parameters such as category, location, description and data about the campaign creator are taken from crowdfunding platforms and used in two of the models. Investor location was determined using data publicly available in platform user profiles.

Campaign characteristics of all completed Kickstarter projects were analysed and compared to determine their impact on project success. The conclusions that they reach become the framework on top of which our models are built. The following variables were used in the analysis:

- Project goal: The amount founders desire to raise through crowdfunding.

- Investors: The number of investors in the project.

- Avg. Investment: The average contribution amount.

- Updates: Capital seekers are encouraged to post progress information, called updates. These events represent efforts by founders to reach out to current and potential investors, and to inform interested backers about the developments in the project.

- Comments: Investors can post questions and comments in the discussion sections of active and inactive campaigns.

- Duration: The number of days during which a project accepts investments. Kickstarter allows this period to be anywhere between 30 and 60 days.

The coefficients associated with the significance of each campaign variable are listed in table 3 . The examination of campaign variables suggests that the leading positive factors for success in finished projects are the number of campaign updates and the average contribution. The leading negative factors for successful projects are duration and the total goal.

Table 4 shows the average value for each of the parameters in all projects as well as the same measurement for successful projects and campaigns in seven of the most popular product categories. This initial analysis suggests that on average successful projects had a goal twice smaller than the global mean. Additionally, the creators of successful projects were twice as active in terms of campaign updates as the average. There seems to be a big difference in the levels of activity of campaign creators between categories with design and technology projects performing well above the mean. The mean goal and contribution (pledge/backer) also 
TABLE 3 Crowdfunding Success Factors

\begin{tabular}{lrrrrrr}
\hline & $(1)$ & $(2)$ & $(3)$ & $(4)$ & $(5)$ & $(6)$ \\
\hline (1) Goal & -0.16 & & & & & \\
(2) Investors & 0.13 & -0.01 & & & & \\
(3) Avg. Investment & 0.19 & 0.12 & 0.02 & & & \\
(4) Updates & 0.45 & 0.03 & 0.16 & 0.09 & & \\
(5) Comments & 0.05 & 0.13 & 0.56 & 0.02 & 0.11 & \\
(6) Duration & -0.15 & 0.07 & -0.03 & 0.02 & 0.03 & 0.01 \\
\hline
\end{tabular}

TABLE 4 Crowdfunding Factor Averages

\begin{tabular}{lrrrrrrrr}
\hline Variable & $(1)$ & $(2)$ & $(3)$ & $(4)$ & $(4)$ & $(5)$ & $(6)$ & $(7)$ \\
\hline Successful & 0.486 & 1 & 0.485 & 0.391 & 0.455 & 0.466 & 0.53 & 0.62 \\
Avg. Funded \% & 0.762 & 1.524 & 1.12 & 0.66 & 0.789 & 0.553 & 0.611 & 0.823 \\
Goal & 12504 & 7462 & 13071 & 6974 & 11532 & 4395 & 7530 & 8347 \\
Investors & 70.3 & 132.5 & 167.3 & 45.2 & 192.2 & 64.5 & 66.1 & 53.5 \\
Updates & 3.99 & 6.42 & 5.12 & 2.11 & 5.31 & 3.12 & 3.83 & 3.68 \\
Comments & 8.53 & 17.2 & 21.34 & 3.13 & 4.56 & 2.74 & 5.23 & 3.12 \\
Duration (days) & 39.324 & 37.442 & 38.12 & 40.56 & 37.52 & 37.38 & 38.13 & 38.72 \\
\hline
\end{tabular}

varies heavily with categories featuring higher campaign goals receiving larger contributions. Ultimately, campaign category seems to be an important success factor.

It is important to note that this initial analysis was performed on data of completed projects, so the relation of all aforementioned variables to project funding dynamics is not made clear. Furthermore, data about comments and updates does not include the time of each action, meaning that they include actions performed after the project had finished. Evidence suggests that after project completion discussion in the form of comments and founder feedback are rare in unsuccessful project. Projects that have successfully reached their target are often actively monitored by those who have invested in the project and are still waiting to receive their reward. Such projects become a centre for discussion regarding shipping and product feedback. This heavily skews the number of comments and updates towards successful projects, thus the data about them in the initial regression should be taken with a grain of salt.

The success of traditional start-ups is often highly influenced by their location due to positive externalities such as spillovers from successful 


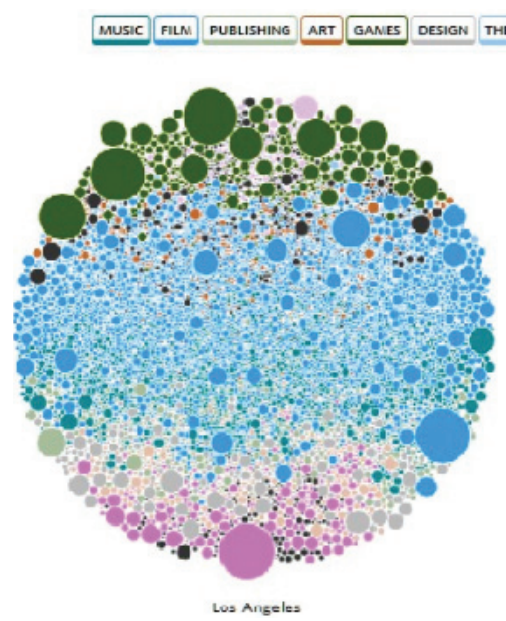

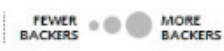

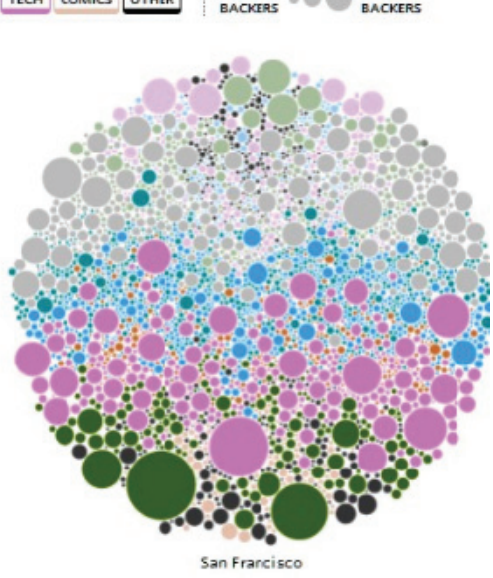

FIGURE 1 Project Distribution by City

projects, industrial clustering and lower hiring costs. In previous examinations by Agrawal, Catalini, and Goldfarb (2011) have shown that crowdfunding is not as dependent on location as venture capitalist projects, however an analysis of campaign location proves that it is an important factor that should not be ignored.

The geographical distribution of projects is uneven. Some regions have a disproportional number of projects in a specific category. Examples include Nashville which has a high concentration of successful music campaigns, Los Angeles which is dominated by film and San Francisco and San Jose which lead the technology and videogame categories. A visualization of the distribution of successful projects shown in figure 1 and figure 2 suggests that in some instances regional trends are very heavy. In particular, more than half of all fully funded projects in the areas of Nashville, Los Angelis, San Francisco and San Jose are in the categories that have traditionally been represented in local businesses. The established local culture and active communities lead to more rapid funding dynamics in projects that fall in these locally dominant categories. This effect is boosted by local-first features in many crowdfunding platforms that feature currently active projects to local investors.

Local and distant investors are different as shown in table 5. Local investors are more likely to invest before the ratio of capital gathered over the capital goal reaches $30 \%$ rather than later. In contrast, distant investors contribute more heavily at the later stages of the campaign when more 
TABLE 5 Crowdfunding Location Breakdown

\begin{tabular}{lrrr}
\hline Distance & Avg. investment & Total investment & \% of total investment \\
\hline Local (under 50 km) & 196 & 228,490 & $13.5 \%$ \\
Distant (over 50 km) & 74 & $1,313,060$ & $77.2 \%$ \\
\hline
\end{tabular}

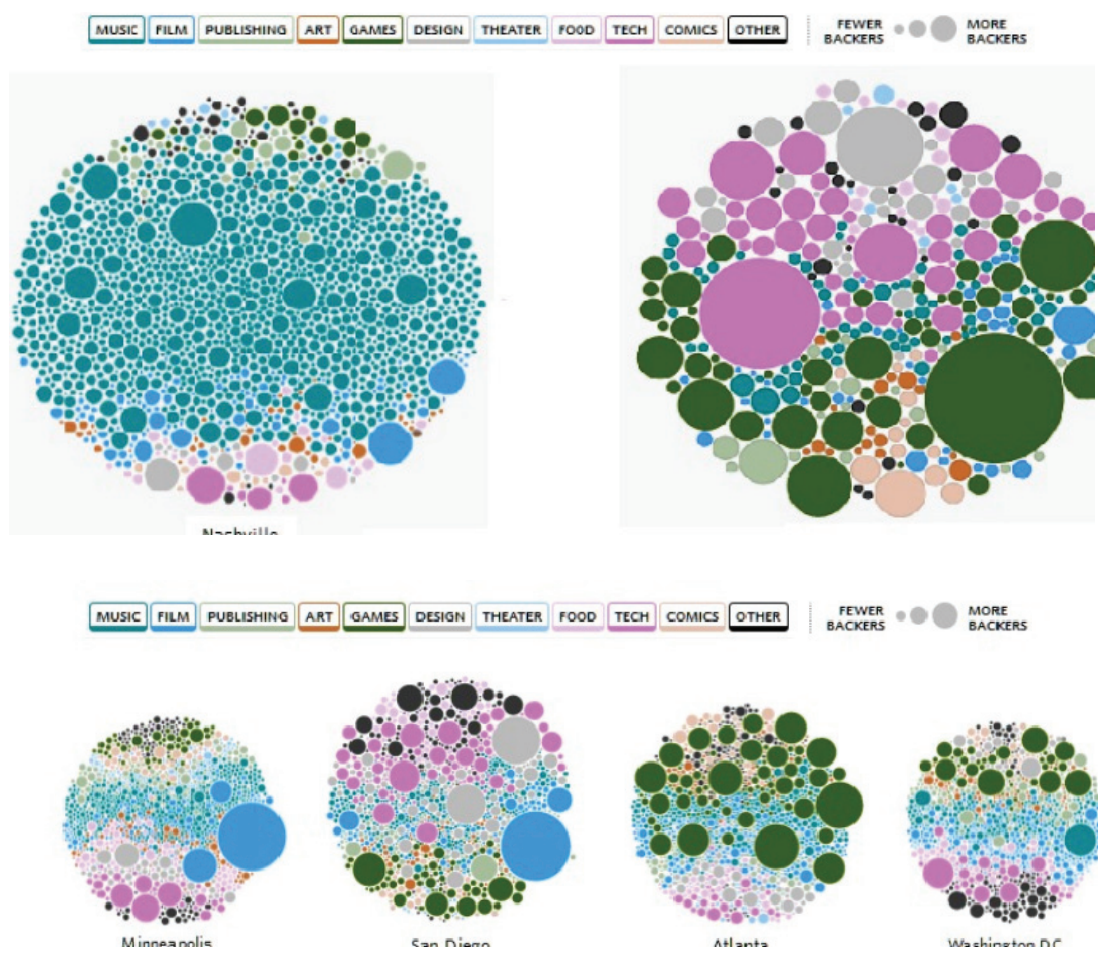

FIGURE 2 Project Distribution by City

than $30 \%$ of the required capital is collected. Additionally, although the total contribution of local investors towards successful projects is much smaller than that of distant investors their average investment is up to 4 times bigger.

There exists a clear relationship between distance, the likelihood to invest and the mean investment. The relation between distance and investment is displayed in table 6 . This makes sense for projects aimed only at the local community, however the same is true for online products made available to the whole world. This is likely due to friend and family connections which are more likely to develop locally. Data from a 
TABLE 6 Crowdfunding Detailed Location Breakdown

\begin{tabular}{lrrr}
\hline Distance & Avg. investment & Total investment & \% of total investment \\
\hline $0-5 \mathrm{~km}$ & 255.76 & 48,850 & $2.9 \%$ \\
$5-50 \mathrm{~km}$ & 184.62 & 179,640 & $10.6 \%$ \\
$50-500 \mathrm{~km}$ & 67.67 & 297,970 & $17.5 \%$ \\
$500-3000 \mathrm{~km}$ & 79.56 & 336,680 & $19.8 \%$ \\
$>3000 \mathrm{~km}$ & 75.15 & 678,410 & $39.9 \%$ \\
\hline
\end{tabular}

TABLE 7 Crowdfunding Relationship Breakdown According to Data from Cumming and Johan (2009)

\begin{tabular}{lrr}
\hline Relation & First \$500 & First 4 weeks \\
\hline Friends \& Family & $34 \%$ & $37 \%$ \\
Not Friends \& Family & $66 \%$ & $63 \%$ \\
\hline
\end{tabular}

survey performed by the crowdfunding platform Kickstarter asked campaign contributors about the reasons why they supported the project. The results showed that friends and family are more likely to contribute at the start of the campaign as shown in table 7. This affirms our findings that the share of the contributions of friends and family falls as the campaign approaches its goal. Moreover, when successful and unsuccessful projects are compared an abnormal percent of the contributions towards unsuccessfully funded campaigns came from friends and family members. However, due to data constraints, it is unclear whether both distance and personal connections are factors weighted by contributors before they support a crowdfunding campaign. Even if distance has no direct relationship on the likelihood investment it seems to be a good predictor of early contributions.

Data collected from several crowdfunding platforms suggests that as the share of gathered capital over the required capital threshold increases the success rate of the project increases non-linearly. This becomes evident from table 8 which shows the final share of collected capital over the capital target for a large number of campaigns with varying capital thresholds. The data shows that a disproportionately large share of the projects are either successfully funded, reaching at least $100 \%$ of their goal, or a relatively small portion of the total threshold

is achieved. Looking even further into the initial 20\% supports these observations as shown in table 9. Furthermore, projects that fail, do so 
TAB LE 8 Crowdfunding Breakdown by Funding Percentage

\begin{tabular}{lrrrrrr}
\hline \% funds raised & $0-19$ & $20-39$ & $40-59$ & $60-79$ & $80-99$ & 100 \\
\hline \% of projects & 55 & 6 & 2.5 & 0.9 & 0.05 & 36 \\
\hline
\end{tabular}

TA b Le 9 Crowdfunding Detailed Breakdown by Funding Percentage

\begin{tabular}{lrrrrr}
\hline$\%$ funds raised & $0-3$ & $4-7$ & $8-11$ & $12-15$ & $16-20$ \\
\hline$\%$ of projects & 62 & 24 & 9 & 3 & 2 \\
\hline
\end{tabular}
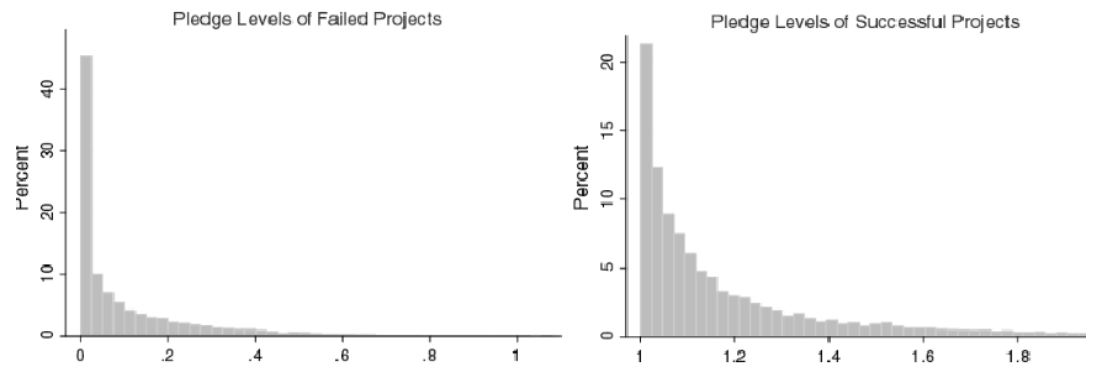

FIgURE 3 Project Distribution by Funding Percentage

by large margins and those who succeed end up with a little over $100 \%$ of their target. This is even more evident in the comparison between successful and failed projects in figure 3 .

This could be the outcome of herd behaviour that results in an increased likelihood to contribute towards projects that are closer to their goal. However, another viable explanation is that the likelihood to invest does not change significantly and founders whose projects succeed have reached a larger audience. Transactional data discussed in the following section sheds more light on this issue. In our analysis of temporal project dynamics we normalize the capital target and the duration of the campaign to 1 . Thus in a project with a capital target of $\$ 500$, an investment of $\$ 100$ made during the halfway mark of the campaign is represented by an investment of size $0.2 \mathrm{k}$ at time period $0.5 \mathrm{t}$.

Figure 4 displays a histogram of the normalized contributions. Each bar stands for the number of contributions received in that period. It is apparent that a large number of contributions are made in the first $10 \%$ of project duration. On average about a quarter of all funds are received in this initial period. The final $10 \%$ of project duration also exhibit a spike in investor activity, with over 50\% more contributions per period than the middle point of the project. 


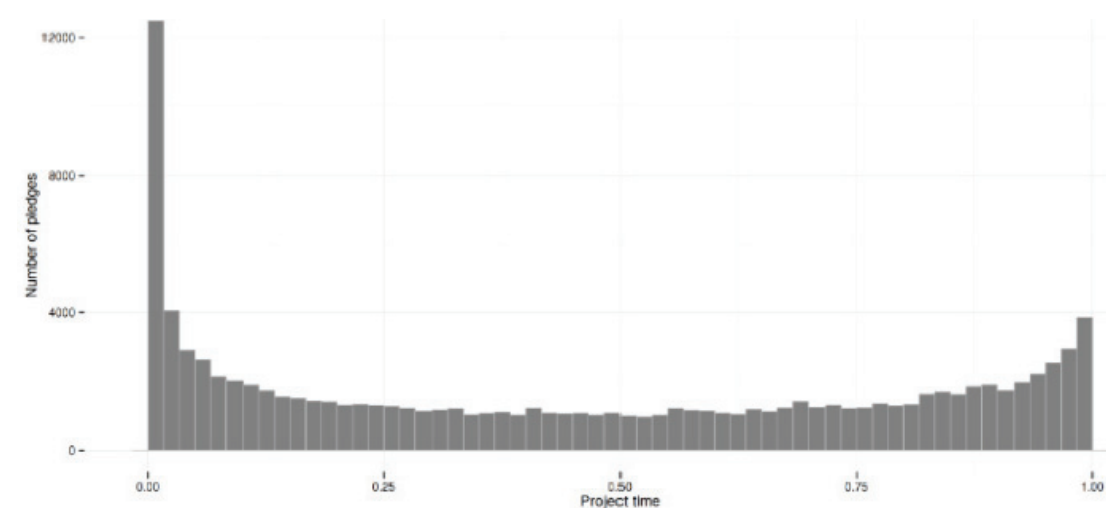

FIGURE 4 Distribution of Pledges over the Normalized Funding Duration

To further examine the dynamics of crowdfunding campaigns, we separate them in two groups depending on the normalized capital ratio that has been reached in the middle of the campaign. The lifespan of projects whose capital ratio is less than 0.5 at the middle of the campaign duration - meaning that the projects have not reached their targets yet - is shown in figure 5. The projects in figure 5 are further separated in two categories. Projects in category A do not manage to reach their capital requirements until the end of the campaign and those in category B do. The data shows a similar distribution of capital ratios in both categories, however projects in category $B$ experience an increase in the rate of contributions after the middle point of campaign duration. This increase becomes more extreme in the final stages of projects in category B, whereas for projects in group A the increase in investments is similar to the one in the initial stages of the campaign.

Figure 6 separates the initially successful projects in three groups group A consists of the projects that did not reach their target, B consists of projects that reached their target and had a capital ratio of less than 1 at the middle of the campaign and group $\mathrm{C}$ is made of all projects that had already reached their capital requirements at the middle of project duration. It is interesting to note that few projects fall in category A as the majority of campaigns that reach $50 \%$ of their capital are usually successful in receiving their full required investments. The low number of observations in group A shows that projects in this group receive investments at a slower rate than they did in the first half of project duration. Campaigns in group B experience almost linear growth. There is an increase in the rate of investments at the last $10 \%$ of project duration but 


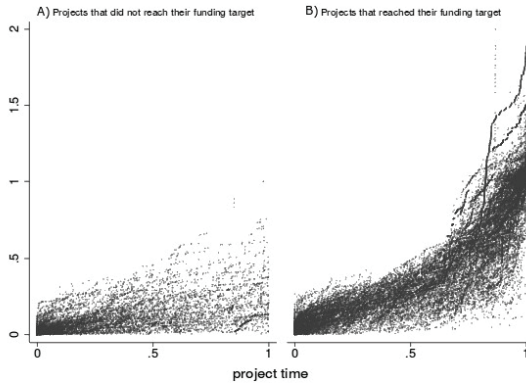

FIGURE 5 Funding Ratio of Initially Unsuccessful Projects

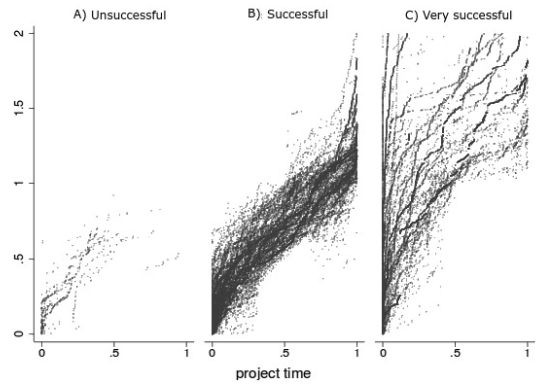

FIGURE 6 Funding Ratio of Initially Successful Projects

this increase is much milder than the one experienced by the initially unsuccessful projects in figure 5. Projects in group $\mathrm{C}$ have little in common - some continue their exponential growth while others do not receive any investments after the middle of the capital requirement has been reached. These observations tell us that the last $10 \%$ of campaign duration are extremely important for projects that do not manage to receive more than half of their capital requirement until the middle of the project duration. For initially successful projects, sustaining the rate of investments is enough to assure success. As shown in figures 5 and 6 a large number of successful projects continue to collect investments after the capital requirement has been reached. On average $16.4 \%$ of all investments are made towards projects that have already reached their goal.

Figure 7 breaks down the findings displayed in figure 4 by project outcome. It takes into account whether the investment was made towards an already successful project, a project that has not reached its goal yet but will do so eventually or a project that will fail.

Figure 8 shows the ratio of investments as a share of all investments in the period to give more insight into the relation of contributions. Campaigns that did not secure enough investments account for a large share of the contributions in the first periods. As time advances the investments towards them virtually disappear. One possible explanation is that investors are able to determine that the project will not be successful, however it is also possible that the effect is due to decreased public attention towards these ventures.

More surprising is the observation that an increasing number of investments in the last periods are made towards projects that have already reached their goal. The number of contributions towards campaigns that 


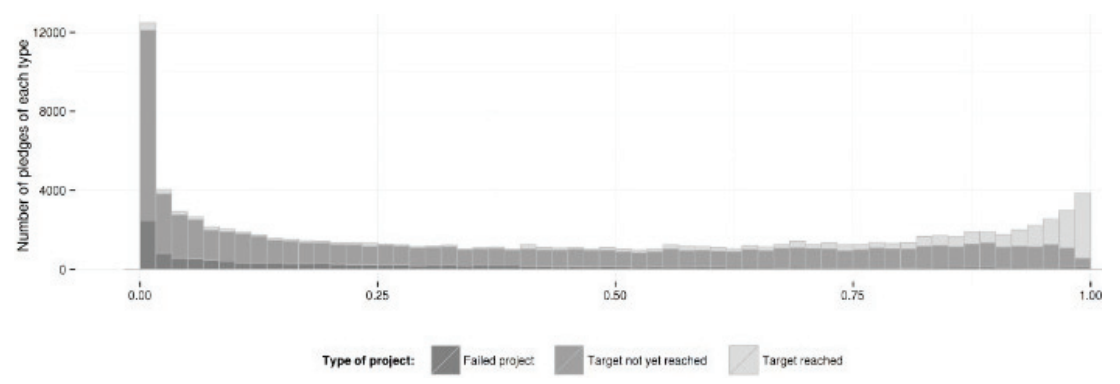

FIGURE 7 Project Investments over Time Breakdown by Project Outcome

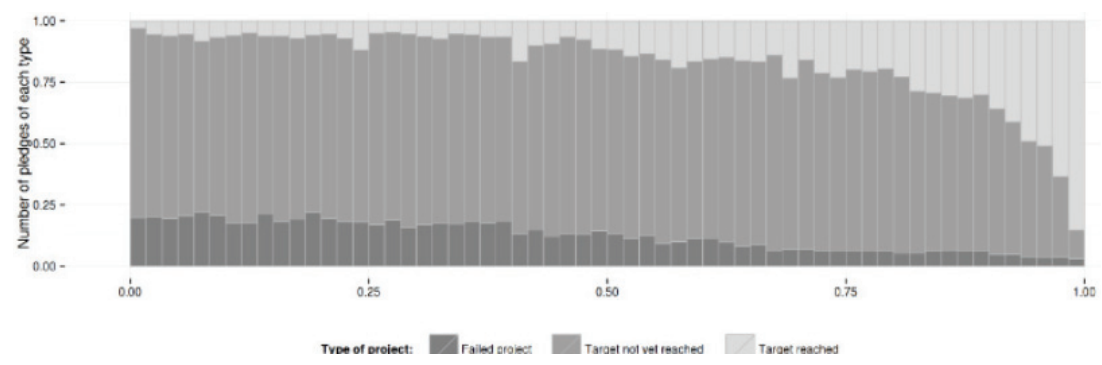

FIGURE 8 Relative Project Investments over Time Breakdown by Project Outcome

haven't reached their targets stays relatively constant which suggests that there is no sudden rush to invest in order to assure project success. However, it is important to understand that the majority of contributions towards projects that are not yet successful in the final periods of figure 7 come from the projects in figure 5 category B. In other words, although the number of contributions stays relatively flat the number of projects that receive these contributions decreases as more and more campaigns reach success as shown in figure 5. Thus there is indeed a rush to invest in projects that are close to reaching success in the final stages of project duration.

Investors are well aware that not all crowdfunding campaigns succeed. According to questionnaires filled by buyers, they take a number of campaign characteristics into account before contributing. Attributes such as team size and experience, the feasibility of the product, its current development stage and the time to product completion are some of the important qualities which buyers watch for. Unsurprisingly, these are to a large extent the characteristics which venture capitalists consider when discounting their expected future returns. Table 1o shows the average discount factor as a function of the stage of development of the product. 
TABLE 10 Venture Capitalist Discount Factors

\begin{tabular}{lrrrrr}
\hline$\%$ development stage & Seed & Angel & Series A & Series B & Bridge \\
\hline \% discount factor & $80-100 \%$ & $50-70 \%$ & $40-60 \%$ & $30-50 \%$ & $25-35 \%$ \\
\hline
\end{tabular}

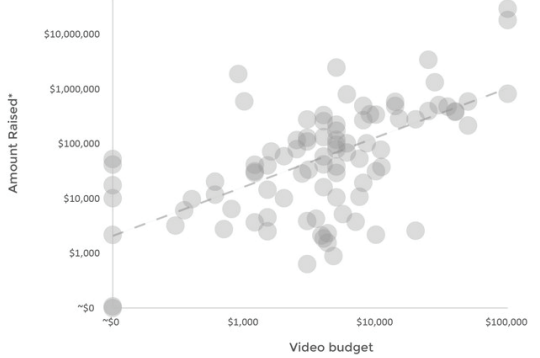

FIGURE 9 Project Breakdown by Video Budget

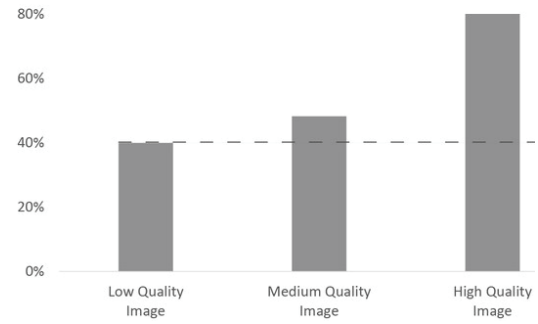

FIGURE 10 Project Breakdown by Video Image Quality

Crowdfunding platforms often encourage campaign creators to satisfy these quality signals when creating new campaigns. For example, Kicksarter heavily promotes the use of videos in addition to project description. Similarly, regular project updates and prompt response to user comments are another signal of quality.

Other campaign signals are often associated with low quality as shown in table 3 and table 4 . Contributors are wary of campaigns with too ambitious goals as their likelihood of success is often small. Even though the all-or-nothing rule assures investors that they will receive their money back if the project fails investors still have to wait until the end of the campaign to get their money back. Naturally, this effect is stronger in projects with longer duration, which as table 3 shows makes campaign duration a negative factor for reaching the desired amount of capital.

These observations help us understand how investors perceive crowdfunding project risk, however an obvious issue in the modelling of risk is that variables such as product quality, team experience and professionalism are open to interpretation. They are hard to analyse for the volumes of data that the present paper considers. Instead we have used data about presentational videos that capital-seekers use to demonstrate their goal and progress. Survey results of project founders and investors reveal that the production cost of videos is directly related to the total goal. Projects seeking up to $\$ 25 \mathrm{k}$ spend less than $\$ 3 \mathrm{k}$ on their video, while projects in the vicinity of $\$ 100 \mathrm{k}$ spend near $\$ 6 \mathrm{k}$ for their project video. Most campaigns 
looking for sums larger than $\$ 1 \mathrm{~m}$ spend upwards of $\$ 2 \mathrm{ok}$. This relation is shown in figure 10.

\section{Models}

Combining the observation from the crowdfunding data we build three distinct models forecasting the success rate of crowdfunding campaigns during any stage of their development. Model A relies on several of the major data relations that we observed - the increased likelihood of local investors to contribute early on, the abnormal concentration of project final funding level near the $0 \%$ and $100 \%$ financing levels, the increased likelihood to invest during the first and last $10 \%$ of project duration and the risk aversion of investors. These characteristics are combined in a unifying model that accounts for investors learning from project investment dynamics in previous periods to predict the total sum of investments gathered after the project ends.

In contrast, Model B performs statistical classification of projects based on all previously discussed data observations using Naive Bayes and Random Forest approaches. Note that while model A predicts total capital model B can only be used to distinguish whether the project was successful in raising the required capital.

Finally, Model C relies only on the category and the funding dynamics of each project to produce a project investment curve. Afterwards the curve is compared to that of already finished projects and using least squares the $N$ most similar projects in terms of funding dynamics are selected. A simple average of the outcomes of these $N$ campaigns is used to predict the end state of the project in question. Similarly to Model B, this approach can only be reliably used to predict whether the campaign is successful.

\section{MODEL VARIABLES}

- Campaign goal: $K^{\star}$ - the goal of each campaign is determined by the project creator and usually cannot be changed after the start of the campaign.

- Financing level: $K_{p}$ - a series of observations measuring the share of investments received in relation to the campaign goal.

- Contribution: $K_{p}$ - individual contribution to the campaign as a share of the total capital goal.

- Campaign duration: $t^{\star}$ - the number of days after which the campaign is either successful of failed. 
- Campaign time passed: $t_{p}$ - a series of measures describing the share of time that has already passed in relation to the project duration for each of the data points in series $K_{p}$.

- Interest rate $r$.

- Investor endowment: $w_{i}$ - a large number of small investments are characteristic of crowdfunding campaigns. Each potential contributor is endowed a different amount depending on the mean monthly income in the region.

- Distance: $d_{i p}$ - the distance between the campaign creator and the potential contributor in kilometers.

- Nation: $n_{i p}$ - a Boolean variable that shows when the campaign creator and the potential investor live in the same country.

- Video budget: $v_{p}$ - reported project video budget in USD. The value is set to zero if the project does not feature a video.

- Project category $c_{p}$ - category identifier normalized to the 15 Kickstarter categories.

- Project location $l_{p}$ - location identifier (country city).

- Investment status $I_{i p}$ - Boolean variable indicating whether the investor has invested in the project in a previous period.

MODEL A

Potential investors consider as given project and investor parameters such as endowment, project goal, video budget, the capital funding level for the previous period, the share of the project duration that has passed up to that point, the distance between the investor and the project location and the country of both the investor and the founder. Investors control the amount they contribute to the project in the current period in order to maximize their utility for the period. Investor utility is approximated using the following three utility functions, each featuring a different level of investor learning (through artificial, or 'machine, learning):

$$
\begin{aligned}
\mathrm{A} 1: u_{i t}= & U\left(w_{i t}-k_{i p t}, d_{i p}, K^{\star}, v_{p}, n_{i p}, I_{i p}, K_{i p t-1}, t_{i p t-1}\right) \\
\mathrm{A} 2: u_{i t}= & U\left(w_{i t}-k_{i p t}, d_{i p}, K^{\star}, v_{p}, n_{i p}, I_{i p}, K_{i p t-1}, t_{i p t-1},\right. \\
& \left.K_{i p t-2}, t_{i p t-2}\right) \\
\mathrm{A} 3: u_{i t}= & U\left(w_{i t}-k_{i p t}, d_{i p}, K^{\star}, v_{p}, n_{i p}, I_{i p}, K_{i p t-1},\right. \\
& \left.t_{i p t-1}, K_{i p t-2}, t_{i p t-2}, K_{i p t-3}, t_{i p t-3}\right)
\end{aligned}
$$

Assumptions: 


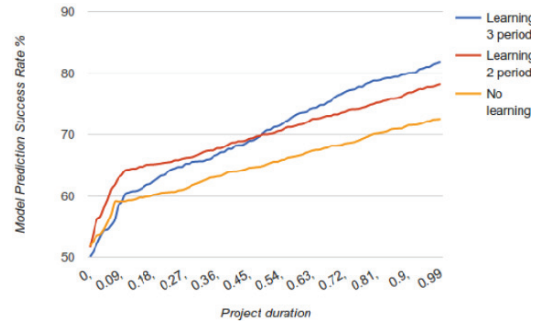

FIgURE 11 Model Prediction Accuracy for Eventually Successful Projects

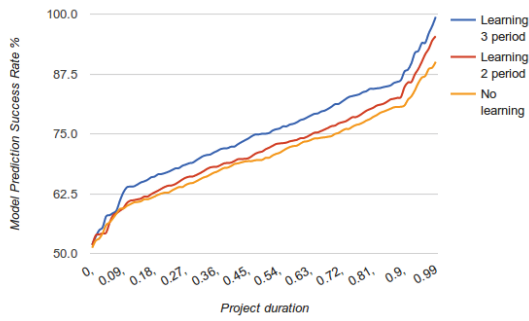

FIgURE 12 Model Prediction Accuracy for Eventually Unsuccessful Projects

- Individuals value the available income they have left after investment.

- Individuals are not risk neutral.

- Individuals are able to determine campaign risk factors such as founding team quality and project goal size.

- Individuals value the success rate of local campaigns higher than the success rate of distant projects.

- Individuals learn from the investment dynamics of the project up to that point.

In order to configure the parameters of the model $80 \%$ of the data was used for optimization and $20 \%$ for validation and testing. The model achieves an overall accuracy of $84 \%$ in predicting whether a project will manage to gather enough investments for all examined data points.

Figure 11 and figure 12 display the evolution of the models' predictions over project duration. Clearly the addition of learning which allows the model to consider the investments made in the previous few periods improves the rate of successful predictions at all stages of project duration.

The two areas of rapid prediction improvement in the beginning and in the end of projects show the impact of the temporal investment factors. These factors allow the model to rapidly increase its accuracy in the first stages of the project. They are relatively more significant for campaigns raising a higher amount in this initial period - thus on average successful project predictions experience a slightly bigger initial accuracy spike.

The model is relatively better at predicting the outcome of unsuccessful campaigns than it is at predicting the end result of projects that eventually turn out to be successful, as shown in figure 7 and figure 8 confirming the observation that failing campaigns are easier for investors to spot. 


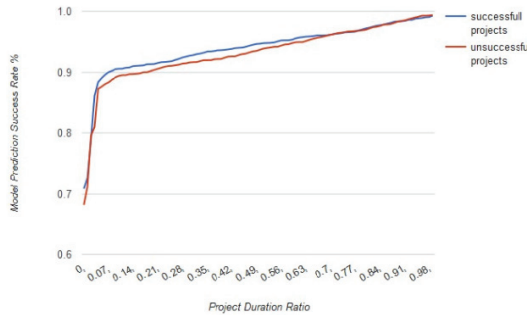

FIgURE 13 Model B Random Forest Prediction Accuracy

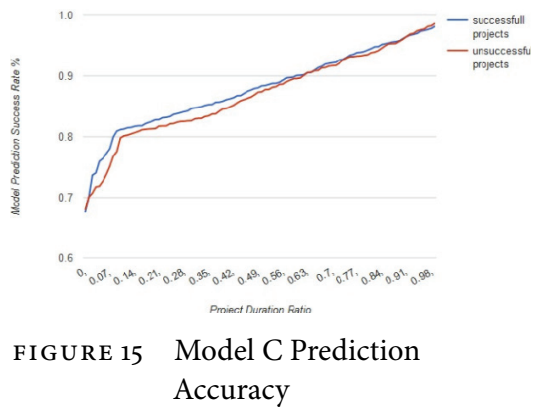

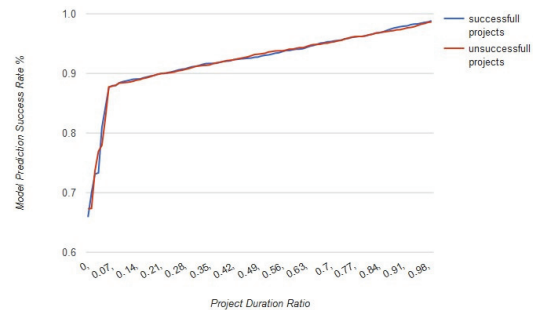

FIgURE 14 Model B Naive Bayes Prediction Accuracy

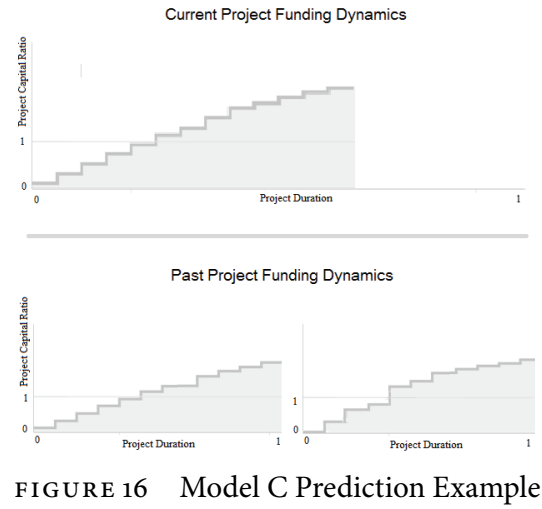

In line with the data observations projects exhibit a spike in investor activity near the end of project duration - the effect can be observed in the failed project predictions (figure 12). The same is not true for successful projects (figure 11) which have a steadily growing prediction rate after the first $10 \%$ of campaign duration.

MODEL B

Using all model variables two distinct machine learning classifiers were used to label projects as successful or unsuccessful. Naive Bayes and Random Forest classifiers were used, yielding similar results. The model averages 93\% accuracy among all projects and unlike Model A behaves symmetrically for failed and successful campaigns.

\section{MODEL C}

Using only the project category model variable, the investment ratio time series and the duration ratio time series a simple curve is constructed to represent the funding dynamics of all past and current projects. To 
predict the success of a currently active project its investment curve is compared to the curves of all projects in the same category and the least squares difference between all of them is computed. Afterwards the $\mathrm{N}$ closest matching previous projects in terms of funding dynamics are used to predict the end state of the currently active project.

The predictions of this simple model are strikingly accurate when a large number of past observations in the current category are available. Similarly to Model A the prediction success rate rapidly increases in the first $10 \%$ of campaign duration and experiences a gradual increase up to the $90 \%$ mark of project duration, when the growth rate of prediction success rate slightly rises. The model averages an $87 \%$ success rate in accurately predicting the end state of the campaign. Its prediction success rate is symmetric across successful and unsuccessful projects. The models' predictions are similar for projects in the final $95 \%$ of project duration compared to Model A. Model C is much more accurate than Model A in making predictions about campaigns that are in their early stages, which shows the importance of project category.

\section{Discussion, Limitations and Conclusions}

Crowdfunding has achieved exponential growth in the last few years and can be regarded as an alternative to traditional financial mediums available to entrepreneurs such as banks, venture capitalists and angel investors. The analysis of transaction level data in this paper could be used by both investors and entrepreneurs to achieve a more satisfying outcome of the crowdfunding process. Furthermore, the models can be employed by crowdfunding platforms to improve the efficiency of the matching process between investors and entrepreneurs. In particular, crowdfunding brings to consumers the ability to preorder desirable products that are not currently available in the market at the cost of taking the risk that that the project may not succeed or the founders may not manage to produce the investment reward after the crowdfunding campaign concludes. The present paper limits its analysis to the duration of the campaign, ignoring risks associated with project execution. The paper makes several observations that can be used by potential investors in order to make informed investments driven by their own risk aversion. Investors using the techniques that the paper proposes for characterizing project risk will be able to determine the probability of project success at all stages of project duration. This will allow them to make more knowledgeable decisions and investment trade-offs such as investing in products only offered to 
early investors versus having their capital locked up for the duration of the whole project, only to find out that the project failed and they will not receive the desired product.

As all three models demonstrate, investors can use the outcome of similar past campaigns whose status is already known to determine the probability of a currently active project not reaching its goal. A simple look of the funding dynamics of comparable projects is a good predictor of the end result as Model $\mathrm{C}$ has shown. A potential investor can use the funding ratio that the currently active project has achieved after $10 \%$ of project duration has passed and compare it with data for similar projects. A safer approach would be to track the growth rate after the $10 \%$ duration mark as in general it is relatively stable across all projects, to determine the likelihood of project success. In general, using the information that founders make available about their own experience and expectation in addition to the quality of their presentation can lead to more accurate forecasts of project risk.

On the other hand, project creators have control over the most important determinants of project success namely the capital goal, campaign duration and the quality of their own presentation to investors. Before starting a new crowdfunding venture, founders should analyse similar past campaigns past as if they were a potential investor. This will allow them to set realistic project parameters. The project updates and comments of previous crowdfunding ventures are a valuable source of information for founders which allows them to see what the concerns of investors are and what problems other founders have faced. After the campaign parameters have been chosen, founders must make sure that they provide adequate information about their own level of experience and plans for the future. Investors are more likely to contribute towards projects that are open about their structure and qualifications. Presentation is very important. Successful projects are shown to spend $5-10 \%$ of requested project goal on professional video production and copywriting.

Similarly, founders should continue to actively monitor the state of their crowdfunding project throughout its duration, providing regular updates and responding to investor comments. After $20 \%$ of project duration has passed they can use the data they have gathered about the funding dynamics of their own campaign to make an adjustment in the investment rewards in order to boost their chances of success. Overall, with the ever evolving technology provided by the crowdfunding platform, and the increase in data availability, the analysis that this paper provides 
can be streamlined, which could potentially allow investors to set their risk premium and receive recommendations about matching projects in their area of interest from the platform. This would increase public understanding of the crowdfunding market and allow efficient discussion, market matching and legislation to take place.

In conclusion, there exists a set of consistent dynamics that govern the development of the majority of crowdfunding ventures. Through analysis of transaction-level data as well as product and platform specifications this paper has shown that the development and even the eventual outcome of crowdfunding projects can be reliably determined at a very early stage. In particular, the models presented in this paper reach an average of $83 \%$ accuracy in predicting the outcome of a crowdfunding campaign at any point throughout its duration. Still, that leaves a lot of room for further improvement in terms of model's forecasting power, and leaves ample venues for future work in that area.

\section{References}

Agrawal, A. K., C. Catalini, and A. Goldfarb. 2011. 'The Geography of Crowdfunding.' NB ER Working Papers 16820, National Bureau of Economic Research, Cambridge, m A.

Allison, T. H., B. C. Davis, J. C. Short, and J. W. Webb. 2014. 'Crowdfunding in a Pro-Social Micro-Lending Environment: Examining the Role of Intrinsic versus Extrinsic Cues.' Entrepreneurship Theory and Practice 39 (1): 53-73.

Belleflamme, N., M. Omrani, and M. Peitz. 2015. 'The Economics of Crowdfunding Platforms.' CORE Discussion Paper 2015015, Universite catholique de Louvain, Ottignies-Louvain-la-Neuve.

Belleflamme, P. L., and T. Schwienbachner. 2011. 'Crowdfunding: Tapping the Right Crowd.' core Discussion Paper 2011032, Universite catholique de Louvain, Ottignies-Louvain-la-Neuve.

Burtch, G., A. Ghose, and S. Wattal. 2013. 'An Empirical Examination of the Antecedents and Consequences of Contribution Patterns in CrowdFunded Markets.' Information Systems Research 24 (3): 499-519.

Centre for Economic Policy Research, London.

Chen, N., A. Ghosh, and N. S. Lambert. 2014. 'Auctions for Social Lending: A Theoretical Analysis.' Games and Economic Behavior 86:367-91.

Cochrane, J. 2005. 'The Risk and Return of Venture Capital.' Journal of Financial Economics 75 (1): 3-52.

Cumming, D., and S. A. Johan. 2009. Venture Capital and Private Equity Contracting: An International Perspective. London: Academic Press. 
Elsner, D. 2013. 'Corporate Crowdfunding.' In Finanzdienstleister der nächsten Generation - Die neue digitale Macht der Kunden, edited by O. Everling, R. Lempka, and M. Müller, 401-22. Frankfurt am Main: Frankfurt-School-Verlag.

Everett, C. 2010. 'Group Membership, Relationship Banking and Loan Default Risk: The Case of Online Social Lending.' Banking and Finance Review 7 (2): 15-54.

Freedman, S., and G. Jin. 2014. 'The Signaling Value of Online Social Networks: Lessons from Peer-to-Peer Lending.' N B E R Working Paper 19820, National Bureau of Economic Research, Cambridge, MA.

Gerber, E., J. Hui, and P. Kuo. 2012. 'Crowdfunding: Why People Are Motivated to Post and Fund Projects on Crowdfunding Platforms.' https://www.researchgate.net/publication/261359489_Crowdfunding _Why_People_are_Motivated_to_Post_and_Fund_Projects_on _Crowdfunding_Platforms

Haas, P., I. Blohm, and J. Leimeister. 2014. 'An Empirical Taxonomy of Crowdfunding Intermediaries.' Paper presented at the International Conference on Information Systems (ICIS) 2014, Auckland, 14-17 December.

Hemer, J. 2011. 'A Snapshot on Crowdfunding.' Working Papers Firms and Regions R2/2011, Fraunhofer Institute for Systems and Innovation Research (ISI), Karlsruhe.

Herzenstein, M., and R. Andrews. 2008. 'The Democratization of Personal Consumer Loans? Determinants of Success in Online Peer-toPeer Lending Communities.' http://ssrn.com/abstract $=1147856$

Hildebrand, T., M. Puri, and J. Rocholl. 2013. 'Adverse Incentives in Crowdfunding.' http://ssrn.com/abstract $=1615483$

Iovino, F., and G. Migliaccio. 2016. 'E-Marketing by Energy Companies.' In 9th Annual Conference of the EuroMed Academy of Business: Innovation, Entrepreneurship and Digital Ecosystems, edited by D. Vrontis, Y. Weber, and E. Tsoukatos, 1034-46. Cyprus: Euromed Press.

_. (In press). 'Mobile Marketing and Strategy by Energy Companies.' International Journal Public Sector Performance Management.

Kim, K., and S. Viswanathan, S. 2013. 'The Experts in the Crowd: The Role of Reputable Investors in a Crowdfunding Market.' ss R N Working Paper 2258243, Social Science Research Network.

Koning, R., and J. Model. 2013. 'Experimental Study of Crowdfunding Cascades: When Nothing is Better than Something.' http://ssrn.com/ abstract $=2308161$

Kuppuswamy, V., and B. L. Bayus. 2013. 'Crowdfunding Creative Ideas: The Dynamics of Project Backers in Kickstarter' Research Paper 2013-15, UnC Kenan-Flagler Business School, Chapel Hill. 
Lin, Y., W. H. Boh, and K. H. Goh. 2014. 'How Different Are Crowdfunders?' http://ssrn.com/abstract=2397571

Lin, M., N. R. Prabhala, and S. Viswanathan. 2009. 'Social Networks as Signaling Mechanisms: Evidence from Online Peer-to-Peer Lending.' https://pdfs.semanticscholar.org/o1c5/ o7b28ec8e2f8a1382c4da4b75f31257715bo.pdf

Maeschle, O. 2012. 'Rationing of Excessive Demand on CrowdinvestingPlatforms.' Thünen - Series of Applied Economic Theory Working Papers 126, Leibniz Information Centre for Economics, Leibniz.

Mollick, E. 2013. 'Swept Away by the Crowd? Crowdfunding, Venture Capital, and the Selection of Entrepreneurs.' http://ssrn.com/abstract $=2239204$

- 2014. 'The Dynamics of Crowdfunding: An Exploratory Study' Journal of Business Venturing 29 (1): 1-16.

Ordanini, A., L. Miceli, M. Pizzetti, and A. Parasuraman. 2011. 'CrowdFunding: Transforming- Customers into Investors through Innovative Service Platforms.' Journal of Service Management 22 (4): 443-70.

World Bank. 2013. Crowdfunding Potential for the Developing World. Washington, DC: World Bank.

Viswanathan, S., M., and N. R. Prabhala. 2013. 'Judging Borrowers by the Company They Keep: Friendship Networks and Information Asymmetry in Online Peer-to-Peer Lending,' Management Science 59 (1): 1735 .

Wash, R., and J. Solomon. 2014. 'Coordinating Donors on Crowdfunding Websites.' In CSCW'14: Proceedings of the 17th ACM Conference on Computer Supported Cooperative Work \& Social Computing, 38-48. https://doi.org/10.1145/2531602.2531678

Zvilichovsky, D., Y. Inbar, and O. Barzilay. 2013. 'Playing Both Sides of the Market: Success Andreciprocity on Crowdfunding Platforms.' Paper presented at the International Conference on Information Systems, Milan, 15-18 December. 



\title{
Defining the Unemployment Determinants of the Post-Transition Central European EU Member Countries
}

\author{
Marija Bušelić \\ Juraj Dobrila University of Pula, Croatia \\ mbusel@unipu.hr \\ Jurica Bosna \\ University of Zadar, Croatia \\ jbosna@unizd.hr
}

\begin{abstract}
Aim of the research is to define unemployment determinants of the labor markets on the example of post-transition Central European EU member countries - Poland, Czech, Slovak, Hungary, Slovenia, and Croatia. The purpose of the paper is to point out the role and importance of studying the labor market unemployment determinants of the post-transition countries to provide a proposal for reducing unemployment. In this paper as independent macroeconomic variables have been analyzed gross domestic product, public debt, labor force participation rate and institutional variables like some fixed-term and part-time contracts and expenditures for active and passive labor market policies. An analysis of the labor market unemployment determinants for the Central European EU member countries has been conducted by econometric models of multiple linear regression for each country to determine whether there are differences in unemployment rates between countries within one panel. Results of the research show that in almost all countries, public debt as a macroeconomic variable has a significant impact on unemployment growth, while passive labor market policies of the institutional variables have the most significant impact on the level of unemployment.
\end{abstract}

Key Words: unemployment, determinants, labor market, post-transition

EU countries

JEL Classification: E24, J01

https://doi.org/10.26493/1854-6935.17.79-103

\section{Introduction}

Unemployment has been considered as an important issue, not only for the economy but also for society as a whole. In her paper Tomić (2013) states how due to its complexity, it's not easy to find an unambiguous explanation of the causes of unemployment. However, in a manner to find 
solutions for the suppression of unemployment, we must first investigate its causes.

Domonkos and Konig (2015) conclude that the cost of unemployment has been reflected in reduced state income due to lower tax rates, increased social benefits for the unemployed, lower amounts for pension and health insurance, major issuance for active labor market policies and reduced indirect tax revenues. In his paper Paul (2001) states that apart from the fact that unemployed persons do not receive income, they lose their skills during the time and their inactivity inevitably leads to social isolation. Boeri and Jimeno (2015) state that there is an increasing need for individual research of the European country's unemployment rates because of their differences and the specificities of institutions, interactions with macroeconomic shocks and economic policies of individual countries.

Aim of the research is to define unemployment determinants of the labor markets on the example of post-transition Central European EU member countries - Poland, Czech, Slovak, Hungary, Slovenia, and Croatia. These post-transitional countries of Central Europe were chosen because they were until the 199os planned economy and then entered the transition of the political and economic system. At the time of socialism, these countries did not have a market economy, especially the labor market. Due to the implementation of reforms and economy in all of the above mentioned Central European countries, unemployment increased in the nineties of the 2oth century. National labor markets marked high and long-term unemployment rates and extremely rigid labor legislation. New jobs in the private sector did not open at the same rate as workers lost their jobs. These inactivities have lasted (except in Croatia) until 2000 when the labor market of Central Europe stabilized. As they approached the date of their entry (2004), apart from Croatia (2013), they significantly modified the institutions and labor market policies according to the experience of the existing EU member states. Croatia did the same, but the changes were slower due to the Homeland War. All the countries with the liberalization of the European labor market have reduced their unemployment.

Analysis of the unemployment determinants for the selected countries will be conducted by using the econometric models of multiple linear regression for each country. To express the aim of the paper, the dependent variable in the models is the unemployment rate while macroeconomic and institutional variables that were not highly correlated in the 
model were considered as important for research. Since it was necessary to distinguish between countries within the same panel they do not look for common effects (as they are later explored) then this is what an exploratory question answered using regressions for individual countries and then tested how different parameters exist between countries the same panel is statistically significantly different.

The work structure with the introduction and conclusion deals with the following topics: The theoretical background of macroeconomic and institutional determinants of unemployment, chapter two deals with previous studies of macroeconomic and institutional variables of unemployment, in the third chapter Empirical analysis of unemployment determinants research on labor market and unemployment as well as on the variables affecting it, In the fourth chapter, the post-transition countries labor markets describe the labor markets of the observed countries in the posttransitional period, Research methodology is shown in the fifth chapter, in the sixth Results and discussion the results are presented and a review of the results obtained.

\section{The Theoretical Background of Macroeconomic and Institutional Determinants of Unemployment}

\section{MACROECONOMIC DETERMINANTS OF UNEMPLOYMENT}

This chapter presents an overview of important macroeconomic factors affecting the level and the movement of unemployment rates such as gross domestic product, public debt, direct foreign investment, labor productivity, and labor cost, labor force structure and labor force participation rates. The increase in economic activity, which affects the decline in unemployment, maybe due to increased investment and increased exports as a component of gross domestic product, which is the most common indicator of economic trends in the economy. Encinas-Ferrer and VillegasZermeño (2015) in their paper state that investments are a dynamic element of the gross domestic product that enables increased domestic production and increase employment.

Determining the relationship between real GDP growth and unemployment is important for policymakers to enable sustainable growth of living standards. Namely, real GDP growth allows for a reduction in unemployment, which by empirical analysis has been discovered by Bogdan et al. (2015), Umair and Ullah (2013), Ogueze and Uka Odim (2015) and many others. 
The high amount of government debt relative to the gross domestic product is particularly related to high levels of public spending and in the long run, it causes an increase in the unemployment rate. Public debt is a burden on future generations because it imposes a tax increase, which causes a further increase in unemployment and generates a vicious circle (Fedeli and Forte 2012).

The growing public debt obligations are an obstacle to the establishment of new development projects and thus prevent the reduction of unemployment. Therefore, public borrowing should only be justified in those situations where it is used for capital projects that can open up new jobs and positive financial indicators (Christiana Ogonna et al. 2016).

Mucuk and Tahir Demirsel (2013) investigated the relationship between foreign direct investment and unemployment, and they also concluded that in some countries direct foreign investment has a positive effect on unemployment while in other countries they have a negative impact. The relationship between direct foreign investment, employment, and unemployment differ significantly from country to country depending on the structure of the economy, the type of foreign direct investment received, and the different periods, whereby the structure of the economy can change significantly just like the types of foreign direct investment deadline.

Labor costs that include employee wages, benefits, taxes paid by employees and employers affect the employment decision and can contribute to unemployment if they are not aligned with labor productivity. Therefore, rising labor costs are not a problem if they are aligned with increasing labor productivity, which is considered a natural process of convergence of income (Kovtun et al. 2014).

Gallegati et al. (2014) state that in the long term there is a strong negative link between labor productivity and unemployment but also their strong positive relationship in the short term. In the medium term, new technology will reduce the workforce and increase the unemployment rate. However, in the long term, new technology (innovation process) to increase labor productivity contributes to the competitiveness of the company and the economy, which is affecting the reduction of the unemployment rate. Many countries are faced with changing the structure of the workforce and will face even more dramatic demographic changes in the coming years. From a theoretical perspective, reducing the number of working-active populations can reduce unemployment due to greater labor force outflows and a smaller number of the new workforce. 
Lee and Parasnis (2014) explored the ratio of labor force unemployment rates and labor force participation rates of developed and developing countries, while they concluded that increasing labor force participation rate causes an increase in the unemployment rate. However, it is particularly interesting and important to point out that the change in unemployment rates varies significantly between developed countries and developing countries. In developing countries, the increased labor force participation rate leads to a significant increase in the rate of unemployed people in contrast to developed countries that absorb more efficiently the increase in the number of workforces.

\section{INSTITUTIONAL DETERMINANTS OF UNEMPLOYMENT}

Cazes and Nesporova (2006) in their paper state that labor market institutions imply institutions and policies created for intervention in the labor market to improve the link between supply and demand for work, protect existing employees, enable workers to move to other jobs and help restore equality and equity for different social groups on the labor market.

Institutional labor market factors include employment protection regulations, active labor market policies, benefits for unemployed, labor taxation and collective bargaining (Pesliakaite 2016). The role and importance of legislative protection of employment has been intensively studied over the last decade due to modern labor market conditions, which means that the country through reform of legislative protection of employment attempts to increase employment and reduce unemployment through the efficient establishment of various legislative branches of employment protection (Aleksynska and Eberlein 2016).

Muller and Berger (2013) conclude that more rigid legal employment protection hurts the level and length of unemployment of observed countries, where women and young people are particularly vulnerable.

Strict legislative employment protection encourages companies to hire workers on fixed-term contracts (Di Porto, Elia, and Tealdi 2016).

The role and importance of the contract are increasing since they allow greater flexibility for employers and workers. The employer benefits from increased options for adjusting demand fluctuations for its products and can use temporary contracts as a cheaper way of gaining labor. For workers, they allow easier access to employment and the path to a contract for an indefinite period (Eurofound 2015).

It is interesting to point out that Cappellari, Dell'Aringa, and Leonardi (2012) have been concluded that the increased flexibility in the legislative 
protection of employment for temporary employment in practice results in the replacement of various types of temporary contracts where employment remains at the same level.

Active labor market policies include various instruments such as various incentives to work such as job opening incentives, job sharing, workplace change, training, or special assistance for disadvantaged groups. Active labor market policies are being designed and implemented to support mobility in the labor market and integrate unemployed and inactive persons into working people, with their content different from country to country.

Initially, policymakers considered that it is necessary to increase expenditure on active labor market policies to counteract unemployment. However, later experience of the countries revealed an interesting fact certain countries with relatively low labor market expenditures maintained a low unemployment rate, while other countries with aboveaverage spending on active labor market policies faced rising structural unemployment. Also, policymakers have neglected the fact that economic theory at the time emphasized, referring to the important interaction between the system of generous unemployment insurance, the size and the mix of active labor market policies, and the degree to which benefits for unemployed affect job search (Martin 2014).

Laporšek and Dolenc (2012) point out that the generous measures of the passive labor market policy are in a negative correlation with the transition from unemployment to employment. Research that has been conducted by Guzmán (2014) shows obvious evidence that passive labor market policies in the form of unemployment insurance have a significant impact on increasing the number of unemployed persons.

Establishing a minimum wage has caused several different views on its effectiveness. Barriers to the establishment of a minimum wage justify its introduction because it allows the income of workers to ensure their basic needs while the opponents of the establishment of the minimum wage point out its impact on the increase in the number of unemployed persons (Sika 2016).

However, many papers point out the negative impact of minimum wages for people with the lowest employment potential, and the conclusion that minimum wages and salaries only increase unemployment can't be avoided. Many authors dealing with labor market issues emphasize further potential negative aspects of relatively high established minimum wages that are mostly associated with the inability to hire low- 
productivity people, which thus remain unattractive to work (Bejaković 2015).

Labor tax burden significantly affects the level of personal consumption and employment. Although labor taxation has limited power to address economic imbalances, it nevertheless contributes to the establishment of labor market balance, which points to the importance of observing its impact on labor market efficiency (Šimović and Deskar-Škrbić 2015).

The high tax wedge, hence the high tax burden on wages, is directly influenced by high unemployment. The increase in labor taxes reduces the average duration of employment in the formal sector, significantly reduces the number of employees in the formal sector and significantly increases the informal sector and the readiness of the workforce to accept the job in the informal sector.

From the research conducted by Dolenc and Laporšek (2010) has been finding out that reducing tax wage contributes to increasing employment, decreasing unemployment and consequently leads to greater productivity and competitiveness.

\section{Empirical Analysis of Unemployment Determinants}

In his paper Scarpetta (1996) clearly points out how it is impossible to set up a comprehensive model that can fully satisfy and show the movement of unemployment, given that unemployment is influenced by numerous institutional, cultural and historical facts which determine the efficiency of the labor market and is not possible to include them all in the model. Purnama-Trimurti and Komalasari (2014) state that authors most commonly, when analyzing unemployment determinants, in models include institutional and macroeconomic variables to analyze the issue comprehensively. Analysis of the unemployment determinants starts with the identification of the potential institutional factors which could have an impact on the labor market efficiency, whose theoretical strength derives from different theories of unemployment and ends with an analysis of more important macroeconomic factors. Also, certain models analyze unemployment determinants from micro or macro aspects, labor supply or demand and the development of certain countries.

The impact of institutional and macroeconomic factors on unemployment has been reflected in the failure of the labor market - its adjustment to the general economic situation of the observed country. The first attitude of the Organization for European Economic Co-operation (OECD) 
and International Monetary Fund (IMF) was that labor market failures are the result of its inflexibility, which stems mainly from market institutions and that systematic institutional deregulation is needed to reduce unemployment. Point of view that the institutional structure causes the rigidity of the labor market is widely accepted by policymakers, whereby the claim in question stands at the base of unemployment theories that establish a link between labor market institutions and long-term unemployment (Pesliakaite 2011).

Some of the authors emphasize that mostly institutional factors of the labor market can explain unemployment trends, while others analyze macroeconomic variables. However, they have concluded that macroeconomic stability has a significant impact on unemployment. Labor market institutions have a different impact on unemployment due to different economic opportunities and labor market policies (Sturn 2011).

In her paper, Jandrić (2013) states that many economists considered that the unemployment in Europe would be solved by removing labor market regulations, protecting laws, reduction of unemployment benefits, reducing the power of syndicates, and by decentralization of the wage determination process. That was a message of an OECD job study from 1994. that emphasized the significance of wage flexibility, the danger of employment protection legislation (E PL) and the need for unemployment benefits limitation. Also, the author furtherly emphasizes how the IMF in its study from 2003. points out that causes of unemployment can be found in labor market institutions that are the main cause of high unemployment rates according to the attitudes of many experts. Accordingly, countries with high unemployment rates have been constantly encouraged to undertake comprehensive structural reforms that would reduce the rigidity of the labor market (high unemployment benefits, employment protection, minimum wages), improve the right-setting mechanism and encourage an adequate wage tax system.

Blanchard and Wolfers (2000) state how labor market institutions do not affect so directly unemployment rate but their negative impact is most likely to be reflected when macroeconomic shocks occur in the economy, and then institutions accelerate a negative effect on unemployment. They also suggest that a more favorable macroeconomic environment and the improvement of labor market institutions should have a significant impact on reducing unemployment. Nickell et al. (2002) are the initiators of the approach of studying unemployment through institutional determinants and macroeconomic stability. 
'The general impact of individual institutional variables on labor market efficiency is still not sufficiently clarified because the effects of certain institutional arrangements are not the same for different labor market groups. A large number of recent studies don't give a clear answer to the question of whether an inflexible labor market directly causes high unemployment rates, nor does empirical research uniquely confirm liberalorthodox attitudes. There is no consensus about the impact of the labor market institutions on the unemployment rate, primarily about the statistical significance of some institutional variables, and in some cases about the sign of impact' (Jandrić 2013, 69).

Based on analyzed literature, Jandrić (2013) concludes how certain countries that have a more rigid labor market in the long term achieve better performance than some countries with far more flexible labor markets. In their paper Tasci and Zenker (2013) state how countries with highly flexible institutions and labor market policies have been characterized by greater fluctuations in the unemployment rate during economic cycles, as opposed to countries with more rigid labor market features.

According to the Guidelines for the Implementation of Active Employment Policy Measures (2013), a comprehensive approach for solving the problem of unemployment is needed by linking the institutions responsible for creating policies for education, economy, work, and regional development as well as social partners and civil society organization. Without social dialogue and wider dialogue with the interested public, it's not possible to achieve solutions that will be truly effective and sustainable in the long run.

Also, Zubović and Domazet (2012) consider that in spite of the extraordinary efforts for improving labor market policies, a significant increase in employment will not be possible without the overall increase in economic activity. Mrnjavac (2013) emphasizes how the height and dynamics of the unemployment rates in Europe reflect economic trends while changes in the functioning of the labor market did not have a significant impact on unemployment. Therefore, growth policy allows the creation of new jobs as a basic prerequisite for reducing the number of unemployed.

Although the issue of unemployment is important for economic theory and society as a whole, we can conclude from the analyzed literature that there is no clear and unique answer to the question about the correct specification of the labor market unemployment determinants and that there is no general conclusion about the determinants of unemployment 
which certainly shows the complexity of the unemployment. According to the analyzed literature, it can be concluded that the determinants of unemployment can be divided into macroeconomic, institutional and other factors.

\section{Characteristics of the Observed Post-Transition Countries Labor Markets}

During the early transition periods in the nineties of the 2oth century, unemployment in the countries of Central Europe increased due to rapid labor market reforms. New jobs in the private sector had not been open at the same rate as workers lost their jobs (Boeri and Terrell 2002). National labor markets marked high and long-term unemployment rates and extremely rigid labor legislation (Nesporova, 2000). These changes also marked growing inactivity until 2000 when the Central European labor market started to stabilize (European Commission 2008).

Cazes and Nesporova (2003) indicate that increased labor market flexibility in the Central European countries didn't contribute to the improvement of the labor market performance but has hurt employment, redistribution and labor productivity. However, Pesliakaite (2016) concluded by exploring the determinants of unemployment in the long run for the Central European countries, that the institutional structure causes labor market flexibility, which has an impact on the unemployment as well as indicators of macroeconomic stability. Therefore, the author emphasizes that structural reforms and increased labor market flexibility are needed for lowering unemployment rates in Central European countries.

Cazes and Nesporova (2006) point out that the countries of Central Europe have significantly modified the institutions and labor market policies in a manner to respond to the challenges of labor recruitment. As the date of entry into the European Union approached, Central European countries accelerated the adaptation of labor market institutions and policies according to the experience of existing member states. Scutariu (2015) states that it is a clear positive effect of increasing employment while the pace of the falling unemployment rate has been accelerated with the accession of Central European countries into the European Union. In her paper, Kunovac (2013) states that in the period from 2008. to 2013. has been obvious a strong trend in reducing legal protection of employment in most Central European countries, primarily in the form of individual layoffs, regular employment contracts, while temporary employment protection has been slightly strengthened. 
Labor demand has a strong impact on the movement of unemployment, while there is a significant link between the unemployment and employment rate in the case of Poland labor market suggesting that reduction of the unemployment rate is not the cause of increased labor inactivity (Strawinski 2008). Qiddah (2013) states that Poland has one of the strongest European economies. Membership in the European Union has helped Poland to attract more financial resources and increase employability while Ambrosetti - The European House (2016) points out that Poland has one of the most flexible labor markets in the European Union.

When we look at the unemployment of Poland from the regional point of view, we come to the knowledge that there are very different local unemployment determinants. Generally speaking, differences in local unemployment rates are mainly influenced by local demographic factors, levels of education and structure of individual sectors as opposed to labor demand (Cizkowicz, Kowalczuk, and Rzonca 2014).

Accession to the European Union in 2004 led to numerous changes in the Czech labor market, the most significant of which is the increase in flexibility (Knězáčková and Volejníková 2014). Based on the labor flow of unemployment from unemployment to employment, we can conclude that the Czech is lagging in creating new jobs. The significantly low capacity of the Czech labor market in absorption, especially low educated and senior labor, points to the presence of structural disparities between the above categories of labor with the needs of the labor market. It is, therefore, necessary to establish an efficient active labor market policy, to provide more flexible forms of employment and to introduce stronger measures against the gray economy (Flek and Mysikova 2015).

In his paper Kwiatkiewicz (2010) states that the general character of the Czech labor market is a low level of unemployment but whereas a more detailed analysis of the labor market indicates huge regional inequalities of unemployment rates, whereby it is important to highlight gender differences and the lack of appropriate skills (Pavelka and Roster 2013).

Slovakia's labor market has some similar characteristics with other post-transition EU member countries. For example, the labor force participation rate is slightly below the European Union average, while the inactivity of the older population (over 55) and women are particularly pronounced, unlike other European Union countries. Regarding labor market institutions, we can conclude that the Slovak Republic has a flexible labor market. Also, it has the lowest amounts of unemployment 
benefits and social benefits in general (European Commission 2014).

Long term unemployment is the main problem on the Slovakian labor market while main causes of unemployment in Slovakian labor market are poor structure of the economy, exclusion of low-skilled population, tax burdens on labor income, low skill levels and declining trends in the demand for manual workers, impact of minimum wage on Slovakian labor market, high level of regulations and bureaucracy, and low mobility of Slovakian labor force (Zeman 2018).

In the period from 2008 to 2013, Hungary's unemployment gradually declined as a result of public employment - active labor market measures, which accounted for almost half of the newly opened jobs and required significant fiscal expenditures (Adam 2014). However, in his paper, Tvrdon (2016) states that since 2013 Hungary's structural unemployment has increased due to internal economic problems in the area of public finances and the growth of the state debt.

The highly qualified and productive labor force is an important characteristic of the Hungarian labor market what is the reason why foreign investors invest in Hungary (Horvath 2011). The Hungarian labor market is characterized by a moderate unemployment rate, a relatively low rate of labor force participation and flexible labor market institutions (European Economic Advisory Group 2012). Low labor force participation rates and employment rates are characteristics of the Hungarian labor market (Galgoczi 2010).

The issues facing the Slovenian labor market are the results of labor market institutions that were not adequately prepared for the changes in the post-transition period. The Republic of Slovenia has a complex system of employment and dismissals where employers are reluctant to employ a new workforce. It is worth to point out that the employers hire workforce mainly on the fixed term contract that indicates insecurity of job retention (Joyce 2014). The expenditures for active labor market policies have a negative and statistically significant effect on the unemployment rate, whereas the expenditures for passive labor market policies have a positive and statistically significant effect on the unemployment rate (Južnik Rotar 2018, 55).

Low labor market activity rates and employment rates are indicators that probably best illustrate the weaknesses of the Croatian labor market, while a relatively high unemployment rate confirms problems with creating a sufficient number of jobs even in the conditions of low labor supply. The current situation on the labor market of the Republic of Croa- 
tia can be seen as a result of three key factors: cyclical low demand for labor, structurally high unemployment, inadequate labor supply, and institutional (regulatory) rigidity that enhances adverse effects of cyclic and structural factors (Nestić 2015, 43-44).

\section{Research Methodology}

An analysis of labor market unemployment determinants in post-transition EU countries has been conducted by using econometric models of multiple linear regression for each country. An econometric model unemployment rate represents dependent variable while independent variables are macroeconomic (real gross domestic product, public debt expressed as a percentage of the GDP and labor force participation rate) and institutional variables (number or fixed and part-time contracts and expenditures for the active and passive labor market policies).

The index of the legal protection of employees is not taken into account because there are no uniform indicators for all the years to be analyzed.

Quarterly data have been used for the period from 2000 to 2015. The reason why the analysis started in 2000 was that these countries were planners until 1990. Croats and Slovenes were part of Socialist Yugoslavia, while Czech, Slovak, Polish, and Hungarian were influenced by Soviet politics. With the beginning of the 1990 s entering the transition (political, legal and economic system). How transition has introduced the transformation of ownership (from planning to market). Unemployment in Central European countries increased due to rapid labor market reforms (introduced by the transition). At the same time, there was very rigid working legislation that was understandable due to the previous way of life. These negative changes lasted until the year 2000 when the Central European labor market stabilized except Croatia. Precisely from this analysis was started with the 2000 year. For the models of the observed countries data were collected from the Eurostat database while data for active and passive labor market policies were found from the oECD database on an annual basis, which was transformed into quarterly data by the frequency distribution method because they are flow variables.

Gross domestic product is an indicator of the economic activity and demand for the labor force, public debt is an indicator of the government's ability to cope with high rates of unemployment, by the labor force participation rate we can see how the activity of the workforce affects the movement of unemployment, fixed-term contracts as well as the number of part-time workers are indicators of labor market flexibility, active labor 


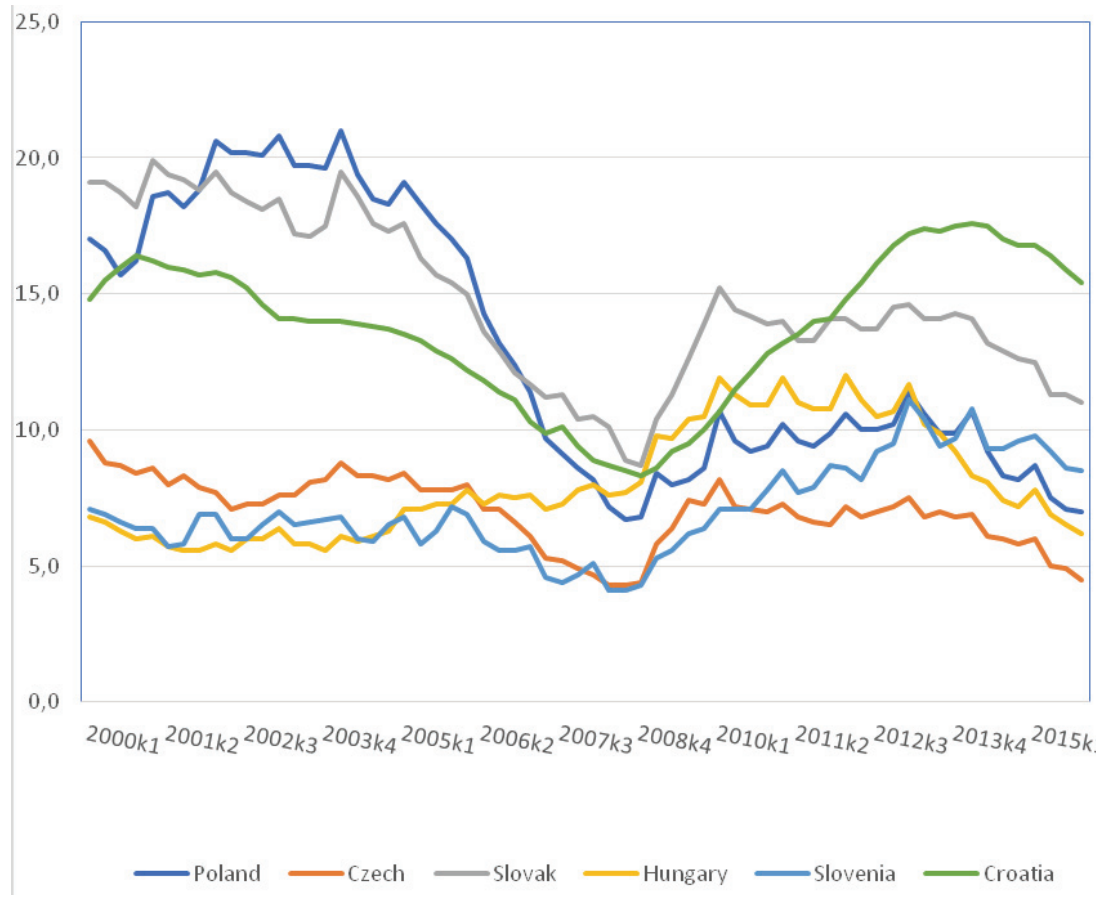

FIGURE 1 Movements of the Unemployment Rates

market policies represent effectiveness in combating unemployment and ultimately passive labor market policy that are potential source of labor force passivity on the labor market in finding employment.

Highly correlated variables (import, export, foreign direct investment, interest rate, inflation) were omitted from the analysis. All variables from the model have been seasonally adjusted by ARIMA X11 methodology in a manner to avoid links between variables due to common seasonal movements rather than some of their direct links. Also, all variables are expressed in the natural logarithm, which allows us to have models with constant elasticity as most macroeconomic theoretical models assume. Moreover, these log-log models allow a simpler interpretation of the obtained coefficients since it is about partial coefficients of elasticity. The models have included three broken trends by the dummy variables in a manner to get stationary variables.

From figure 1 we can see, based on the unemployment movement that the countries in the analyzed period went through three phases: before the crisis, the crisis and after the crisis. 


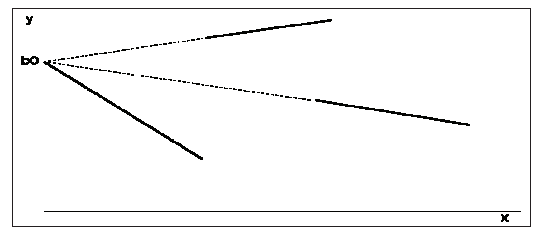

FIGURE 2 Ordinate Line Section

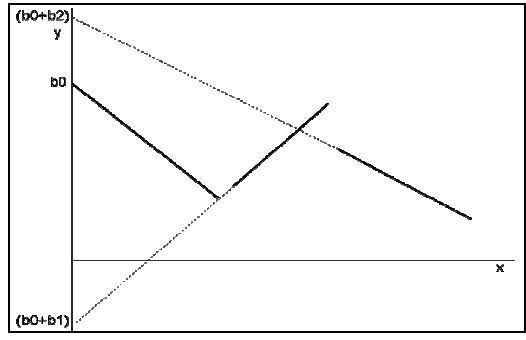

FIGURE 3 Different Line Slides on Ordinate

It has been taken period of the crises from the fourth quarter of the 2008 until the fourth quarter of the 2013 due to consistency and comparability of all individual models. To obtain breaks in models, the following dummy variables were included:

$$
\begin{aligned}
& \text { before_trend }=\left\{\begin{array}{l}
t \text { for } 2008 \mathrm{q} 4-2013 \mathrm{q} 4 \\
o \text { for other periods }
\end{array} \quad t=1,2,3, \ldots,\right. \\
& \text { crisis_trend }=\left\{\begin{array}{l}
t \text { for } 2008 \mathrm{q} 4-2013 \mathrm{q} 4 \\
\text { o for other periods }
\end{array} \quad t=1,2,3, \ldots,\right. \\
& \text { after_trend }=\left\{\begin{array}{l}
t \text { for } 2008 \mathrm{q} 4-2013 \mathrm{q} 4 \\
o \text { for other periods }
\end{array} \quad t=1,2,3, \ldots,\right.
\end{aligned}
$$

to get three different trends of unemployment depending on the period and two more constant members where it is important not to limit the directions in order to have the same odds on the ordinate (figure 2).

Lines should be allowed to get different sections by additional dummy variables that will allow shifts to vary depending on the observation period. Additional dummy variables are the following:

$$
\begin{aligned}
& \text { crisis_con }=\left\{\begin{array}{l}
t \text { for } 2008 \mathrm{q} 4-2013 \mathrm{q} 4 \\
o \text { for other periods }
\end{array} \quad t=1,2,3, \ldots,\right. \\
& \text { after_con }=\left\{\begin{array}{l}
t \text { for } 2008 \mathrm{q} 4-2013 \mathrm{q} 4 \\
0 \text { for other periods }
\end{array} \quad t=1,2,3, \ldots,\right.
\end{aligned}
$$

by which we get a different line slides on ordinate (figure 3).

Parameter linked to crisis_con is b1 and parameter linked to after_con is 
TABLE 1 Results of the Regressions

\begin{tabular}{|c|c|c|c|c|c|c|}
\hline & Poland & Czech & Slovakia & Hungary & Slovenia & Croatia \\
\hline GDP & $\begin{array}{l}0.164 \\
(1.42)\end{array}$ & $\begin{array}{l}-0.488 \\
(-1.27)\end{array}$ & $\begin{array}{r}-0.760 \\
(-1.33)\end{array}$ & $\begin{array}{l}-0.623^{* * *} \\
(-3.71)\end{array}$ & $\begin{array}{l}-0.795^{* * *} \\
(-5.304)\end{array}$ & $\begin{array}{l}0.506 \\
(1.61)\end{array}$ \\
\hline PUD & $\begin{array}{l}1.223^{* * *} \\
(6.35)\end{array}$ & $\begin{array}{l}0.344^{*} \\
(2.46)\end{array}$ & $\begin{array}{l}1.106^{* * *} \\
(4.41)\end{array}$ & $\begin{array}{l}0.485 \\
(1.57)\end{array}$ & $\begin{array}{l}0.483^{\star * *} \\
(12.27)\end{array}$ & $\begin{array}{l}0.508^{\star *} \\
(4.24)\end{array}$ \\
\hline LFPR & $\begin{array}{l}4.697^{* * *} \\
(3.71)\end{array}$ & $\begin{array}{l}4.579 \\
(1.37)\end{array}$ & $\begin{array}{l}-2.532 \\
(-1.22)\end{array}$ & $\begin{array}{l}-0.509 \\
(-0.34)\end{array}$ & $\begin{array}{r}-0.738 \\
(-0.4571)\end{array}$ & $\begin{array}{l}-1.375^{* *} \\
(-3.19)\end{array}$ \\
\hline FTC & $\begin{array}{l}0.313^{\star *} \\
(3.30)\end{array}$ & $\begin{array}{r}0.317 \\
(1.02)\end{array}$ & $\begin{array}{r}-0.0439 \\
(-0.43)\end{array}$ & $\begin{array}{l}-0.271 \\
(-1.96)\end{array}$ & $\begin{array}{l}0.378^{\star} \\
(1.815)\end{array}$ & $\begin{array}{r}0.0809 \\
(1.32)\end{array}$ \\
\hline PTC & $\begin{array}{l}0.638^{* *} \\
(2.96)\end{array}$ & $\begin{array}{l}-0.869^{*} \\
(-2.09)\end{array}$ & $\begin{array}{l}0.156 \\
(1.17)\end{array}$ & $\begin{array}{r}-0.0982 \\
(-0.77)\end{array}$ & $\begin{array}{r}-0.098 \\
(-0.5995)\end{array}$ & $\begin{array}{l}-0.0112 \\
(-0.24)\end{array}$ \\
\hline ALMP & $\begin{array}{r}0.0314 \\
(0.71)\end{array}$ & $\begin{array}{l}0.633^{* * *} \\
(5.74)\end{array}$ & $\begin{array}{r}0.0838 \\
(1.26)\end{array}$ & $\begin{array}{r}0.0794 \\
(1.54)\end{array}$ & $\begin{array}{r}0.0595 \\
(1.040)\end{array}$ & $\begin{array}{r}-0.0208 \\
(-0.80)\end{array}$ \\
\hline PLMP & $\begin{array}{l}0.422^{* * *} \\
(3.56)\end{array}$ & $\begin{array}{l}0.348^{\star} \\
(2.34)\end{array}$ & $\begin{array}{r}-0.0611 \\
(-0.61)\end{array}$ & $\begin{array}{l}0.339^{\star * *} \\
(3.86)\end{array}$ & $\begin{array}{l}0.2157^{* * *} \\
(3.587)\end{array}$ & $\begin{array}{l}0.270^{* * *} \\
(4.65)\end{array}$ \\
\hline crisis_trend & $\begin{array}{r}-0.0101 \\
(-1.68)\end{array}$ & $\begin{array}{r}0.000517 \\
(0.04)\end{array}$ & $\begin{array}{r}-0.0194 \\
(-1.79)\end{array}$ & $\begin{array}{l}0.0192^{* *} \\
(3.37)\end{array}$ & $\begin{array}{r}0.0187 \\
(2.63)\end{array}$ & $\begin{array}{l}0.0191^{* *} \\
(3.25)\end{array}$ \\
\hline cons & $\begin{aligned} & 28.65^{* * *} \\
&(-4.99)\end{aligned}$ & $\begin{array}{l}-18.69 \\
(-1.09)\end{array}$ & $\begin{array}{r}17.54 \\
(1.72)\end{array}$ & $\begin{array}{r}5.832 \\
(0.89)\end{array}$ & $\begin{array}{r}8.288 \\
(1.518)\end{array}$ & $\begin{array}{r}0.895 \\
(0.24)\end{array}$ \\
\hline$R^{2}$ & 0.992 & 0.904 & 0.938 & 0.974 & 0.928 & 0.986 \\
\hline
\end{tabular}

NOTES GDP - gross domestic product (in bn of euros, in real terms), PUD - public debt (\% of GDP), LFPR - labor force participation rate, FTC - fixed term contract (number of fixed term contracts), P TC - part time contract (number of part time contracts), ALMP - active labor market policies (in mil of euros), PLMP - passive labor market policies (in mil of euros); $t$-statistics are in brackets below the coefficients while probabilities are in brackets below the $t$-statistics; significance levels are denoted as: ${ }^{*}$ significant at $5 \%$, ${ }^{* *}$ significant at $1 \%,{ }^{* * *}$ significant at $0,1 \%$.

b2 from figure 3, while coefficients of slope direction are dummy variables - before_trend, crisis_trend and after_trend.

\section{Results and Discussion}

Regression results on the example of Poland show how public debt, labor force participation rate, fixed-term contracts, part-time contracts, and passive labor market policies have a significant and positive impact on the movement of the unemployment rate. The greatest impact on the movement of the unemployment rate has a labor force participation rate. One percent increase in labor force participation rate increases unemployment for $4.70 \%$ (table 1 ). 
Employment rates are less than the labor force inflow rates in Central European countries, which is particularly evident on the Polish example. Poland has reached a high degree of labor market flexibility and needs further strong economic growth to combat unemployment while public debt and increasing labor force inflow represent major obstacles.

On the example of Slovak Republic, from all variables of the regression model, only public debt had a significant impact on the movement of the unemployment rate - one percent increase of public debt increases unemployment rate by $1.11 \%$.

Huge structural unemployment of Slovak Republic shows that unemployment is the cause of a mistaken institutional framework rather than short-term fluctuations such as economic cycles. Incorrectly established institutional framework implies inadequate institutional incentives in the area of taxation and social benefits, labor market rules, education system, ect. Therefore, in order to significantly reduce unemployment, it is necessary to bring and establish effective institutional changes with no attention being paid solely to economic growth (Goliaš 2014). Also, in her paper Martincova (2013) states that Slovak public debt has particularly large impact on the movements of unemployment.

Based on the labor flow from unemployment to employment, we can conclude that the Czech Republic is lagging behind in creating new jobs. The significantly low capacity of the Czech labor market in absorption, particularly low educated and senior work force, indicates the presence of structural mismatches of the above mentioned categories of labor with the needs of the labor market. It is therefore necessary to establish an effective active labor market policy to provide more flexible forms of employment and to introduce stronger measures against the gray economy (Flek and Mysikova 2015).

Czech has increased labor market flexiblity according to the regression results, especially part time contracts that decrease unemployment. On the example of Czech Republic, it can bee seen that public debt (0.34), part time contracts ( -0.87 ), active labor market policies (o.63) and pasive labor market policies (0.35) have significant impact on the movement of the unemployment rate. One percent increase of public debt increases unemployment rate for $0.34 \%$, one percent increase of part time contracts decreases unemployment for $0.87 \%$, one percent increase of active labor market policies increases unemployment for $0.63 \%$ and one percent increase of pasive labor market policies increases unemployment for $0.35 \%$.

Significant impact on Hungarian unemployment rate had GDP and 
passive labor market policies. GDP had a negative impact (-0.62) while the passive labor market policies had a positive impact on the movement of the unemployment rate (o.34). Other variables from the model were not significant which means that in the observed period they did not have impact on the movement of the unemployment rate.

Hungarian labor market has a highly qualified and productive labor force that is a significant feature of the hungarian labor market and is also important determinant for foreign direct investments. Also, it is important to point out how foreign direct investments have significant positive role on the hungarian economic development and for opening new jobs (Horvath 2011). Hungary indicates economic situation that has a large space for increasing labor market flexibility which will in the future require further strong economic growth.

On the example of Slovenia GDP has significant impact on reduction of unemployment rate (-0.79) while public debt (o.48), fixed term contracts (0.38) and passive labor market policies (o.21) had significant positive impact on unemployment. In his paper Joyce (2014) state how fixed term contracts in a short period of time decrease unemployment while employers are not willing to employ workforce on indefinite period of time for the rigidity of the labor market.

Significant determinants of unemployment of the Republic of Croatia in the observed period are public debt (0.58), labor force participation rate $(-1.37)$ and passive labor market policies $(0.27)$. One percent increase of public debt increased unemployment for $0.58 \%$, labor force participation rate decreased unemployment for $1.37 \%$ and pasive labor market policies increased unemployment for $0.27 \%$. Therefore, the strongest impact on unemployment of the Republic of Croatia had labor force participation rate while its one percent increase led to decrease of unemployment for $1.37 \%$. Labor force participation rate represents the ratio of the labor force and the total population which indicates the workforce activity while the increase in the rate of labor participation may be also due to the emigration of labor force.

The Republic of Croatia needs to establish more efficient active and passive labor market policies, work on reduction of the public debt and set up measures and policies that will have impact in reducing unemployment rates and the outflow of working-age population. Higher labor demand than the size of the workforce certainly leads to a reduction of the unemployment rate. Therefore, recent research in the analysis of unemployment determinants include the employment finding rates and the 
job loss rates. In the models of this paper coefficients of determination for each regression are higher than $90 \%$ which indicates a strong connection between the dependent and independent variables and how independent variables describe well movements of the dependent variables.

\section{Conclusion}

Unemployment as an indicator of the economic and social condition is a result of different macroeconomic, institutional and other important factors that points out its complexity. Based on the results of the regressions, it can be concluded that each observed country has different determinants of unemployment. Despite the countries having similar features, they differ to a smaller or greater extent which is reflected in their labor market.

So at the beginning of the crisis in 2008, the Czech had an unemployment rate of $4.4 \%$, Croatia $8.6 \%$, Hungary $7.8 \%$, Poland $7.1 \%$, Slovenia $4.4 \%$ and Slovakia 9.6\%. According to the level of unemployment, the crisis in these countries has lasted for a long time because the unemployment rate for 2012 in the Czech was 7.0\%, Croatia 15.8\%, Hungary 11.0\%, Poland 10.1\%, Slovenia 4, 4\% and Slovakia 9.6\%. In 2015, unemployment rates were lower than in 2012 in the Czech by $5.1 \%$, Hungary by $6.8 \%$, Poland by $7.5 \%$ and Slovakia by $11.5 \%$, although Poland and Slovakia still have a higher unemployment rate in 2008 . Slovenia has a $9 \%$ unemployment rate in 2015 and Croatia $16.1 \%$. These are twice the higher rates compared to 2008 , indicating that the economies have not fully recovered from the crisis and especially Croatia whose GDP was negative from 2009 to 2015 . The analysis of the unemployment rate after 2015 for the countries surveyed shows that they are all the Czech decreased to $2.2 \%$, Croatia at $8.5 \%$, Hungary to $3.7 \%$, Poland to $3.9 \%$, Slovenia to $5.1 \%$ and Slovakia to $6.5 \%$. The unemployment rate in Croatia significantly decreased, partly due to the growth of the gross domestic product, but also due to the opening up of European labor markets (all except Austria). Thus, Croatians have the possibility of free employment and departure to European countries. This has also affected the size of the supply of labor and the need for greater imports of seasonal workers.

According to this research, it is obvious how public debt as a macroeconomic variable in most countries has the strongest positive impact on unemployment. The reason is that the public debt as a share of the GDP leads to the extrusion of investments, the reduction of exports and debt servicing, and thus the reduction of economic growth. Certainly, these 
negative consequences reflect significantly on the level of unemployment. From the institutional variables have been observed the significant impact of the passive labor market policy on unemployment. This policy primarily refers to the material protection of unemployed persons in the form of unemployment benefits and mostly do not stimulate the unemployed workforce in the job-seeking process. Although their amount was significantly higher at the beginning of the transition period in all observed countries, as the number of unemployed increases, this benefit decreases and is regulated differently in each country. However, these benefits serve unemployed persons as a security measure rather than a temporary form of financial support until finding a job. As a result, this institutional variable has a significant impact on the level of unemployment.

Labor market rigidity has been often used as a cause of unemployment, but labor market flexibility can't solve the long-term unemployment problem because its measures are only effective in short-term unemployment suppression. Therefore, further efforts in the labor markets need to be directed towards a more effective establishment of the concept of flexicurity, one of the strategic goals of the European Union. In a EU document has been emphasized the necessity of pursuing policies aimed at achieving 'full employment,' 'improving quality' and 'work productivity.' Considering that this document in the field of employment relations highlights the need for flexibility and security because the flexicurity model emphasizes job security on employability security (Bušelić 2017). Activities for increasing flexibility and safety on the labor market require the presence of effective active employment policies, lifelong learning, labor mobility policies and an adequate social security system to provide adequate support to employees and the unemployed.

Although flexicurity policy should encourage economically efficient and social fair labor market by reducing unemployment and increasing employment, in conditions where there is no economic growth and new investments, previously mentioned effects can't be expected (Bušelić 2017, 142).

Work is important for the academic community, policymakers, experts, students of economics and management, as well as for the wider public interested in the labor market. It also provides important insight into further design and development of labor market middle-European countries.

Since this work resulted from the analysis of Central European coun- 
tries using multiple linear regression for each country, the results for each country were obtained based on which they could compare and differentiate between them. The common features of the observed countries, ie macroeconomic or institutional variables, are also identified in the paper as the causes of their unemployment. Therefore, for future research, it is proposed to expand independent variables (both macroeconomic and institutional) as well as expand the number of countries (comparisons of Baltic or South European) with more recent data using panel analysis.

\section{References}

Adam, Z. 2014. Fight Against Unemployment: The case of Hungary. Budapest: Institute for Economic Research.

Aleksynska, M., and F. Eberlein. 2016. 'Coverage of Employment Protection Legislation.' IZA Journal of Labor Policy 5 (17): 1-20.

Ambrosetti - The European House. 2016. 'Poland: A Sustainable Transformation to a Leading Economy.' Position paper, Cernobbio. http:// docplayer.net/41097927-Poland-a-sustainable-transformation-to-a -leading-economy.html

Bejaković, P. 2015. 'A Revision of the Shadow Economy in Croatia: Causes and Effects.' Economic Research 28 (1): 422-40.

Blanchard, O., and J. Wolfers. 200o. 'The Role of Shocks and Institutions in the Rise of European Unemployment: The Aggregate Evidence.' The Economic Journal 110 (462): 1-33.

Boeri, T., and F. Jimeno. 2014. 'The Unbearable Divergence of Unemployment in Europe.' Banco de Espana Working Paper 1534, Banco de Espana, Madrid.

Boeri, T., and K. Terrell. 2002. 'Institutional Determinants of Labor Reallocation in Transition.' Journal of Economic Perspectives 16 (1): 51-76.

Bogdan W., D. Boniecki, E. Labaye, T. Marciniak, and M. Nowacki. 2015. Poland 2025: Europe's New Growth Engine. N.p.: McKinsey \& Company.

Bušelić, M. 2017. Suvremeno tržište rada. Pula: Sveučilište Jurja Dobrile u Puli.

Cappellari, L., C. Dell'Aringa, and M. Leonardi. 2012. 'Temporary Employment in Italy.' Cesifo DICE Report, ifo Institut, Leibniz.

Cazes, S., and A. Nesporova. 2003. Labour Markets in Transition: Balancing Flexibility and Security in Central and Eastern Europe. Geneva: ILo.

Cazes, S., and A. Nesporova. 2006. 'Combining Flexibility and Security for Employment and Decent Work in the Western Balkans.' South-East Europe Review for Labour and Social Affairs 9 (2): 7-24.

Christiana Ogonna, I., O. Stephen Idenyi, A. Charity Ifeyinwa, and N. Udochukwu Gabriel. 2016. 'The Implications of Rising Public Debt on 
Unemployment in Nigeria: An Auto Regressive Distributed Lag Approach.' Asian Research Journal of Arts \& Social Sciences 1 (1): 1-15.

Cizkowicz, P., M. Kowalczuk, and A. Rzonca. 2014. 'Heterogeneous Determinants of Local Unemployment in Poland.' Narodowy Bank Polski Working Paper 188, Economic Institute, Warsaw.

Di Porto, E., L. Elia, and C. Tealdi. 2016. 'Informal Work in a Flexible Labour Market.' Oxford Economic Papers 69 (1): 143-64.

Dolenc, P., and S. Laporšek. 2010. 'Tax Wedge on Labour and Its Effect on Employment Growth in the European Union.' Prague Economic Papers 4:344-58.

Domonkos, T., and B. Konig. 2015. 'Estimation of the Cost of Unemployment in Slovak Republic.' Politicka Ekonomie 63 (4): 498-516.

Encinas-Ferrer, C., and E. Villegas-Zermeño. 2015. 'Foreign Direct Investment and Gross Domestic Product Growth.' Procedia: Economics and Finance 24:198-207.

Eurofound. 2015. Recent Developments in Temporary Employment: Employment Growth, Wages and Transitions. Luxembourg: Publications Office of the European Union.

European Commission. 2014. 'Path Dependence and the Persistence of Unemployment in the Slovak Republic.' EFCIN Country Focus 11 (3): 1-9.

European Economic Advisory Group. 2012. 'The Hungarian Crisis.' The EEAG Report on the European Economy, Center for Economic Studies, Munich.

Fedeli S., and F. Forte. 2012. 'Public Debt and Unemployment Growth: The Need for Fiscal and Monetary Rules. Evidence from oECD Countries (1980-2009).' Economia Politica 29 (3): 399-427.

Flek, V., and M. Mysikova. 2015. 'Uneployment Dynamics in Central Europe: A Labour Flow Approach.' Prague Economic Papers 1:73-87.

- 2015. 'Youth Labour Flows and Unemployment in Great Recession: Comparing Spain and the Czech Republic.' Review of Economic Perspectives 15 (2): 179-95.

Galgoczi, B. 2013. 'A Continuous Shrinking of the Unemployment Benefit System.' In Unemployment Benefit Systems in Europe and North America: Reforms and Crisis, edited by F. Lefresne, 281-92. Brussels: Etui.

Gallegati, M., M. Gallegati, J. Ramsey, and W. Semmler. 2014. 'Does Productivity Affect Unempoyment? A Time Frequency Analysis for the us.' In Wavelet Applications in Economics and Finance, edited by M. Gallegati and W. Semmler, 23-46. Dynamic Modeling and Econometrics in Economics and Finance 20. Cham: Springer.

Goliaš, P. 2014. 'How to Decrease Unemployment in Slovakia.' http://www .ineko.sk/file_download/788/How+to+decrease+unemployment+in + Slovakia.pdf 
Guzmán, G. 2014. 'How Effective Are Active Employment Policies to Reduce Unemployment in EU Countries?' Atlantic Review of Economics 2:1-15.

Horvath, J. 2011. 'Evaluation of the Hungarian Labor Market in Terms of a Shortage of Skilled Labor in Germany.' In Eu Strategy for the Danube Region: Perspectives for the Future, edited by I. Tarrósi and S. Milford, 149-60. Pécs: IDM.

Jandrić, M. S. 2013. 'Fleksibilnost i sigurnost na tržištu rada i uticaj na nezaposlenost u zemljama u tranziciji. $\mathrm{PhD}$ dissertation, University of Belgrade.

Joyce, B. 2014. 'The Struggle of Trade Unions and Slovenian Labor Market Reform.' Slovenia: Challenges and Opportunities, 47-58. Bethlehem, PA: Lehigh University.

Južnik Rotar, L. 2018. 'The Effects of Expenditures for Labour Market Policy on Unemployment Rate.' Business Systems Research 9 (1): 55-64.

Knězáčková, R., and J. Volejníková. 2014. 'The Labour Market in the Czech Republic after Accession to the Eu. In The 8th International Days of Statistics and Economics: Conference Proceedings, 687-97. Libuše Macáková: Melandrium.

Kovtun, D., A. Meyer Cirkel, Z. Murgasova, D. Smith, and S. Tambunlertchai. 2014. 'Boosting Job Growth in the Western Balkans.' I MF Working Paper 14/16. International Monetary Fund, Washington, DC.

Kunovac, M. 2013. 'Employment Protection Legislation in Croatia.' Financial Theory and Practice 38 (2): 139-72.

Kwiatkiewicz, A. 2010. 'The Implementation of Flexicurity and the Role of the Social Partners. Joint Study of the European Social Partners.' http://erc-online.eu/wp-content/uploads/2014/04/2011-00557-E.pdf

Laporšek, S., and P. Dolenc. 2012. 'Do Flexicurity Policies Affect Labour Market Outcomes? An Analysis of Eu Countries.' Revija za socijalnu politiku 19 (2): 107-29.

Lee, G. H. Y., and J. Parasnis. 2014. 'Discouraged Workers in Developed Countries and Added Workers in Developing Countries? Unemployment Rate and Labour Force Participation.' Economic Modelling 41:908.

Martin, J. P. 2014. 'Activation and Active Labour Market Policies in OECD Countries: Stylized Facts and Evidence on Their Effectiveness.' IZ A Policy Paper 84, Institute for the Study of Labor, Bonn.

Martincova, M. 2013. 'Impact of the Global Crisis on Labor Markets and Unemployment in Slovak Republic.' European Scientific Journal 1:16o5.

Mrnjavac, Ž. 2013. 'Active Labour Market Policy: Fighting a Dragon with a Toothpick.' Zagrebački ekonomski forum (7): 39-53. 
Mucuk, M., and M. Tahir Demirsel. 2013. 'The Effect of Foreign Direct Investments on Unemployment: Evidence from Panel Data for Seven Developing Countries.' Journal of Business Economics and Finance 2 (3): 53-66.

Muller, L., and D. P. Berger. 2013. 'The Impact of a Country's Employment Protection Legislation on Its Economic Prosperity'. International Journal of Humanities and Social Science 3 (12): 1-13.

Nestić, D. 2015. Ključni problemi hrvatskog tržišta rada: projekt "Zaposlimo Hrvatsku«. Zagreb: Hrvatska gospodarska komora.

Nickell, S., L. Nunziata, W. Ochel, and G. Quintini. 2002. The Beveridge Curve, Unemployment and Wages in the OECD from the 1960s to the 1990s. London: Centre for Economic Performance, London School of Economics and Political Science.

Ogueze, V. C., and O. Uka Odim. 2015. 'The Cost of Unemployment and Its Effects on GDP Growth in Nigeria.' World Applied Sciences Journal 33 (1): 86-95.

Paul, S. 2001. 'A Welfare Loss Measure of Unemployment with an Empirical Illustration.' The Manchester School 69 (2): 148-63.

Pavelka, T., and T. Loster. 2013. 'Changes in Regional Unemployment Rates in the Czech Republic during Economic Cycle.' Intellectual Economics 7 (4): 510-22.

Pesliakaite, J. 2011. 'Determinants of Unemployment in CE E-10 Economies: The Role of Labour Market Institutions and the Macroeconomic Environment in 2002-2012.' http://mpra.ub.uni-muenchen.de/66041

Pesliakaite, J. 2016. 'Determinants of Unemployment in Central and Eastern European Economies.' Ekonomska teorija i praksa 1:30-49.

Purnama-Trimurti, C., and Y. Komalasari. 2014. 'Determinants of Unemployment: Empirical Evidences from 7 Province in Indonesia.' Scientific Research Journal 2 (8): 5-9.

Qiddah, D. 2013. 'Country Profile: Republic of Poland.' https://www.sidf.gov .sa/en/MediaCenter/ResearchandStudies/

ExportInformationCountryProfileCurrent/2013-CP-Poland.pdf

Scarpetta, S. 1996. 'Assessing the Role of Labour Market Policies and Institutional Settings on Unemployment: A Cross Country Study'. OECD Economic Studies 26:43-98.

Scutariu, A. L. 2015. 'An Analysis of Unemployment in the Countries of Eastern and Central Europe in the Context of EU' The USV Annals of Economics and Public Administration 15 (Special): 80-86.

Sika, P. 2016. 'The Relationship of the Minimum Wage and Unemployment in the Slovak Republic.' Paper presented at the 16th International Scientific Conference on Economic and Social Development: The Legal Challenges of Modern World, Split, 1-2 September. 
Strawinski, P. 2008. 'What Drives the Unemployment Rate in Poland' Munich Personal RePEc Archive 11372, Munich.

Sturn, S. 2011. 'Labour Market Regimes and Unemployment in OECD Countries.' Macroeconomic Policy Institute, Düsseldorf.

Šimović, H., and M. Deskar-Škrbić. 2015. 'Efficency of Value Added Tax in Croatia.' In Proceedings of the 9th International Conference European Entrepreneurship Forum 2015: Efficiency in the Private and the Public Sector, 144-51. Prague: Newton College.

Tomić, I. 2013. 'Essays on the Labour Market in a Post-Transition Economy: The Case of Croatia.' PhD dissertation, University of Ljubljana.

Tvrdon, M. 2016. 'Decomposition of Unemployment: The Case of the Visegrad Group Countries.' Ekonomie 9 (1): 4-16.

Umair, M., and R. Ullah. 2013. 'Impact of GDP and Inflation on Unemployment Rate: A Study of Pakistan Economy in 2000-2010.' International Review of Management and Business Research 2 (2): 388-400.

Zeman, M. 2018., 'Unemployment in Slovakia between 1998 and 2016: One of the Systemic Problems of the National Economy'. Ecoforum 7 (1): 1-8.

Zubović, J., and I. Domazet. 2012. New Challenges in Changing Labour Markets. Belgrade: Institute of Economic Science.

This paper is published under the terms of the Attribution-

NonCommercial-NoDerivatives 4.o International (CC B Y-NC-ND 4.0)

License (http://creativecommons.org/licenses/by-nc-nd/4.o/). 

Digitalno okolje in internetni mobilni trendi:

perspektiva hotelov in potovalnih agencij

Daniela Garbin Praničević, Anja Križan in Judita Peterlin

Strokovnjaki menijo, da so zaradi procesa digitalizacije podatki, zbrani s snemanjem digitalnih sledi, postali dragocen vir za analizo različnih vidikov vedenja strank. $\mathrm{V}$ tem okviru raziskovanje podatkov mobilnega prometa ponuja nov vpogled $\mathrm{v}$ dinamiko trga $\mathrm{v}$ turizmu. Vedno bolj ključno postaja spoznavanje tako novih okvirov, kot tudi sistemov za nadzor v realnem času, saj lahko le z njihovo pomočjo razumemo, kako dinamika kupcev - ki jo zaznava mobilni promet - oblikuje strukturo turističnega sektorja in pripomore $\mathrm{k}$ sprejemanju boljših odločitev pri načrtovanju in izboljšanju upravljanja. Glede na navedeno, ima študija sledeče cilje: (i) izpostaviti pomembne značilnosti digitalnega okolja E U-27, (ii) predstaviti in razviti internetne mobilne trende, na splošno in na področju storitev hotelov in potovalnih agencij in ( iii) okrepiti ozaveščenost turističnih upravljavcev glede vpliva mobilnega interneta na poslovne koristi. $\mathrm{V}$ raziskavi, tako $\mathrm{v}$ teoretičnem kot tudi $\mathrm{v}$ empiričnem delu, so obdelani in predstavljeni sekundarni podatki držav EU-27, predvsem tisti, ki so povezani s Hrvaško in Slovenijo. V zaključku so predstavljene perspektive mobilnega interneta $\mathrm{v}$ trenutnem digitalnem okolju, pa tudi njegov položaj na področju storitev hotelov in potovalnih agencij.

Ključne besede: Internetni mobilni trendi, mobilni promet, EU-27, hoteli, potovalne agencije

Klasifikacija JEL: M15

Managing Global Transitions 17 (1): 5-17

\section{Velika depresija v postkapitalizmu, ne kapitalizmu}

(New Deal kot vodstvena revolucija in razumevanje našega časa) Tonči Kuzmanić

Glavni cilj prispevka je ponovno opozoriti na problem kapitalizma $\mathrm{z}$ dveh različnih vidikov. Prvič $z$ vidika »jezikovnih iger « v smislu wittgensteinske metodologije. Znotraj tovrstnega »wittgensteinskega argumenta « je povezava med »imenom « (kapitalizem) in »stvarjo« (pragma, v fizičnem smislu) izjemnega pomena. Poudarja namreč, da kapitalizem ni samo »stvar«, ampak mnogo več. Drugič pa prispevek poskuša ponovno odpreti problem »velike depresije« in dokazati, da je kapitalizem, 
kot ga običajno razumemo, že »izhlapel« v tridesetih in štiridesetih letih 20. stoletja. Cilj tega drugega dela in hkrati celotnega prispevka je dokazati, da je postkapitalizem (»vodstvena revolucija « ne samo v smislu Burnhama, ampak predvsem FD Roosevelta) dejansko že premagal kapitalizem, ne pa tudi svojih jezikovnih iger, ki jih je moč slišati še danes. Osrednjo tezo prispevka predstavlja trditev, da brez resnega premisleka o nepovratnih revolucionarnih (!) spremembah iz tridesetih in štiridesetih let ne moremo resno razumeti današnje "globalizacije« in »svetovne krize« (pravzaprav nove postmoderne depresije) in smo torej dobesedno obsojeni na neuspeh pri razmišljanju o dani "globalni družbi«.

Ključne besede: postkapitalizem, kapitalizem, smrt kapitalizma, »jezikovne igre«, depresija, gospodarstvo, »vodstvena revolucija«, »Velika družba «

Klasifikacija JEL: A12, NoO, P16

Managing Global Transitions 17 (1): 19-49

\section{Napovedovanje stopnje uspešnosti nagrajenih projektov množičnega financiranja Ivelin Elenčev in Aleksandar Vasilev}

$\mathrm{V}$ pričujočem prispevku je opisan razvoj treh modelov, ki pomagajo pri napovedovanju stopnje uspešnosti in dosegljive ravni naložb v spletna podjetja za množično financiranje. To je mogoče doseči z uporabo standardne ekonomske teorije in tehnik strojnega učenja, od računalništva, do novega sektorja za spletno množično mikrofinanciranje. V nasprotju s predhodnimi raziskavami na tem področju ta dokument poleg podatkov o zaključenih projektih skupinskega financiranja analizira tudi podatke na ravni transakcij. S tem je omogočena edinstvena perspektiva pri razvoju množičnega financiranja. Modeli v povprečju dosegajo 83odstotno natančnost pri napovedovanju izida kampanje za množično financiranje v kateremkoli trenutku preko celotnega obdobja trajanja. Ugotovitve dokazujejo, da na uspeh vplivajo številni parametri izdelka in projekta. Prispevek v nadaljevanju na podlagi navedenih meril podaja napotke iskalcem kapitala in vlagateljem, ter omogoča bolj racionalne odločitve vseh udeležencev na trgu množičnega financiranja.

Ključne besede: mikrofinanciranje, financiranje podjetnikov, množično financiranje

Klasifikacija JEL: G17, G19

Managing Global Transitions 17 (1): 51-77 
Določanje dejavnikov brezposelnosti v post-tranzicijskih srednjeevropskih državah članicah EU

Marija Bušelić in Jurica Bosna

Namen raziskave je opredelitev dejavnikov brezposelnosti na trgih dela na primeru post-tranzicijskih srednjeevropskih držav članic EU - Poljske, Češke, Slovaške, Madžarske, Slovenije in Hrvaške. Namen prispevka pa je opozoriti na vlogo in pomen proučevanja dejavnikov brezposelnosti na trgu dela v post-tranzicijskih državah, z namenom oblikovanja predlogov za zmanjšanje brezposelnosti. V tem prispevku so kot neodvisne makroekonomske spremenljivke analizirani bruto domači proizvod, javni dolg, stopnja udeležbe delovne sile in institucionalne spremenljivke, kot so na primer pogodbe za določen čas in krajši delovni čas, ter izdatki za aktivne in pasivne politike trga dela. Analiza določilnih elementov brezposelnosti na trgu dela v srednjeevropskih državah članicah EU je bila opravljena $z$ ekonometričnimi modeli večkratne linearne regresije za vsako posamezno državo, da bi ugotovili, ali obstajajo razlike v stopnjah brezposelnosti med državami znotraj ene skupine. Rezultati raziskave kažejo, da v skoraj vseh državah javni dolg kot makroekonomska spremenljivka pomembno vpliva na rast brezposelnosti, medtem ko imajo pasivne politike trga dela institucionalnih spremenljivk najpomembnejši vpliv na stopnjo brezposelnosti.

Ključne besede: brezposelnost, dejavniki, trg dela, post-tranzicijske države članice $\mathrm{E} U$

Klasifikacija JEL: E24, J01

Managing Global Transitions 17 (1): 79-103 